\title{
REAL-TIME RT-PCR ANALYSIS OF TWO EPITOPE REGIONS ENCODED BY THE VP2 GENE OF INFECTIOUS BURSAL DISEASE VIRUS
}

\section{DISSERTATION}

\author{
Presented in Partial Fulfillment of the Requirements for the \\ Degree Doctor of Philosophy in the Graduate \\ School of The Ohio State University \\ By \\ Claudia Silva Mickael, B.S., M.S. \\ $* * * * *$ \\ The Ohio State University \\ 2005
}

Dissertation Committee:

Professor Daral J. Jackwood

Approved by

Professor Jeffrey LeJeune

Advisor

Graduate Program in Veterinary

Professor Teresa Y. Morishita

Preventive Medicine

Professor Kenneth W. Theil 


\begin{abstract}
Infectious bursal disease virus (IBDV) causes an immunosuppressive disease in chickens and leads to economic losses in the poultry industry. The virus has a bisegmented RNA genome, which codifies 5 proteins (VP1 to VP5). VP2 constitutes the outer capsid and contains conformational neutralizing epitopes. Forty-eight bursa samples were collected from IBDV infected commercial broiler flocks in the US. The samples were tested by Real-Time RT-PCR using probes designed for two epitope regions denominated minor peak 1 and peak B and subsequently sequenced. The probes were complementary to nucleotide sequences of Del-E, STC and F15 IBDV strains. It was observed that 23, 48 and 44 samples tested with the minor peak probes, respectively, had a lower melting temperature (Tm) than expected. On the other hand, 44, 41 and 48 samples tested with the probes designed for peak B also had a lower Tm. The nucleotide sequencing revealed that most of the samples that had shifts in their melting temperatures (Tm) when tested by real-time RT-PCR had nucleotide mutations when were sequenced. Additionally, most of the mutations resulted in amino acid substitutions and to different amino acid groups. Consequently, these mutations may be responsible for antigenic changes. In order to improve vaccination efficacy it is necessary to employ vaccines
\end{abstract}


based on the antigenic subtypes present in the flock's environment. RT-PCR can infer the presence of IBDV variants, which may assist in the development of effective vaccination strategies.

IBDV induced immunosuppression is reported to increase susceptibility to pathogens such as Salmonella spp., E. coli and other food-borne pathogens. A study was designed to attempt to establish a possible correlation between IBDV-induced immunosuppression and Campylobacter jejuni colonization and shedding in chickens. Six experiments were performed with specific pathogen free chickens and were designated A, B, C, D, E and F. Each experiment had one control group, a group inoculated with $C$. jejuni only and another group inoculated with IBDV and C. jejuni. The experiments varied in the dosage, time of inoculation and strain of $C$. jejuni used. Intestinal contents were collected from the cloaca, cecum and jejunum, and the samples were cultured in appropriate media. Colonies that resembled Campylobacter jejuni were submitted to PCR to confirm the diagnosis. At the time of the necropsies, the bursa of each bird was collected and weighed, and based on that a bursa/body weight ratio was calculated. In addition, the viral RNA was extracted from the bursas and submitted to real-time RT-PCR. It was observed that the groups inoculated with C. jejuni and IBDV displayed a prolonged shedding and higher amounts of $C$. jejuni which were significantly different when compared to the other groups. The results indicated that IBDV-induced immunosuppression exacerbates $C$. jejuni shedding and colonization in chickens. These observations support the idea that IBDV may have an indirect impact on food-borne diseases and reinforce the importance of IBDV control in commercial flocks. 
Dedicated to my beloved husband Nagi

And to my parents Geraldo and Cáritas 


\section{ACKNOWLEDGMENTS}

A special thanks to my advisor Dr. Daral Jackwood, for all help, support and guidance during my entire program. His dedication, patience and comprehension were a fundamental part in making this challenge a wonderful experience. Also I would like to thank Dr. Teresa Morishita, Dr. Kenneth Theil, Dr. Jeff LeJeune and Dr. Srinand Sreevatsan for their assistance and advice.

I wish to express my sincere appreciation to Susan Sommer-Wagner for all her support in the lab during my experiments and for her friendship. I would also like to thank Katie Subler for being a wonderful "experiment partner". Most of all, I am grateful for her companionship, patience and support through the entire course of my graduate program. I would not make it without all those laughs!!!

I want to express my gratitude to all Food Animal Health staff and students for their support. A special thanks to Marli Azevedo and my surrogate family, the Azevedos, for all encouragement, assistance and counseling provided when I moved to the US to initiate my graduate studies. Thanks also Amy Wetzel and Sarah Wagmiller for your friendship and comfort in good and bad times.

I guess words will never be enough to express all my appreciation to my family in Brazil. My immense and eternal gratitude to my father, Geraldo, and to my mother, 
Cáritas, for all love, care and motivation throughout the course of my studies and life. You guided and inspired me to always do my best. I also would like to thank my sisters Lílian and Mônica, my brother Sérgio and my dearest niece and nephews Ana, Caio and Tasso for all emotional support and counseling. Thank you all for supporting me along all the way, from the moment I chose this career till now. I would never make it without you. Finally, I would like to express my deep appreciation to my husband, Nagi, for supporting and enlightening me during every step of the way. I don't think the word thanks is good enough to describe the dimension of my gratitude, but I guess it is the only one I can use. Thanks for being my companion, best friend, love giver, and for all your sweet care. Thanks for being here with me and for temporarily giving up your dream to help me pursue mine. You are a fundamental part of all this. 


\section{VITA}

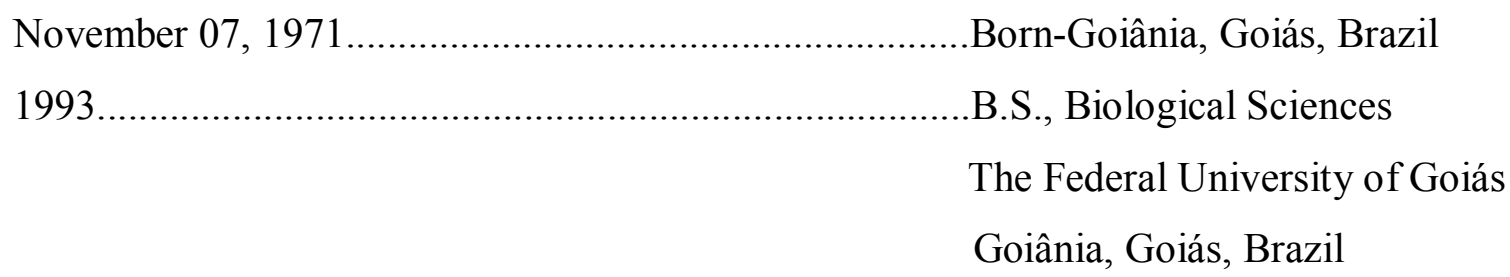

1994-1996. Specialization in Microbiology The Federal University of Goiás Goiânia, Goiás, Brazil

1996-1998 Temporary Professor of Virology The Federal University of Goiás Goiânia, Goiás, Brazil

1997-2000. M.S., Tropical Medicine The Federal University of Goiás Goiânia, Goiás, Brazil

1998-2000. Director and co-owner of a Clinical Laboratory

Goiânia, Goiás, Brazil 
Physiology and Evolution

Goiás Catholic University

Goiânia, Goiás, Brazil

2002-present. Graduate Research Associate FAHRP/ OARDC

The Ohio State University

\section{PUBLICATIONS}

1. SILVA, C.O., AZEVEDO, M.S.P., SOARES, C.M.A.. Seroprevalence of hepatitis B virus infection in individuals with clinical evidence of hepatitis in Goiânia, Goiás: detection of viral DNA and determination of subtypes. Rev. Inst. Med. trop. S. Paulo, Nov./Dec. 2002, vol.44, no.6, p.331-334.

2. MICKAEL, C.S., JACKWOOD, D.J. Real-Time RT-PCR analysis of two epitope regions encoded by the VP2 gene of infectious bursal disease viruses. J. Virol. Methods, 2005, In print.

\section{FIELD OF STUDY}

Major Field: Veterinary Preventive Medicine

Studies in Virology and Molecular biology 


\section{TABLE OF CONTENTS}

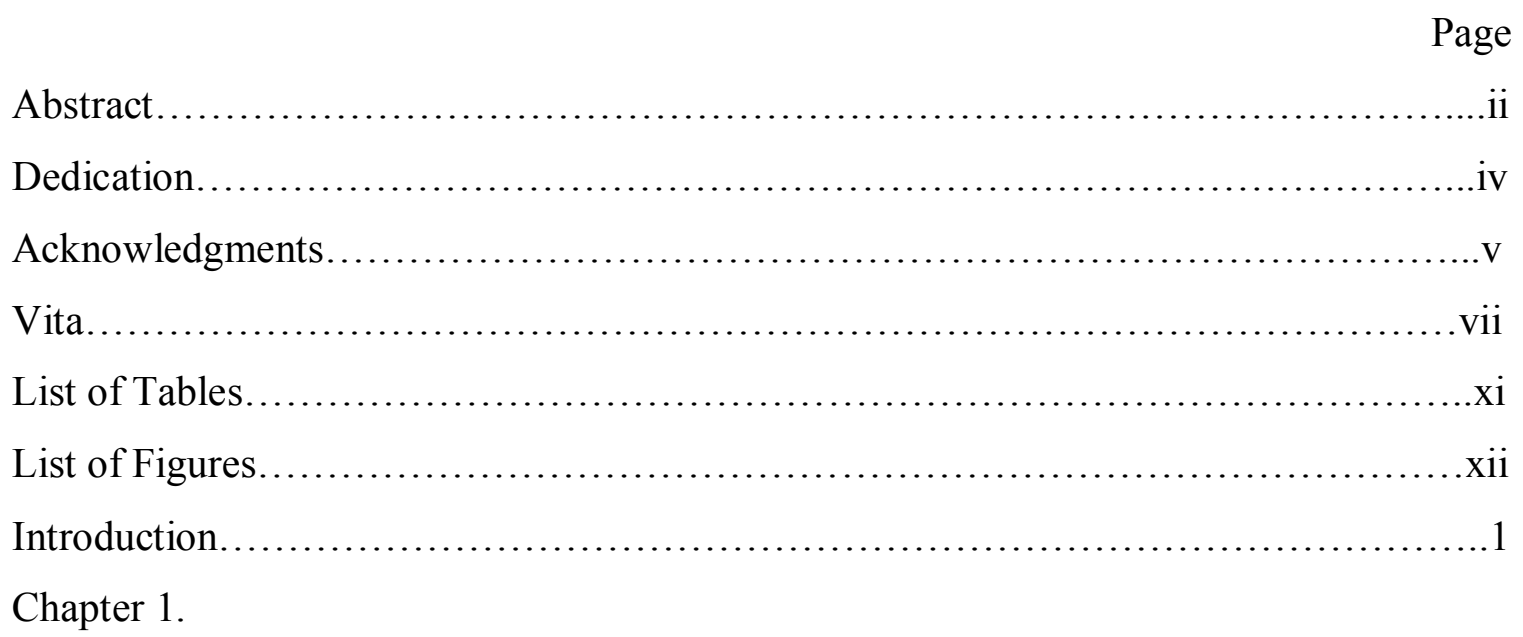

LITERATURE REVIEW: Infectious Bursal Disease Virus

History............................................................

Virus classification and structure...................................6

Viral genome................................................ 8

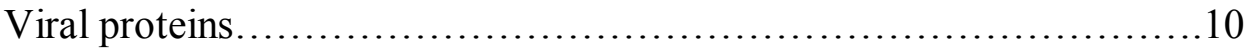

Virus replication..............................................13

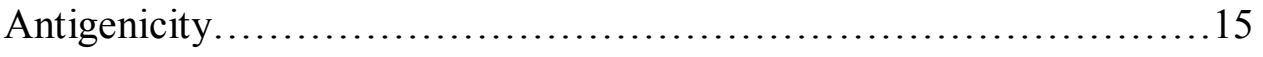

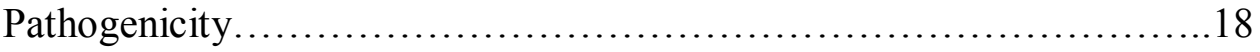

Lesions and clinical signs.......................................22

IBDV Immunity and immunosuppression.........................24

Epidemiology............................................27

Vaccination..................................................... 28

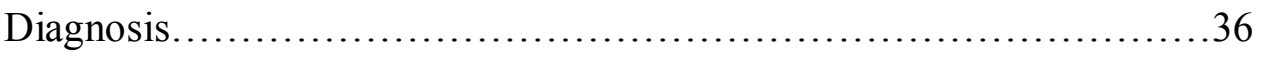

References...............................................43

ix 


\section{LITERATURE REVIEW: Campylobacter jejuni}

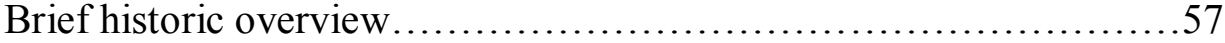

Campylobacter general characteristics...............................58

C. jejuni reservoirs and transmission in poultry......................58

Colonization in poultry............................................ 59

Clinical signs and transmission to humans.............................61

Prevention and Control..............................................62

References........................................................ 65

Chapter 2.

REAL-TIME RT-PCR ANALYSIS OF TWO EPITOPE REGIONS ENCODED BY THE VP2 GENE OF INFECTIOUS BURSAL DISEASE VIRUSES

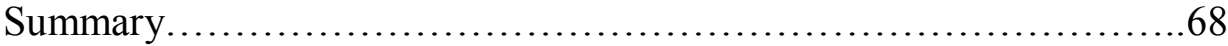

Introduction................................................. 70

Materials and Methods.......................................... 72

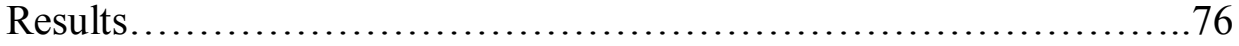

Discussion.................................................... 78

Conclusion..................................................... 82

References..................................................... 85

Chapter 3.

ANALYSIS OF INFECTIOUS BURSAL DISEASE VIRUS-INDUCED IMMUNOSUPPRESSION AND CAMPYLOBACTER JEJUNI COLONIZATION AND SHEDDING IN CHICKENS

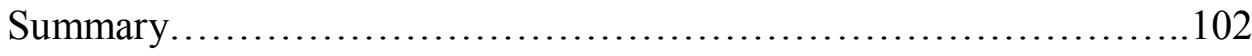

Introduction.....................................................

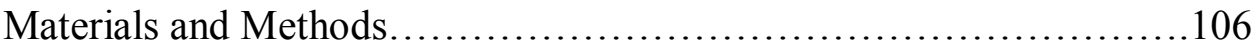

Results......................................................... 110

Discussion...................................................... 112

References..................................................... 118

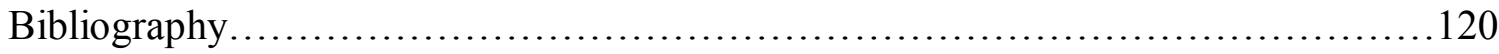




\section{LIST OF TABLES}

Table Page

Table 2.1.: Mutation and anchor probe nucleotide sequences that are complementary to the minor peak region of the VP2 gene.................87

Table 2.2.: Mutation and Anchor probe nucleotide sequences that are complementary to the peak B region of the VP2 gene.

Table 2.3.: Nucleotide sequence comparison of DEMP probe (minor peak 1) with sequenced samples............................................... 88

Table 2.4.: Nucleotide sequence comparison of Del-E probe (peak B) with sequenced samples.

Table 2.5.: Nucleotide comparison of STMP probe (minor peak 1) with sequenced samples.

Table 2.6.: Nucleotide sequence comparison of STC probe (peak B) with sequenced samples.

Table 2.7.: Nucleotide sequence comparison of F15MP probe (minor peak 1) with sequenced samples.............................................99

Table 2.8.: Nucleotide sequence comparison of F15 probe (peak B) with sequenced samples.

Table 3.1.: Bursa/ body weight ratios from Experiment A...........................113

Table 3.2.: Bursa/ body weight ratios from Experiment B.........................113

Table 3.3.: Bursa/ body weight ratios from Experiment C...........................114

Table 3.4.: Bursa/ body weight ratios from Experiment D..........................114 
Table 3.5.: Bursa/ body weight ratios from Experiment E.........................115

Table 3.6. Bursa/ body weight ratios from Experiment F........................ 116 


\section{LIST OF FIGURES}

Figure $\quad$ Page

Fig. 2.1. Melting temperature (Tm) results in degrees Celsius obtained using probes after real-time RT-PCR reaction.....................95

Fig. 2.2. Real-time RT-PCR melting curves of samples tested with the DEMP probe (minor peak probe) .............................96

Fig. 2.3. Real-time RT-PCR melting curves of samples tested with the Del-E probe (peak B probe).

Fig.2.4. Real-time RT-PCR melting curves of samples tested with F15MP (minor peak probe).

Fig. 2.5. Real-time RT-PCR melting curves of samples tested with F15 (peak B probe).

Fig. 2.6. Real-time RT-PCR melting curves of samples tested with STMP (minor peak probe)

Fig. 2.7. Real-time RT-PCR melting curves of samples tested with STC (peak B probe)

Fig. 3.1. Real-time PCR melting curves of bursa samples tested with the Del-E probe. 


\section{INTRODUCTION}

Infectious bursal disease virus causes immunosuppression in young chickens and an acute disease in chickens between 3 and 6 weeks old. The syndrome is also called Gumboro disease after the geographic location in the state of Delaware where the first outbreaks occurred. The disease is endemic and it is present in $95 \%$ of the Office of International Epizooties member countries, despite intensive vaccination and biosafety practices. This fact indicates that the current control measures of this virus are not very effective. The disease causes economic losses due an increased susceptibility to other pathogens and it decreases vaccination efficacy, which is a major control measure in the poultry industry for diseases such as infectious bronchitis, Newcastle Disease and Marek's disease. Impaired growth and death are also common, and the mortality rates can vary from insignificant to $100 \%$, depending on the strain present in the flock. The disease can also lead to higher condemnation of carcasses due to hemorrhages in the muscles.

The virus is very stable in the environment and it has been reported that IBDV can persist in poultry houses after cleaning and disinfection. Therefore, in order to control this virus, vaccination is mandatory. Usually, the parent flock is vaccinated with a live attenuated vaccine followed by a series of inactivated vaccines which will confer passive 
protection to the offspring in the first weeks of life, during which they are more susceptible to immunosuppression. It has been reported that vaccination with homologous strains confers better protection, and therefore they are more effective. However, virus characterization by the current available techniques is difficult. Virus neutralization assays are difficult to perform, as field viruses do not grow well in cell culture. The RT-PCR-Restriction Fragment Length Polymorphism (RFLP) assay has been used as the molecular standard for characterization of this virus, but it analyzes only mutations at the restriction sites and therefore has limited capacity for analysis. Consequently, there is an increasing demand for diagnostics tests that are able to characterize IBDV strains more effectively. Particularly tests that can compare the strains present in the flock's environment with vaccine candidates. In this context, we adapted the light cycler technique to be able to examine different genomic regions that encode two antigenic regions of IBDV: minor peak 1 and peak B. Our long term goal is to improve vaccination efficacy and therefore improve prevention and control of this disease.

Previous reports have demonstrated that IBDV induced immunosuppression can increase susceptibility against other infectious agents, mostly food-borne pathogens, such as E. coli and Salmonella spp.. A study was developed to try to establish a possible correlation between IBDV induced immunosuppression and Campylobacter jejuni colonization and shedding in chickens. 


\section{CHAPTER 1}

\section{LITERATURE REVIEW}

\section{History}

Infectious bursal disease was first reported by Cosgrove in the fall of 1957. The first field cases of the disease affected broiler flocks in the town of Gumboro, in southern Delaware which explains why the disease was first named Gumboro disease. The disease was described as "infectious and contagious" and the clinical signs included ruffled feathers, severe prostration and watery diarrhea. In addition, it was observed that the disease would recur several times. The syndrome was more apparent in young chickens, and presented mortality rates that varied from 1 to $15 \%$, being higher in birds between 2 and 4 weeks old. Because the chickens presented tubular degenerative lesion in the kidneys the disease was named "avian nephrosis". The use of antibiotics did not assist in the control of the disease and the it was suspected that it was caused by a viral agent (Cosgrove, 1962). Additionally, it was observed that the disease would persist in poultry houses even after treatment with several disinfectants, which demonstrated the hardy nature of the etiological agent (Parkhurst, 1964). 
Three years after the first reported cases in Delaware, the disease was detected in other regions of the US, starting from Mississipi in the early 1960's, followed by Alabama, Georgia and North Carolina. By 1964, all southeastern poultry producing states had reported cases (Lasher and Davis, 1997). Rapidly the disease spread throughout the United States and currently it is widely spread worldwide.

In 1964 Parkhurst speculated that Gumboro disease was caused by two agents: infectious bronchitis virus and an infectious bursal agent. Because of the lesions in the kidney, it was believed that the disease was caused by a variant of the infectious bronchitis virus denominated Gray strain. Later on, it turned out that the two infections occurred simultaneously, and it was difficult to isolate the etiological agent with the available diagnostic tools, therefore the misconception (Lasher and Davis, 1997). The L\&M laboratory, from Berlin, Maryland, was the first group that tried to identify the etiological agent of this disease and determined that it was, indeed, very different from infectious bronchitis (Lasher and Davis, 1997).

In February of 1966, during an Annual Poultry Health and Management Meeting, it was decided that the term "avian nephrosis-nephritis" would be replaced by "infectious bursal disease". In 1967, Benton's and Edgar's groups concluded that the etiological agent of disease was possibly a virus, which was resistant to extreme $\mathrm{pH}$ and several chemical treatments. However, it was not till 1976 that the structural and growth characteristics of the virus were known in detail to place the agent in the Birnaviridae family. 
Early attempts to immunize flocks were accomplished by spreading infected litter in the poultry house (Hitchner, 2004). In 1967, Moulthrop and Snedeker-Wills adapted a mild isolate to the chicken embryo system which turned out to become the first licensed vaccine, Bursa $\operatorname{Vac}{ }^{\circledR}$. Almost at the same time Peckhan adapted a field isolate to embryos and used it to immunize 5000 chickens by drinking water. These were the first attempts to try to control this devastating syndrome (Lasher and Davis, 1997).

In 1970 Cho suggested that IBDV infection was equivalent to a "biological bursectomy" after exposing chickens of 1 day old to IBDV and subsequently to Marek's disease virus. In 1972, another report from Britain about the interaction of IBDV and Newcastle disease virus also identified the same phenomenon which was indicative of immunosuppression (Faragher et al., 1974). Giambrone et al., observed later that the responsiveness to the New Castle disease vaccine was decreased when the birds were raised in houses previously contaminated with IBDV (Giambrone et al., 1976).

Recently, the US poultry producers are facing a new challenge: the continuous emergence of antigenic variants, which are able to infect chickens even in the presence of maternal antibodies. In addition, in the late 1980's, a highly virulent strain, which caused high rates of mortality, was isolated in Europe. The strain, currently denominated very virulent IBDV (vvIBDV), rapidly spread to other continents including Asia, Africa and South America (van den Berg, 2000). The reason of the emergence of antigenic variant and very virulent strains remains unclear. 


\section{Virus classification and structure}

Infectious bursal disease virus (IBDV) is a member of the genus Avibirnavirus family Birnaviridae, which is characterized by a bi-segmented double-stranded RNA. This family includes the genus Aquabirnavirus which is represented by infectious pancreatic necrosis virus (IPNV) of fish, tellina virus (TV) and oyster virus (OV) of bivalve mollusks; additionally it comprises the genus Entomobirnavirus which has the drosophila virus (DXV) of the fruit fly Drosophila melanogaster as a member (Kibenge et al., 1988). IBDV has been isolated from chickens, turkeys (McNulty and Saif, 1988), ducks (McFerran et al., 1980), ostriches (Lukert and Saif, 1997), penguins (Gough et al., 2002) and guinea fowl (Saif, 1998).

The viral genome is enclosed by an icosahedrical single shelled capsid composed of 32 capsomers with a $T=13$ lattice and diameter of 60 to $70 \mathrm{~nm}$. The outer part of the capsid has 780 subunits which are clustered in 260 trimers. In the inner surface of the capsid, the trimer units appear as $200 \mathrm{Y}$-shaped features. The outer trimers correspond to the protein VP2, carrying the neutralizing epitopes, while the inner trimers correspond to protein VP3, which has a basic C-terminal region that interacts with the viral RNA and may be responsible for stabilizing functions (van den Berg, 2000; Caston et al., 2001). The C-terminal segment of VP3 contains two functional domains. The very last five amino acid residues of VP3 control both assembly and capsid architecture and the five preceding residues constitute the VP1 binding domain. The C-terminus of VP3 appears to be a molecular switch that triggers capsid assembling upon VP1 binding and possibly in 
interactions with pVP2/VP2 (Chevalier et al., 2004; Tacken et al., 2002; Tacken et al., 2003).

IBDV has a sedimentation rate of $460 \mathrm{~S}$ in sucrose gradients. The buoyant density of mature virus in caesium chloride $(\mathrm{CsCl})$ gradients is $1.33 \mathrm{~g} / \mathrm{ml}$. Incomplete virus particles have buoyant densities lower than $1.33 \mathrm{~g} / \mathrm{ml}$. When a preparation of one virus was submitted to $\mathrm{CsCl}$ gradients, several virus containing bands were observed. These bands were analyzed by electron microscopy and SDS-PAGE and it was observed that the prominent band of $1.33 \mathrm{~g} / \mathrm{ml}$ contained particles that appear like IBDV. A band of $1.32 \mathrm{~g} / \mathrm{ml}$ contained possibly incomplete particles with small amounts of dsRNA. Another band has $1.31 \mathrm{~g} / \mathrm{ml}$ consisted of incomplete particles with no RNA. When analyzed by SDS-PAGE, the three different particles presented similar patterns. When a band of $1.29 \mathrm{~g} / \mathrm{ml}$ was analyzed, it was observed that the particles were not completely assembled and had irregular shape and did not resemble the incomplete particles found in the other analyzed bands. These types of particles were commonly seen when IBDV replicates in chicken embryo fibroblast cell (CEF) cultures. On the other hand, viruses that are recovered from the bursa of Fabricius not always had this band and presented a different polypeptide pattern (Kibenge et al., 1988). Incomplete particles formed at infected bursa cells are rare; conversely, several passages of IBDV in CEF cells resulted in a stable phenotype with interfering ability and massive production of incomplete particles (Kibenge et al., 1988). 


\section{Viral Genome}

The genome of IBDV consists of two segments of double stranded (dsRNA) that sediment as 14S in sucrose gradients (Muller et al., 1979). In addition, IBDV dsRNA are resistant to RNAses in the presence of high molarities of salts (Spies et al., 1987), has a buoyant density of $1.62 \mathrm{~g} / \mathrm{ml}$ in caesium sulphate gradients, a GC content of $55.3 \%$ and a melting point of $95.5{ }^{\circ} \mathrm{C}$ when digested with RNAse. The molecular weights of each strand are approximately $2.2 \times 10^{6}$ and $2.5 \times 10^{6}$ (Muller et al., 1979).

The larger segment, denominated segment A has approximately 3400 bp and contains two partially overlapping open reading frames (ORF). The larger ORF is monocistronic (Hudson et al., 1986) and encodes a polyprotein precursor of $108 \mathrm{kDa}$ in the order $\mathrm{NH}_{2}-\mathrm{pVP} 2-\mathrm{VP} 4-\mathrm{VP} 3-\mathrm{COOH}$ which is cotranslationally processed through the proteolytic activity of VP4 to generate VP2 precursor (pVP2) of 45-50 kDa (aa position 1-512) ,VP4 (aa 213-755, $32 \mathrm{kDa}$ ) and VP3 (aa 756-1012, $28 \mathrm{kDa}$ ) (Sanchez and Rodriguez, 1999; Lejal et al., 2000). pVP2 is further processed at its C terminus to become VP2 through the cleavage of three alanine-alanine bonds (positions 487 to 488 , 494 to 495 , and 501 to 502) and an alanine-phenylalanine bond (positions 441 to 442 ) (Da Costa et al., 2002). The final processing from pVP2 to VP2 is controlled by the correct assembling of VP3 (Chevalier et al., 2002). The 71-amino acids at the C-terminal specific domain of pVP2 are essential for the establishment of the VP2-VP3 interaction (Ona et al., 2004). The smaller ORF encodes VP5, a non-structural protein of $17 \mathrm{kDa}$. 
Segment B has $2.8 \mathrm{~Kb}$ and encodes a $97 \mathrm{kDa}$ protein VP1, the viral RNA polymerase which is contained within the viral particle (van den Berg, 2000) and interacts with VP3 (Tacken et al., 2000).

Segments A and B are flanked by non-coding regions (NCR), which are similar in size when compared to other dsRNA viruses (Mundt and Muller, 1995). In segment A, the 5'-NCR consist of 96 nucleotides (nt) and in segment B the NCR spans $111 \mathrm{nt}$. There is a highly conserved motif within the first 32 nt in both segments. Segment A has a 3' NCR with $95 \mathrm{nt}$ in length and the NCR of segment B consists of 82 nt in serotype 1 strains and $79 \mathrm{nt}$ in the serotype 2 strain. In addition, a highly conserved motif was found in both segment A and B which is partially complementary to the 3' end of chicken reticulocyte $18 \mathrm{~S}$ rRNA. However, if this motif is the binding site of the $18 \mathrm{~S} \mathrm{RNA}$ and the role of this interaction in translational and replication processes is still unclear (Mundt and Muller, 1995). Previous studies with other RNA viruses have reported important functions of NCRs. For instance, picornavirus has an internal ribosomal entry site at the 5' end of a NCR which is essential for replication of the viral RNA (Le et al., 1993). The Influenza virus has 5' and 3' NCR regions that may be involved in endonuclease activity of the virus polymerase (Hagen et al., 1994). The NCR's in wound tumor virus are involved in encapsidation processes (Anzola et al., 1987). However, the role of the NCR in Birnaviruses replication or interaction with the host remains unclear. 


\section{Viral proteins}

VP1 is the RNA dependent RNA polymerase (RdRp) and is responsible for the replication of genome and the synthesis of the mRNA (Spies et al., 1987; von Einem et al., 2004). A recent study demonstrated that the polymerase activity decreases substantially at $40^{\circ} \mathrm{C}$, and the optimal temperature for polymerization is $37^{\circ} \mathrm{C}$ (von Einem et al., 2004). Additionally the same study found that although $\mathrm{Mg}^{++}$was essential for polymerase activity, it could be partially replaced by $\mathrm{Mn}^{2+} \mathrm{or} \mathrm{Co}^{2+}$ ions which indicates that the metal ion coordination is important in the polymerization step (von Einem et al., 2004). VP1 is present in small amounts in the virus and it can be found either as a free polypeptide or as a genome-linked protein (VPg) and it has multiple enzyme activities (Muller and Nitschke, 1987; Kibenge and Dhama, 1997). Birnavirus VP1 proteins form a distinct subgroup of RdRp lacking the highly conserved Gly-Asp-Asp (GDD) sequence (van den Berg, 2000; Shwed et al., 2002). IBDV VP1 protein is involved in determination of viral replication efficiency in vivo and in vitro and modulates virulence (Liu and Vakharia, 2004). Amino acid mutations in VP1 have been reported in a very virulent Indian field strain, which is not expected, as this is a conserved region among IBDV strains. The role of these mutations in viral replication, virulence and therefore pathogenesis is still not well understood (Bais et al., 2004).

VP2 has been identified as the host protective antigen as it contains the antigenic region responsible for the induction of neutralizing antibodies. Expression of VP2 induces apoptosis in mammalian cell lines which is counteracted by the $b c l-2$ gene, but it 
is questionable if this process occurs during natural IBDV infection (Fernandez-Arias et al., 1998). In addition, expression of VP2 in the chicken B-lymphocyte cell line RP9 as well as chicken embryo fibroblast cells induced apoptosis (Yao and Vakharia, 2001), which indicates that this protein is able to induce apoptosis in host cells. A recent study by Da Costa et al., demonstrated that the processing of pVP2 generates VP2 and four other small peptides (residues 442 to 487,488 to 494,495 to 501 and 502 to 512 ). In addition, it was observed that the residues 442 to 487,488 to 494 and 502 to 512 were associated with viral particles. However, deletion of the domains 442 to 487 and 502 to 512 did not allow virus recovery. Thus these peptides may play an important role within the virus cycle (Da Costa et al., 2002). Studies have demonstrated that the virulence, pathogenic-phenotype markers, viral entry, tissue culture infectivity and attenuation of IBDV resides in VP2 amino acid positions 253 (Q or H) 279 (D or N) and 284 (A or T) (Brandt et al., 2001; Liu and Vakharia, 2004; van Loon et al., 2002; Wang et al., 2004; Kwon and Kim, 2004; Mundt, 1999). In addition, mutations in positions $242(\mathrm{P} \rightarrow \mathrm{A}), 256$ $(\mathrm{V} \rightarrow \mathrm{I})$ and $294(\mathrm{~L} \rightarrow \mathrm{I})$ have been implicated in increased virulence and used as molecular markers of very virulent IBDV strains (Brandt et al., 2001; Cao et al., 1998).

VP3 is a group-specific antigen that is recognized by non-neutralizing antibodies. VP3 is thought to interact with both VP2 and VP1, and the interaction between VP1 and VP3 is an important step in the morphogenesis of the virus (van den Berg, 2000). A recent study identified an oligomerization domain within a 24-amino acid stretch near the C-terminal end of the polypeptide, partially overlapping the VP1 binding domain. It was 
observed that inactivation of this domain abolished virus-like particle formation (Maraver et al., 2003), indicating the importance of this protein in virus assembly.

VP4 is a virus encoded protease that shares a number of features with bacterial Lon proteases. The protein is responsible for auto-processing of the polyprotein, producing $\mathrm{pVP} 2, \mathrm{VP} 3$ and VP4. The amino acids responsible for this proteolytic activity were characterized as a serine-lysine catalytic dyade (Ser-652 and Lys-692) (Muller et al., 2003). It is very likely that Ser-652 represents the nucleophilic residue, as its substitution for alanine or threonine shut down the self-cleavage activity of the polyprotein, whereas its substitution by cysteine resulted in a mutant protein with good activity. All substitutions of Lys-692 yielded in inactivation of the protease activity suggesting that this residue acts as a general base at the catalytic site (Lejal et al., 2000). It is proposed that the pVP2 to VP2 conversion in infected cells involves one or more cleavages, probably by the proteolitic activity of VP4 (Azad et al., 1987; Kibenge et al., 1997). This hypothesis is strongly supported by the identification of three alternative cleavage sites in the C-terminal domain of VP4 (Lejal et al., 2000).

VP5 is a non-structural small protein that is not essential for viral replication and could play a role in virus release and dissemination. A study demonstrated that VP5 may act a class II membrane protein with a cytoplasmic N-terminus and an extracellular Cterminal domain. Its expression led to high cytotoxic activity, probably by accumulating in the cell membrane (van den Berg, 2000; Lombardo et al., 2000). VP5 has been considered to be involved in apoptosis in some cell lines. This suggests an important role 
for VP5 in viral pathogenesis, as it could allow the spread of the viral progeny to neighboring cells at later stages of the infection (Yao and Vakharia, 2001).

\section{Virus replication}

The replication process of IBDV has not been completely elucidated and the information available has mostly relied on studies with IPNV. Three forms of viral RNA have been described in IPNV. First, there is a putative transcription intermediate, which is the most abundant form of RNA produced in the early parts of the cycle. Secondly, there is a genome length single stranded (ssRNA) of $24 \mathrm{~S}$ that is believed to be the viral mRNA. Third, a 14S dsRNA indistinguishable from virion RNA by gradient centrifugation and gel electrophoresis is present (Kibenge et al., 1988).

A recent report has demonstrated that the VP1 protein from IBDV is indeed an RNA dependent RNA polymerase (RdRp) and it ruled out the possibility that VP1 activity requires an interaction between IBDV proteins VP1 and VP3 as well as binding of ds-RNA by VP3. This study also hypothesized that the mechanism of RNA synthesis by VP1 in vitro probably follows a "copy-back" mechanism, in which the 3' end of a template primes the synthesis of an antisense strand that falls back to form an RNA hairpin (von Einem et al., 2004).

As IBDV has a genome linked protein (VPg), like other Birnavirus, it is speculated that they replicate their genome by a strand displacement (semi-conservative) mechanism (Spies et al., 1987). In addition, the Birnavirus RNA possesses a small 5'UTR, which impairs the formation of complex secondary or tertiary structures 
responsible for forming 5' cap structures and an internal ribosome entry site (IRES) which play a role in recruiting cell encoded factors. Therefore, the VPg at the 5' untranslated region (UTR) of birnavirus mRNA is believed to play a role in the initiation of the translation process (Dobos, 1995). Whereas the VPg present in the mRNA is the same VPg as the genomic RNA remains unknown.

The 3' termini of both positive and negative strands of IBDV and IPNV have two constitutive cytosines which allows protein primed initiation of secondary RNA synthesis using VPg linked guanines (Dobos, 1993). Additionally, the 3' end of the Birnavirus RNA does not have a poly (A) tail; therefore, as the poly (A) has an important function in recruiting translation factors, it is not known how Birnavirus resolves this issue. However, a recent study has demonstrated that the presence of stem-loop structures may play a role in translation efficiency as well as initiation of replication (Boot and PritzVerschuren, 2004). Using a computer model, segments A and B from IBDV are able to form small stem-loop structures (secondary structures) in the last $25 \mathrm{nt}$ of the 3'untranslated regions (UTRs). Site directed mutagenesis studies in regions that could destabilize the stem-loop demonstrated that mutations in this area impair and sometimes make the rescue of infectious virus from cell culture impossible. However, once infectious viruses were obtained, replication was reestablished, and it was observed that the mutations were rapidly reverted to the original form or other mutations occurred in other regions to compensate for the introduced mutations. Stem-loop structures in the 
3'UTR are present in other RNA virus as for instance picornavirus (Pilipenko et al., 1992) and coronavirus (Yu and Leibowitz, 1995). They have been considered to play a role in RNA replication, genome packaging, protection against 3'-5' exonucleases and interactions between the 5'- and 3'- UTRs (Boot and Pritz-Verschuren, 2004). Consequently, it is expected that this structures may play a similar role in IBDV, although this assumption has not been confirmed by further studies. von Einem et al.(2004), demonstrated that the polymerase activity was dependent on the 3'end of segments A and B and speculated that the VP1 in combination with the 3'end could be responsible for some specificity in the replication step. This finding supports the idea that the hairpin-loop at the 3 'end may be involved in initiation of the replication process.

\section{Antigenicity}

There are two recognized serotypes of IBDV, designated 1 and 2 which are distinguished by cross-neutralization and cross-protection tests. Serotype 2 is apathogenic in both chickens and turkeys and does not induce protection against serotype 1 strains in chickens (Chettle and Wyeth, 1989). Serotype 1 is pathogenic to chickens (Saif, 1998). The IBDV antigenic subtypes, determined by virus neutralization tests, are classified as classical virulent, variant or very virulent. Studies by Ismail and Saif (1991) have demonstrated that cross-protection can occur between many of the IBDV antigenic subtypes. While classic viruses confer only partial protection against variant viruses, variant viruses can confer full protection against variant and classic viruses. However, the 
level of protection is dependent on the titer of the challenge strain. By using monoclonal antibodies it was shown not only that the variant strains are antigenically different from classical strains, but also that the differences could also be demonstrated between the different variant strains (Snyder et al., 1988; Snyder et al., 1992). A variety of subtypes of classic and variant strains and are commonly encountered. Very virulent strains are antigenically related to classic strains and antigenically different from the variant strains and serotype 2 viruses (Abdel-Alim and Saif, 2001). There is no evidence of antigenic variability in the very virulent strains as observed in variant strains in the US. However, a modified epitope was identified on a vvIBDV strain by the use of neutralizing antibodies (Eterradossi et al., 1997) which corresponded to a mutation of amino acid at position 222 located in hydrophilic peak A. Other mutations have been encountered in very virulent strains but their antigenic and epidemiological significance is questionable (Cao et al., 1998; Eterradossi et al., 1998). The available data in the literature indicate that vvIBDV strains are evolving, but the significance of several modifications still needs to be demonstrated by using cross-neutralization tests.

Sequencing of the VP2 gene of numerous IBDV strains and selection of escape mutants have proven that this variable domain represents the molecular basis of antigenic variation (Schnitzler et al., 1993; Oppling et al., 1991). A previous study has inferred a mutation frequency per nucleotide of about $0.24 \%$ across the hypervariable region of the VP2 gene in very virulent Nigerian isolates (Owoade et al., 2004). Compared with Rotavirus, another double stranded RNA virus, the mutation rate of IBDV is about 10 
times higher in this region (Blackhall et al., 1996). The identification of quasispecies also indicates that IBDV is highly mutable (Jackwood and Sommer, 2002a).

The VP2 protein is conformational dependent, which could be detected by Mabs that react to immunoprecipitated protein but do not react to VP2 in a western blot (Rodriguez-Chavez et al., 2002; van den Berg, 2000). In addition, VP2 is a hydrophobic protein with hydrophilic regions at each terminus, denominated antigenic peaks A and B which span aa 210 to 225 and aa 312 to 324, respectively (Heine et al., 1991; Bayliss et al., 1990). These two hydrophilic peaks are located at the surface of the virus and constitute the neutralizing epitopes, which are under selective pressure by the chicken immune system. Important changes in the sequences of these peaks might determine an antigenic shift, as described for serotype 2 viruses. Two smaller hydrophilic areas of the VP2 variable domain, denominated minor peak 1 (aa 249 to 254) and minor peak 2 (aa 279 to 290) are also responsible for IBDV antigenicity (van den Berg and Gonze, 1996). Point mutations inside or outside these peaks may lead to antigenic drift, giving raise to subtypes such as the serotype 1 variant strains described in the US (van den Berg, 2000). In a recent study, identification of crucial residues of conformational epitopes on VP2 was made using the phage display technique. It was observed that not only the residues in both peak A (222-223) and peak B (317-322) were crucial for IBDV antigenicity, but also amino acid positions 249 (Q), 251 (S), 282 (T) and 313 (V) affect antigenicity. Also, the same study hypothesized that the extreme ends of the variable region of VP2 are important to fold and stabilize the structure so the two hydrophilic regions could be 
properly displayed on the surface of the VP2 protein as well as the central region (Cui et al., 2003).

Contrary to VP2, VP3 is more conserved among IBDV strains or isolates and does not contain any variable region as found in VP2. At least 3 group serotype-specific epitopes are located in VP3 (Oppling et al., 1991). The role of VP3 proteins in inducing neutralizing antibodies is discordant. In a study by Fahey et al. (1985), chickens immunized with VP3 proteins of IBDV which were prepared by eletroelution from sodium dodecyl sulfate-polyacrylamide gel eletrophoresis (SDS-PAGE), produced antibodies that passively protected them against IBDV infection. However, it was reported later on that passive protection could not be achieved with the administration of antibodies against VP3 (Fahey et al., 1985; Fahey et al., 1991). In addition, in a recent study in which VP3 was expressed in a baculovirus insect cell system, this protein failed to induce protection against IBDV infection (Martinez-Torrecuadrada et al., 2000).

\section{Pathogenicity}

IBDV is responsible for causing an acute disease in young chickens. Although turkeys, ducks and ostriches are susceptible to the infection, they are resistant to the clinical disease (Lukert and Saif, 1997; McNulty et al., 1979). However, a recent study isolated serotype 1 very virulent strains in symptomatic turkey flocks with a high mortality rate (Owoade et al., 2004). Whether IBDV was the cause or the result of the disease or immunosuppression requires further investigation. 
Although the amino acid changes in VP2 represents the molecular basis for antigenic variation, no definite genetic regions that determine pathogenicity have been identified (van den Berg, 2000). Studies comparing nucleotide sequences between pathogenic and non-pathogenic serotype 1 strains have found nucleotide changes throughout the genome on segments $\mathrm{A}$ and $\mathrm{B}$, indicating that mutations in different parts of the genome probably contribute to a multigenic nature of virulence (van den Berg, 2000). Recently, Liu and Vakharia (2004), using the reverse genetics system, developed a recombinant virus which contained the segment B from the strains GLSBD (GLS bursa derived) and D78 and segment A from GLSTC (GLS tissue culture adapted). The recombinant virus was able to replicate but exhibited delayed replication kinetics in Vero and chicken embryo fibroblast cells. In vivo studies demonstrated that the recombinant virus propagated more efficiently in the bursa of Fabricius and caused severe bursal lesions. The results indicate that VP1 protein is involved in the efficiency of viral replication and modulates the virulence in vivo (Liu and Vakharia, 2004). Another study by Boot et al., has shown, also by reverse genetics, that VP2 is not the only determinant of the very virulent phenotype (Boot et al., 2000).

IBDV can be classified according to the pathotype as apathogenic (serotype 2) and pathogenic (serotype 1). The pathogenic strains vary from mild, intermediate, intermediate plus and very or hypervirulent (van den Berg, 2000). Several viruses like chicken anemia virus and dengue virus have been reported to have virulence (and attenuation) partially correlated with loss or modification of neutralizing epitopes 
(Scott et al., 2001; Lim and Ng, 1999). But apparently this is not what occurs with IBDV. Several studies have analyzed IBDV pathotypes based on the VP2 variable region. However, a recent study characterized strains based not only on the nucleotide sequence of VP2, but also the ability of the virus to bind to a panel of neutralizing monoclonal antibodies through antigen capture enzyme-linked immunosorbent assays (AC-ELISA). They also examined virulence in SPF chickens after inoculation with a standardized dose. Differences in pathogenicity could be observed between strains belonging to the same antigenic group and genetic lineage. The results demonstrated that analysis of IBDV pathotypes based on the VP2 variable region may not be sufficient for the classification of IBDV strains (van den Berg et al., 2004).

The outcome of an IBDV infection largely depends on the strain and the amount of the infecting virus, the age and the breed of the bird, the route of inoculation, and the presence or absence of neutralizing antibodies (Muller et al., 2003). The severity of the disease is directly proportional to the number of susceptible cells in the bursa; therefore, chickens aged between 3 to 6 weeks are more susceptible, as the bursa reaches the maximum development at this age (van den Berg, 2000). Under field conditions, the most common route of infection is the fecal-oral route. Some studies indicate that the IBDV cell receptor is composed of an $\mathrm{N}$-glycosylated protein (Ogawa et al., 1998). In addition, other studies have indicated that the virus receptor may be located in VP2 (Yamaguchi et al., 1996; Ogawa et al., 1998). Yamaguchi et al.(2002), reported an anti-idiotypic antibody against the monoclonal antibody GI-11 which was not able to prevent the virus 
binding and infection of the target cells, indicating that the epitope recognized by GI-11 is not directly involved in the binding of the virus to the target cells. Another study reported the identification of proteins of 110,82 and $70 \mathrm{kDa}$ in the surface of chicken $\mathrm{B}$ lymphoblastoid cell line, (LSCC-BK3) by monoclonal antibodies that may be associated with the binding of virulent IBDV (Setiyono et al., 2001), and a previous study identified two proteins of 40 and $46 \mathrm{kDa}$ expressed on the surface of lymphoid cells (Nieper and Muller, 1996). Therefore, probably IBDV has several cellular receptors that will bind to the virus or not depending on unknown variables. Once the virus infects the host, it reaches the gut and from there the virus is transported to other tissues, probably by the blood stream. Other cells can play a role in dissemination of the virus as for instance monocytes and macrophages. A few hours after infection the virus can be detected in the kidneys and liver, but the primary viral replication takes place in bursa of Fabricius (BF) (Kibenge et al., 1988; Sharma et al., 2000). The virus infection will result in cytolysis, which leads to a dramatic reduction in circulating $\operatorname{IgM}^{+} \mathrm{B}$ cells, as they are IBDV target cells. There is no evidence that IBDV replicates in thymic cells, although thymus atrophy and apoptosis occurs (Sharma et al., 2000). Once the virus reaches the bursa, it will spread to the follicles and by $13 \mathrm{~h}$ post-inoculation most of the follicles are positive for the virus. A second viremia occurs by $16 \mathrm{~h}$ post inoculation which may lead to disease and death. The virus replication leads to destruction of lymphoid cells in the bursa of Fabricius and to a lesser extent in other lymphoid organs such as cecal tonsils and spleen (van den Berg, 2000). 


\section{Lesions and clinical signs}

An incubation period of approximately 2 to 4 days precedes the clinical disease. The exact cause of the clinical signs has not been established, and apparently it is not only related to the lesions and bursal damage. It has been speculated that the clinical signs could be due a septic shock syndrome, in which many cytokines are released (van den Berg, 2000). In addition, mortality and clinical signs of infectious bursal disease have been associated with formation of immune-complexes and depletion of circulating levels of haemolytic complement and clotting abnormalities (Kibenge et al., 1988).

IBDV infected young birds ( $<2$ weeks of age) generally show no clinical signs or mortality but develop a subclinical infection characterized by microscopic lesions in the bursa of Fabricius and may be immunosuppressed during their lifetime, which leads to an increased susceptibility to opportunistic infections and an ineffective response to vaccines. On the other hand, in a susceptible flock (between 3 and 6 weeks of age) the acute disease leads to economic losses due the impaired growth and death, and from condemnation of carcasses due the hemorrhages in the skeletal muscles (Kibenge et al., 1988).

The virus replication results in extensive lymphoid tissue damage in the bursal follicles, which is accentuated by necrosis and apoptosis, mainly in immature $\mathrm{T}$ and $\mathrm{B}$ cells, which may lead to immunosuppression. A direct effect from the viral proteins VP2 and VP5 has been implicated in apoptosis induction. Conversely, apoptosis has been observed in antigen-negative bursal cells which implies the existence of another 
mechanism, probably immunological that triggers this event (Tanimura and Sharma, 1998; Nieper and Muller, 1996). Also, IBDV infection changes the potassium current properties of chicken embryo fibroblast. These might cause alterations of membrane permeability, which affects homeostasis and results in cytolysis and death of the infected cells (Muller et al., 2003).

Lesions include bursal atrophy, dehydration and darkened discoloration of pectoral muscles, and haemorrhagies in some muscle tissues and bursa. Lymphocyte necrosis is the most common histologic lesion and is accompanied by edema, hyperemia, and accumulation of heterophils. Cystic cavities replace lymphocytes in follicles and later there is some regeneration of lymphocytes (Saif, 1998; Sharma et al., 2000). Although the $\mathrm{BF}$ is the primary site of replication, lesions can be located also in the spleen, thymus, cecal tonsils, and gland of Harder (Saif, 1998). Variants are different from classical strains in that they cause a very rapid bursal atrophy associated with a minimal inflammatory response (Sharma et al., 1989). Symptoms vary from ruffled feathers, anorexia, depression, diarrhea, prostration and death. Previous studies have indicated that serotype 1 could be recovered from the bursa of Fabricius up to 16 days post-infection (Moradian et al., 1990) and the viral genome up to 16 days and 24 days with classic and variant strains, respectively (Henderson and Jackwood, 1990). On the other hand, another study using the variant strain Del-E has demonstrated the presence of IBDV RNA until 6 weeks post-infection (Elankumaran et al., 2002). The mortality indexes may range from insignificant to $100 \%$ and the morbidity is usually of $100 \%$ (Saif, 1998). For instance, classical virulent strains isolated in the US in the early 60's (Edgar 2512 and Irwin 
Moulthrop (IM)) caused 30-60\% mortality in light-breed chickens. The variant viruses first isolated from vaccinated farms in the US did not cause mortality and induced rapid bursal atrophy (Snyder et al., 1988; Snyder et al., 1992). Very virulent strains may lead to $70 \%$ mortality and induce lesions in other immune organs like bone marrow and thymus (Brown et al., 1994).

\section{IBDV Immunity and Immunosuppression}

Chickens infected with IBDV mount a vigorous antibody response which is probably the most important response against this disease (Lukert and Saif, 1997).

IBDV infection leads to immunosuppression which is more pronounced if the virus exposure occurs early in life which is demonstrated by the complete lack of IgG and the presence of only a monomeric IgM (Ivanyi, 1975). The exact mechanism of IBDV induced immunosuppression is still not fully understood, but it is known that it causes extensive necrosis of B cells and the proteins VP2 and VP5 induce apoptosis. In addition, it has been demonstrated that IBDV interferes with transcription of interferon (IFN) RNA to evade the chicken immune surveillance, and this may be an important factor in the virus induced immunosuppression (Ragland et al., 2002).

IBDV infected chickens produce sub-optimal levels of antibodies against a number of infectious and non-infectious agents (Kim et al., 1999). Recent data has demonstrated that IBDV-induced humoral deficiency can be reversible, and that the restoration of the bursal follicles is directly related to the production of normal levels of antibodies 
(Sharma et al., 2000). In addition, while the primary antibody response is impaired, the secondary antibody response does not modify (Rodenberg et al., 1994; Giambrone et al., 1977; Sharma et al., 1989).

Some studies have demonstrated that, although the B cell response is important to confer immune protection to the chickens, non-B cell immunity may play an important role in protection (Rautenschlein et al., 2003). Additionally, T cells may modulate IBDV pathogenesis in two ways: they limit viral replication in the bursa in the early phase of the disease (at 5 days post infection) and also intrabursal $\mathrm{T}$ cells promote bursal tissue damage and delay tissue recovery possibly through the release of cytokines and cytotoxic effects (Rautenschlein et al., 2002). In another study by Sharma et al.(2000), infiltration of $\mathrm{T}$ cells was detected at the $\mathrm{BF}$ after the emergence of viral antigen. This event persisted even after the clearance of the viral antigen. The extensive T-cell infiltration into the BF may also be involved in limiting virus spread and thus initiating the recovery process. Also, it is possible that the IBDV-induced T-cells may enhance viral induced lesions.

Previous data have demonstrated that in vitro mitogenic proliferation of $\mathrm{T}$ cells of chickens exposed to IBDV is compromised, mainly during the first 3 to 5 days of virus exposure. During this period, the T-cell of IBDV infected chicken also displayed a severe impairment in IL-2 secretion. However, how this T cell mitogenic inhibition in vitro translates to pathogenesis in vivo remains unknown (Sharma et al., 2000). In addition, it has been hypothesized that macrophages may play a role in the decreasing of mitogenic 
proliferation of $\mathrm{T}$ cells when stimulated by cytokines such as IFN $\gamma$, which may trigger the production of nitric oxide (Kim et al., 2000).

There is evidence that the $\mathrm{T}$ cell response may be involved in IBDV induced immunosuppression (Sharma and Fredericksen, 1987; Sharma et al., 1989) by mechanisms such as development of suppressor cells or by impairment of helper T cells (Sharma and Fredericksen, 1987). However, studies to support this hypothesis have not been reported. The virus induced immunosuppression increases susceptibility against other pathogens such as Salmonella sp. and E. coli species (Bautista et al., 2004; Wyeth, 1975), decreases feed conversion, hatchability and leads to a poor vaccination response to common vaccines used in the poultry industry. In addition, birds that survive the acute phase of the disease may recover completely if infected older in life, while young chickens may become immunosuppressed for their lifetime span. Consequently, the IBDV induced immunosuppression leads, either directly or indirectly, to economic losses in the poultry industry.

A previous study analyzed the influence of the MHC on IBDV vaccine response in chickens and it was demonstrated that there is indeed, a MHC haplotype effect on the specific antibody response against IBDV, with the BW1 haplotype having higher antibody levels and also significant lower bursal lesion score when compared with the haplotypes B19 and B131 at 8 days post infection. Therefore protective immunity against IBDV may be related to the MHC complex of the chicken (Juul-Madsen et al., 2002). 


\section{Epidemiology}

IBDV is spread worldwide and during the $63^{\text {rd }}$ General Session of the Office International des Epizooties (OIE, Paris, 15 to 19 May 1995), it was found that the disease is present in $95 \%$ of the OIE member countries, which denotes and emphasizes its importance. Therefore, the current control measures against this virus are not efficient. Variant strains have been reported in the US since 1984 (Saif, 1998; Snyder et al., 1988), in Australia (Sapats and Ignjatovic, 2000), Central and South America (Jackwood and Sommer, 1999; Banda et al., 2003) and they have been reported to overcome immunity induced by vaccination with classical strains (Ismail and Saif, 1991). The very virulent strains emerged in Europe in 1986 and since then they spread to Africa, Asia and South America and nucleotide sequencing of the VP2 gene has demonstrated that they are genetically similar to each other (Eterradossi et al., 1999). Very virulent strains were first found in Europe at the end of the 80's, then in Japan in early 90's and from there it rapidly spread to Asia. Since then they have been isolated in other countries like Brazil (Ikuta et al., 2001), Egypt (Abdel-Alim et al., 2003), Croatia (Lojkic et al., 2003), and in Asian countries (Cao et al., 1998; Sun et al., 2003). On the other hand, in countries like the US, Australia, New Zealand and Canada, no outbreaks have occurred so far.

The reason for the emergence of antigenic variants in the US is not clear, but probably changes in the field situation led to adaptation of this new strain. For instance, poultry production has adapted to the market needs with dense populations turning over very fast which creates a favorable environment for mutable viruses. In addition, the 
widespread use of vaccines increases the selective pressure on these pathogens; therefore it promotes the survival of mutants that diverge from the commercial strains. On the other hand, phylogenetic analysis of the very virulent (vv) IBDV strains indicated that segment B nucleotide sequence forms a distinguished cluster. This indicates that very virulent strains probably emerged from a reassortment event from a still non identified source.

The first outbreaks caused by vvIBDV are described in Europe in the late 1980s. However, a study by Owoade et al.(2004) suggests that West-Africa may be the origin of the vvIBDV variants found across the Old World, as a high degree of sequence diversity among Nigerian vvIBDV isolates was reported.

\section{Vaccination}

IBDV is highly infectious, very resistant in the environment and can persist in the poultry houses after cleaning and disinfection. The virus is also resistant to ether and chlorophorm, it is inactivated at $\mathrm{pH} 12.0$ but unaffected at $\mathrm{pH} 2.0$. Consequently the virus can persist in the chicken houses for long periods (Benton et al., 1967). Additionally, in order for poultry production to be feasible economically, some measures are necessary such as short intervals between batches and sometimes use of the same litter. Therefore, hygienic measures alone are not enough to control this disease and vaccination is necessary (Kibenge et al., 1988).

Several vaccines have been used to combat IBDV infection. Classical live vaccines are attenuated virus that mimics the natural infection in the host. These vaccines 
may have residual pathogenicity and an attenuated strain can revert to its virulent form. Another form of immunization being used is the inactivated vaccines, which are also able to induce sufficient protection via maternal transfer of antibodies to progeny. These vaccines have been used in the field successfully till the emergence of the hypervirulent or very virulent strains.

Live vaccines vary in the degree of attenuation and are recognized as mild, intermediate and hot; the latter is able to cause lesions in the follicles and therefore it may cause immunosuppression in vaccinated birds, impairing the effectiveness of vaccination against other important infectious pathogens. However, these vaccines cause no mortality (van den Berg, 2000). Several vaccination programs are currently being used, depending on the field situation encountered. Before the emergence of hypervirulent strains, the standard procedure was to vaccinate the hens with an oil-emulsion vaccine just before the laying period in order to provide passive protection to the offspring for the first 2 to 3 weeks of life. This practice was efficient to protect against classical strains, but did not confer protection against very virulent strains. Currently, a common commercial practice is to vaccinate chickens with live vaccines during the first 3 weeks of life (Kibenge et al., 1988). The timing of vaccination is crucial as the presence of maternal antibodies may neutralize the vaccine used (Muller et al., 2003). Fully attenuated IBDV strains do not induce immunity in chickens in the presence of maternal antibodies. In order to protect against vvIBDV strains, it was necessary to use less attenuated strains or hot vaccines which may lead to bursal damage and consequently immunosuppression (Kibenge et al., 1988). 
High levels of maternal antibodies can protect chickens from the disease caused by classical strains (Wyeth and Chettle, 1982; Wood et al., 1983). The relation between the serological response of chickens after the use of inactivated vaccines and the protection of the vaccinated chickens is dependent on the IBDV challenge strain and the vaccinal IBDV strain. For instance, maternal antibodies induced by inactivated vaccines based on the strains D78 and Winterfield 2512 were able to protect 2 week old chicks against clinical signs when challenged with the classical virulent strain 52/70 as well as with very virulent IBDV (D6948). However, vaccination did not prevent subclinical infection, even in the presence of high titers of neutralizing antibodies. In addition, higher antibody titers were necessary to prevent the clinical signs in very virulent strains (Maas et al., 2001).

Vaccination was able to control IBD (infectious bursal disease) till the 1980's, when new antigenic variants emerged in the US. These strains were able to break through maternal immunity provided by vaccination and therefore, caused infection and disease. Vaccination with classical strains does not protect against variant strains. Conversely, vaccines made of variant viruses can elicit protection against classic and variant strains, depending on the dose employed (Ismail and Saif, 1991). It has been reported that serotype 1 IBDV strains may have considerable antigenic variation which was demonstrated by neutralization assays (Jackwood and Saif, 1987). Based on this, it is possible that an IBDV vaccine strain that is more similar to the challenge strain induces better protection against this strain than a less related vaccine strain. 
Chickens infected with IBDV develop a strong anti-IBDV neutralizing antibody response which is critical for disease recovery (Lukert and Saif, 1997). Because of this, immunization against IBDV has been focused primarily on developing strong humoral responses. However, recent studies have demonstrated the important role of the cellular response in protection against IBDV infection (Rautenschlein et al., 2002).

Several vaccines have been developed to create a new vaccine able to confer better levels of protection; additionally, in order for the vaccine to be feasible, it needs to be easily delivered and economically practical. The latest attempts to achieve this goal will be discussed in the next paragraphs.

Several vaccines were developed to try to overcome the interference of maternal antibodies. A vaccine in which the vaccine virus is complexed in vitro with antibodies, denominated immune complex vaccine was developed and used for in ovo vaccination. The vaccine was able to protect the chickens when they were challenged with STC, even in the presence of different levels of maternal antibodies (Haddad et al., 1997). The mechanism of the vaccine is still poorly understood, although it was hypothesized that the complex was taken up by follicular dendritic cells and the virus persists in these cells until maternal antibodies decrease (Jeurissen et al., 1998). However, it is unknown if this vaccine is able to protect chickens against infection by other IBDV strains.

Another vaccination strategy is based in the use of recombinant vaccine viruses. They are designated to avoid maternal antibody interference with vaccination and eliminate the need for less attenuated vaccines. They are usually based on insertion of the gene 
encoding the most immunogenic protein of IBDV in an apathogenic viral vector. In a study by Rogel et al.(2003), segment A (VP2, VP4, VP3) was introduced into the Escherichia coli expression vector pET21a and the recombinant was used for intramuscular vaccination. The vaccinated chickens were protected against the challenging strain (Gep5). However, it is possible that if other challenge strains were used, different results would be observed. In addition, the use of intramuscular vaccine is not feasible for large scale commercial flocks. In another study, Goutebroze et al.(2003), prepared a recombinant vaccine expressing the VP2 protein of IBDV in a herpesvirus (HVT) vector. Conventional broilers were vaccinated subcutaneously at one day of age and challenged with a very virulent strain of the virus under experimental conditions and in a field trial. The vaccination conferred immunity despite the presence of maternal antibodies and was maintained through the broiler's lifespan, without need for boosters.

In a study by Martinez-Torrecuadrada, the immunogenicity and protective efficacy of different IBDV-derived particles expressed in a baculovirus vector was assessed. It was observed that VP2 capsids, VPX (VP2 precursor) tubules and polyprotein-derived structures were able to induce humoral responses. However, the VP2 icosahedral capsids presented a stronger virus-neutralizing capacity when compared to the other two structures using the same dose, probably because their protein structure mimics the authentic proteins and their conformation. The virus polyprotein expressed in other systems like fowlpox virus and Semliki Forest virus failed to induce neutralizing antibodies in immunized birds, therefore the expression system probably played a role in 
the correct scaffolding of the protein and/or in producing higher amounts of particles. The results demonstrated that VP2 based capsids induce a better antibody response in both quality and quantity (Martinez-Torrecuadrada et al., 2003).

DNA vaccines consist of a recombinant plasmid containing a target gene that encodes viral proteins in the absence of live virus which avoids problems like reversion of virulence, divergent mutants and minimizes the possibility of environmental contamination. In addition, DNA vaccines have proven to elicit both humoral and cellular responses against various infectious agents (Lewis and Babiuk, 1999). However, several factors such as the source of the target genes (from different IBDV strains), the eukaryotic expression vector, the adjuvant, the delivery route and the vaccination dosage play an important role in influencing the efficacy of DNA vaccines against IBDV (Li et al., 2003). The use of a plasmid DNA carrying VP2, VP4 and VP3 genes of the STC strains as a DNA vaccine proved to confer protection of $50-100 \%$ against a STC challenge strain, depending on the number of immunizations (Chang et al., 2001). In another study by Chang et al.(2003), different fragments of segment A of the STC strain were cloned into a eukaryotic expression plasmid vector and used as DNA vaccines. It was observed that the plasmids that contained the VP2 protein were effective in protecting against IBDV infection when challenged with the STC strain. On the other hand, plasmids containing VP3 and/or VP4 but not VP2, were not able to protect the chickens. Consequently, this study confirms that VP2 is a host-protective immunogen and also essential for development of IBD DNA vaccines. On the other hand, a study by 
Li et al., used the complete polyprotein (VP2, VP4, VP3) and VP2 genes of one attenuated strain and one virulent strain to prepare DNA vaccines in the liposome adjuvant. It was observed that the VP2 initiated a very low level of neutralizing antibodies and protected chicken from clinical symptoms and mortality, but not from bursal damage. Conversely the segment VP2/4/3 was able to induce antibodies and protect against virulent IBDV ( $\mathrm{Li}$ et al., 2003). In another study using plasmid DNA vaccine expressing VP2 protein in the presence or absence of IL-2 plasmid DNA, it was observed that the VP2 gene vaccine by itself led to partial protection when challenged with the STC challenge strain, and when this vaccine was coupled with chicken IL-2 plasmid DNA it significantly increased the protection after challenge with the virulent strain (Hulse and Romero, 2004). Another study strongly indicated that the efficacy of avian DNA vaccine can be modulated by simultaneous administration of a plasmid encoding IL-2; therefore it can be used as an option instead of the conventional adjuvants which are not economically feasible and practical to be used in the poultry industry (Li et al., 2004).

In a recent study using plasmid DNA vaccines expressing only VP2 protein or VP243 proteins of very virulent IBDV (Korean SH/92 strain) a higher survival rate and a lower bursal atrophy was observed when compared to the non-immunized groups after challenge, with the chickens immunized with pcDNA-VP243 reaching 70\% survivability. In addition, in a the Con-A-induced lymphocyte proliferation assay, the immunized groups showed higher proliferation responses than non-immunized groups, indicating that 
the cellular immune response may play a important role in the protection of chickens against vvIBDV infection (Kim et al., 2004).

Due to their high cost, individual variability in the response and low humoral response, DNA vaccines may not be feasible to be used in large scale at this time (Eterradossi et al., 1999).

A study by Huang et al., used the reverse genetics approach to devise a recombinant Newcastle disease virus (NDV) vector from a commonly used vaccine strain to express VP2 of a variant IBDV strain GLS-5. The recombinant virus was genetically stable and expressed the VP2 protein. A challenge study using NDV strain Texas GB or IBDV variant strain GLS-5 3 weeks post vaccination demonstrated that vaccination with the recombinant virus provided $90 \%$ protection against NDV and IBDV. Booster immunization conferred $100 \%$ protection against both viruses (Huang et al., 2004). In another study by Mundt et al. (2003), a chimera between both classical (D78) and variant strains (Del-E) was generated by reverse genetics. The chimera vaccine was able to elicit neutralizing antibodies against both D78 and Del-E strains. Furthermore it was able to breakthrough a relatively high titer of maternally derived antibodies. However, the vaccine caused bursal tissue damage, and although the lesions further decreased upon time, they indicate at least a transitory immunosuppression.

Based in the latest information about vaccines, it is reasonable to assume that the proposed new vaccines are still not able to substitute the current immunization programs. Although many of these vaccines are safer and more effective, they are still not feasible 
for commercial scale due the high costs implied in their production, as for instance the purification process, use of adjuvants and others. In addition, most of these proposed vaccines are administered via subcutaneous injection, which is laborious and time consuming considering that it is necessary to vaccinate a large population of birds at the same time. Consequently, in order to manage the current issues in the field, a more suitable solution could be the use of vaccines that are antigenically similar to the strain present in the flock's environment. In this context, a fast identification method could be extremely useful to assist in the prevention and control against this disease.

\section{Diagnosis}

Rapid diagnostic tests are very important in the poultry industry to prevent the spread of the disease and to minimize the economic losses. In the field situation, usually the clinical signs of the chickens are indicative of IBDV infection. Confirmation is generally

done by gross pathological changes in the bursa of Fabricius and histopathological changes combined with presence of virus by immunohistochemistry. The virus can be isolated using embrionated chicken eggs. Antigen-capture enzyme-linked imunosorbent assay (AC-ELISA) or agar-gel precipitin assay can be used to detect viral antigens. ACELISA also can be used to identify very virulent strains, although with some limitations. Additionally, indirect ELISA tests are available (Jackwood et al., 1996b) as well as other tests that are able to detect IBDV-specific antibodies like agar gel precipitation (Hirai et 
al., 1974), and quantitative counterimmunoelectrophoresis (Raj et al., 1994). Recently, another indirect ELISA was developed using multiple antigenic peptides (MAP) with molecular weights of 12.8 and $13.3 \mathrm{kDa}$ derived from VP2, which were highly reactive with IBDV-positive sera but did not cross-react with other avian viruses antisera (Saravanan et al., 2004). MAPs can be a good alternative for use in indirect ELISA other than the previously reported use of baculovirus expressed proteins (Jackwood et al., 1996b) or the use of entire virus in the serum for monitoring and diagnosis of infectious bursal disease (IBD). As maternally antibodies derived from IBDV vaccinated breeder flocks are present in young chicks and this can interfere with vaccination, indirect ELISA has been used to monitor antibody titers in the breeder chickens and their progeny.

However, in general, serologic tests lack specificity and problems with reagent crossreactions occur often.

To securely identify antigenic serotypes and subtypes the only method currently used is the virus neutralization assay (Jackwood and Saif, 1987), which is a very laborious and time consuming method. Also the analysis is difficult because virus neutralization studies require the virus to be adapted and therefore replicate in vitro. The problem is that many field strains are not able to grow in cell culture. This fact denotes the need for tests that are able to detect differences among IBDV strains and isolates. Several molecular tests have been developed but these tests cannot distinguish between the different antigenic subtypes. However, they are very useful in epidemiological studies. The method currently most used for characterization of IBDV strains is the 
reverse transcriptase/ polymerase chain reaction - restriction fragment length polymorphism in the VP2 gene (RT-PCR RFLP). Briefly, primers are designed to amplify a fragment of $743 \mathrm{bp}$ of the VP2 gene. The resulting PCR product is cut using the restriction enzymes $B s t \mathrm{NI}$ and $\mathrm{Mbol}$. This technique is able to identify six different RFLP patterns. However, several strains can not be classified in these groups, which denotes the high genetic variability among strains (Jackwood and Sommer, 1998). In some cases, the genetic variations were correlated with antigenicity (Jackwood and Saif, 1987; Jackwood et al., 1996a) and high virulence among IBDV strains (Lin et al., 1993). On the other hand, another study demonstrated that RFLP profiles and nucleotide sequencing can be used to assess the genetic differences among the IBDV strains but is not able to predict the antigenic differences between viruses (Jackwood et al., 2001). Recently, Tiwari et al., proposed the use of restriction enzyme analysis of the amplified VP1 gene sequence. The technique consisted in amplifying by PCR a fragment of $480 \mathrm{bp}$ and digesting the product with Taql enzyme and Bst NI. The test proved to be useful in analyzing genetic differences between vv strains from India when the Taql enzyme was used. The author proposed that this technique can be used to distinguish field isolates from the classical and vaccine strains, although only two different profiles were observed (Tiwari et al., 2003).

Recently a heteroduplex mobility assay (HMA) was adapted to be used with IBDV, by analyzing a 390-bp PCR product that encompasses the VP2 region. The method basically compares two polymerase chain reaction amplicons, which are mixed 
together in approximately the same amounts and denatured at $94-95{ }^{\circ} \mathrm{C}$. After that, the reaction is cooled down and the single strains hybridize and form double-strand DNA molecules. Homologous hybridization can occur from the strands of the same amplicon as well as heterologous hybridizations will occur among strands of different amplicons originating heteroduplexes, which contain single stranded regions or bubbles due to mismatches. This will slow down the migration pattern in the gel. Therefore, after the gel eletrophoresis, it is possible to distinguish between homoduplexes and heteroduplexes and the distance between them is proportional to the divergence among the two sequences. The patterns of the heteroduplexes correlate with the genotype. This technique was able to distinguish between classic, antigenic variants and very virulent strains and also to detect genetic differences within antigenic subtypes (Banda et al., 2004). This approach has several advantages: it is able to scrutinize the complete nucleotide sequence analyzed; consequently it offers more sensitivity to detect nucleotide changes when compared with RFLP which is able to detect nucleotide mutations located only in the restriction enzyme sites. In addition, this approach may be useful in epidemiological studies and may be able to demonstrate a genetic relationship between the vaccine used in the field and the isolate tested. On the other hand, this technique is not completely standardized and still need adjustments; as for instance to determine the optimal amount of DNA used in the reaction.

Several other molecular tests for IBDV diagnosis have been developed; for instance multiplex polymerase chain reaction (MPCR) and tissue imprint hybridization 
among others. MPCR has been developed and adapted to detect and differentiate simultaneously avian adenovirus group I, avian reovirus, infectious bursal disease and chicken anemia virus from fecal samples. This technique proved to be sensitive, specific, cost effective and can be used in diagnosis, screening and surveillance of flocks (Caterina et al., 2004). Tissue imprint hybridization basically uses a peroxidase labeled PCR generated probe followed by enhanced chemiluminescence hybridization assay to detect IBDV directly from imprints on a nylon membrane. This technique is apparently simple, fast and safe and it may be useful in screening samples, but it has no ability to identify and characterize the IBDV strain present in the flock (Parthiban and Thiagarajan, 2002). Both approaches are not able to identify the IBDV strains, and therefore they have poor application for epidemiological purposes and in assisting vaccination strategies.

Recently Real-Time RT-PCR has been adapted to be used in molecular diagnosis of IBDV, and it has proved to be a powerful tool to assist in the control of this disease. Briefly, the test consists in a two probe system: one mutation probe labeled in the 5 ' end with fluorescein and one anchor probe labeled in the 3' end either with Red 645 or 705. These probes are designed to hybridize adjacent to each other separated by 1 to $5 \mathrm{nt}$ and are complementary to the PCR product. If there is amplification, the probes will hybridize and the fluorescein of the donor probe will excite the red 645/705 of the acceptor probe. During this process, fluorescence resonance transfer occurs (FRET), which is detected by the Light Cycler equipment. After the amplification process the reaction is heated slowly from 35 to $90{ }^{\circ} \mathrm{C}$ and a melting curve is constructed based on 
the denaturation of the complementary strand from the mutation probe. The light Cycler detects the loss of fluorescence and builds a melting curve (Tm), and based on that the Tm of the mutation probe is determined. If the sample is a perfect match with the mutation probe, the Tm will not change. However, if the sample has mutations, the Tm will decrease, as they will destabilize the double-helix (Jackwood and Sommer, 2002b). This technique has been used for identification of IBDV quasispecies, using probes complementary to the VP2 gene of IBDV, which encodes for the neutralizing epitopes (Jackwood and Sommer, 2002a). Another recent study has used real-time RT-PCR to detect and identify selected vaccine strains of IBDV, using probes designed to the VP2 gene. Although the technique can be very valuable for the poultry industry, as the flocks can be screened for viruses that do not match with the vaccines employed, the test analyzes only one antigenic region (peak B), and IBDV has three other neutralizing epitopes which decreases the accuracy of the test. In addition, field samples were not tested using this technology (Jackwood et al., 2003). Another study by Raue and Müller reported the use of real-time RT-PCR assay using SYBR ${ }^{\circledR}$ green detection of the PCR products. A fragment of $723 \mathrm{bp}$ of the VP2 gene was amplified, but they did not observe differences in the Tm of the samples tested or among classic, virulent and very virulent viruses, and therefore the applicability of this test is restricted (Raue and Muller, 2001). A study by Moody et al.(2000), used a TaqMan ${ }^{\circledR}$ multiplex RT-PCR to quantify IBDV RNA levels in blood samples. The method proved to be rapid very sensitive, but its applicability is restricted to diagnosis and is not different from a regular RT-PCR, as the 
presence of the virus through the presence of their RNA can be detected but no further identification is possible as the probe is digested during the amplification step (Moody et al., 2000). 


\section{REFERENCES}

Abdel-Alim, G., M. H. Awaad, and Y. M. Saif. 2003. Characterization of Egyptian field strains of infectious bursal disease virus. Avian Dis. 47:1452-1457.

Abdel-Alim, G. A. and Y. M. Saif. 2001. Immunogenicity and antigenicity of very virulent strains of infectious bursal disease viruses. Avian Dis. 45:92-101.

Anzola, J. B., Z. Xu, T. Asamizu, and D. L. Nuss. 1987. Segment specific inverted repeats found adjected to conserved terminal sequences in wound tumor virus genome and defective interfering RNAs. Proc. Natl. Acad. Sci. U. S. A 84:8305-.

Azad, A. A., M. N. Jagadish, M. A. Brown, and P. J. Hudson. 1987. Deletion mapping and expression in Escherichia coli of the large genomic segment of a birnavirus. Virology 161:145-152.

Bais, M. V., R. S. Kataria, A. K. Tiwari, K. N. Viswas, A. V. Reddy, and N. Prasad. 2004. Sequence analysis of an Indian field isolate of infectious bursal disease virus shows six unique amino acid changes in the VP1 gene. Vet. Res. Commun. 28:641646 .

Banda, A., P. Villegas, and J. El Attrache. 2003. Molecular characterization of infectious bursal disease virus from commercial poultry in the United States and Latin America. Avian Dis. 47:87-95.

Banda, A., P. Villegas, and J. El Attrache. 2004. Heteroduplex mobility assay for genotyping infectious bursal disease virus. Avian Dis. 48:851-862.

Bautista, D. A., S. Elankumaran, and R. A. Heckert. 2004. Effect of a variant infectious bursal disease virus (E/Del) on Salmonella typhimurium infection in commercial broiler chickens. Avian Dis. 48:361-369.

Bayliss, C. D., U. Spies, K. Shaw, R. W. Peters, A. Papageorgiou, H. Muller, and M. E. Boursnell. 1990. A comparison of the sequences of segment A of four infectious bursal disease virus strains and identification of a variable region in VP2. J. Gen. Virol. 71 ( Pt 6):1303-1312. 
Benton, W. J., M. S. Cover, and J. K. Rosenberger. 1967. Studies on the transmission of the infectious bursal agent (IBA) of chickens. Avian Dis. 11:430-438.

Blackhall, J., Fuentes A, and Magnusson G. 1996. Genetic stability of a porcine rotavirus RNA segment during repeated plaque isolation. Virology 225:181-190.

Boot, H. J. and S. B. Pritz-Verschuren. 2004. Modifications of the 3'-UTR stem-loop of infectious bursal disease virus are allowed without influencing replication or virulence. Nucleic Acids Res. 32:211-222.

Boot, H. J., A. A. ter Huurne, A. J. Hoekman, B. P. Peeters, and A. L. Gielkens. 2000. Rescue of very virulent and mosaic infectious bursal disease virus from cloned cDNA: VP2 is not the sole determinant of the very virulent phenotype. J. Virol. 74:6701-6711.

Brandt, M., K. Yao, M. Liu, R. A. Heckert, and V. N. Vakharia. 2001. Molecular determinants of virulence, cell tropism, and pathogenic phenotype of infectious bursal disease virus. J. Virol. 75:11974-11982.

Brown, M. D., P. Green, and M. A. Skinner. 1994. VP2 sequences of recent European 'very virulent' isolates of infectious bursal disease virus are closely related to each other but are distinct from those of 'classical' strains. J. Gen. Virol. 75 ( Pt 3):675680 .

Cao, Y. C., W. S. Yeung, M. Law, Y. Z. Bi, F. C. Leung, and B. L. Lim. 1998. Molecular characterization of seven Chinese isolates of infectious bursal disease virus: classical, very virulent, and variant strains. Avian Dis. 42:340-351.

Caston, J. R., J. L. Martinez-Torrecuadrada, A. Maraver, E. Lombardo, J. F. Rodriguez, J. I. Casal, and J. L. Carrascosa. 2001. C terminus of infectious bursal disease virus major capsid protein VP2 is involved in definition of the T number for capsid assembly. J. Virol. 75:10815-10828.

Caterina, K. M., Frasca S Jr, T. Girshick, and M. I. Khan. 2004. Development of a multiplex PCR for detection of avian adenovirus, avian reovirus, infectious bursal disease virus, and chicken anemia virus. Mol. Cell Probes 18:293-298.

Chang, H. C., T. L. Lin, and C. C. Wu. 2001. DNA-mediated vaccination against infectious bursal disease in chickens. Vaccine 20:328-335.

Chettle, N. J. and P. J. Wyeth. 1989. Failure of maternally derived infectious bursal disease antibodies to serotypes 1 and 2 to protect against heterologous virus. Br. Vet. J. 145:165-169. 
Chevalier, C., J. Lepault, B. Da Costa, and B. Delmas. 2004. The last C-terminal residue of VP3, glutamic acid 257, controls capsid assembly of infectious bursal disease virus. J. Virol. 78:3296-3303.

Chevalier, C., J. Lepault, I. Erk, B. Da Costa, and B. Delmas. 2002. The maturation process of pVP2 requires assembly of infectious bursal disease virus capsids. J. Virol. 76:2384-2392.

Cosgrove, A. S. 1962. An apparently new disease of chickens-Avian Nephrosis. Avian Dis. 6:385-389.

Cui, X., H. S. Nagesha, and I. H. Holmes. 2003. Identification of crucial residues of conformational epitopes on VP2 protein of infectious bursal disease virus by phage display. J. Virol. Methods 109:75-83.

Da Costa, B., C. Chevalier, C. Henry, J. C. Huet, S. Petit, J. Lepault, H. Boot, and B. Delmas. 2002. The capsid of infectious bursal disease virus contains several small peptides arising from the maturation process of pVP2. J. Virol. 76:2393-2402.

Dobos, P. 1993. In vitro guanylylation of infectious pancreatic necrosis virus polypeptide VP1. Virology 193:403-413.

Dobos, P. 1995. Protein-primed RNA synthesis in vitro by the virion-associated RNA polymerase of infectious pancreatic necrosis virus. Virology 208:19-25.

Elankumaran, S., R. A. Heckert, and L. Moura. 2002. Pathogenesis and tissue distribution of a variant strain of infectious bursal disease virus in commercial broiler chickens. Avian Dis. 46:169-176.

Eterradossi, N., C. Arnauld, F. Tekaia, D. Toquin, H. Le Coq, G. Rivallan, M. Guittet, J. Domenech, T. P. Van Den Berg, and M. A. Skinner. 1999. Antigenic and genetic relationships between European very virulent infectious bursal disease viruses and an early West Africa isolate. Avian Pathol. 28:36-46.

Eterradossi, N., C. Arnauld, D. Toquin, and G. Rivallan. 1998. Critical amino acid changes in VP2 variable domain are associated with typical and atypical antigenicity in very virulent infectious bursal disease viruses. Arch. Virol. 143:1627-1636.

Eterradossi, N., G. Rivallan, D. Toquin, and M. Guittet. 1997. Limited antigenic variation among recent infectious bursal disease virus isolates from France. Arch. Virol. 142:2079-2087. 
Fahey, K. J., P. McWaters, M. A. Brown, K. Erny, V. J. Murphy, and D. R. Hewish. 1991. Virus-neutralizing and passively protective monoclonal antibodies to infectious bursal disease virus of chickens. Avian Dis. 35:365-373.

Fahey, K. J., I. J. O'Donnell, and T. J. Bagust. 1985. Antibody to the $32 \mathrm{~K}$ structural protein of infectious bursal disease virus neutralizes viral infectivity in vitro and confers protection on young chickens. J. Gen. Virol. 66 ( Pt 12):2693-2702.

Faragher, J. T., W. H. Allan, and P. J. Wyeth. 1974. Immunosuppressive effects of infectious bursal agent on vaccination against Newcastle disease. Vet. Rec. 95:385388.

Fernandez-Arias, A., S. Martinez, and J. F. Rodriguez. 1998. The major antigenic protein of Infectious Bursal Disease Virus, VP2, Is an Apoptotic Inducer. J. Virol. 71:8014-8018.

Giambrone, J. J., J. P. Donahoe, D. L. Dawe, and C. S. Eidson. 1977. Specific suppression of the bursa-dependent immune system of chicks with infectious bursal disease virus. Am. J. Vet. Res. 38:581-583.

Giambrone, J. J., C. S. Eidson, R. K. Page, O. J. Fletcher, B. O. Barger, and S. H. Kleven. 1976. Effect of infectious bursal agent on the response of chickens to Newcastle disease and Marek's disease vaccination. Avian Dis. 20:534-544.

Gough, R. E., S. E. N. Drury, D. d. B. Welchman, J. R. Chitty, and G. E. S. Summerhays. 2002. Isolation of birnavirus and reovirus-like agents from penguins in the United Kingdom. 151:422-424.

Haddad, E. E., C. E. Whitfill, A. P. Avakian, C. A. Ricks, P. D. Andrews, J. A. Thoma, and P. S. Wakenell. 1997. Efficacy of a novel infectious bursal disease virus immune complex vaccine in broiler chickens. Avian Dis. 41:882-889.

Hagen, M., T. D. Y. Chung, J. I. Butcher, and M. Krystal. 1994. Recombinant Influenza virus polymerase: Requirement of both $5^{\prime}$ and $3^{\prime}$ viral ends for endonuclease activity. J. Virol. 68:1509-1515.

Heine, H. G., M. Haritou, P. Failla, K. Fahey, and A. Azad. 1991. Sequence analysis and expression of the host-protective immunogen VP2 of a variant strain of infectious bursal disease virus which can circumvent vaccination with standard type I strains. J. Gen. Virol. 72 ( Pt 8):1835-1843. 
Henderson, K. S. and D. J. Jackwood. 1990. Comparison of the dot blot hybridization assay with antigen detection assays for the diagnosis of infectious bursal disease virus infections. Avian Dis. 34:744-748.

Hirai, K., S. Shimakura, E. Kawamoto, F. Taguchi, S. T. Kim, C. N. Chang, and Y. Iritani. 1974. The immunodepressive effect of infectious bursal disease virus in chickens. Avian Dis. 18:50-57.

Hitchner, S. B. 2004. History of biological control of poultry diseases in the USA. Avian Dis. 48:1-8.

Huang, Z., S. Elankumaran, A. S. Yunus, and S. K. Samal. 2004. A recombinant Newcastle disease virus (NDV) expressing VP2 protein of infectious bursal disease virus (IBDV) protects against NDV and IBDV. J. Virol. 78:10054-10063.

Hudson, P. J., N. M. McKern, B. E. Power, and A. A. Azad. 1986. Genomic structure of the large RNA segment of infectious bursal disease virus. Nucleic Acids Res. 14:5001-5012.

Hulse, D. J. and C. H. Romero. 2004. Partial protection against infectious bursal disease virus through DNA-mediated vaccination with the VP2 capsid protein and chicken IL-2 genes. Vaccine 22:1249-1259.

Ikuta, N., J. El Attrache, P. Villegas, E. M. Garcia, V. R. Lunge, A. S. Fonseca, C. Oliveira, and E. K. Marques. 2001. Molecular characterization of Brazilian infectious bursal disease viruses. Avian Dis. 45:297-306.

Ismail, N. M. and Y. M. Saif. 1991. Immunogenicity of infectious bursal disease viruses in chickens. Avian Dis. 35:460-469.

Ivanyi, J. 1975. Immunodeficiency in the chicken. II. Production of monomeric IgM following testosterone treatment or infection with Gumboro disease. Immunology 28:1015-1021.

Jackwood, D. H. and Y. M. Saif. 1987. Antigenic diversity of infectious bursal disease viruses. Avian Dis. 31:766-770.

Jackwood, D. J., G. Hanes, and S. H. Miller. 1996a. Infectious bursal disease viral RNA amplification using RT/PCR from bursa tissue following phenol: chloroform inactivation of the virus. Avian Dis. 40:457-460.

Jackwood, D. J., K. S. Henderson, and R. J. Jackwood. 1996b. Enzyme-linked immunosorbent assay-based detection of antibodies to antigenic subtypes of infectious bursal disease viruses of chickens. Clin. Diagn. Lab Immunol. 3:456-463. 
Jackwood, D. J. and S. E. Sommer. 1998. Genetic heterogeneity in the VP2 gene of infectious bursal disease viruses detected in commercially reared chickens. Avian Dis. 42:321-339.

Jackwood, D. J. and S. E. Sommer. 1999. Restriction fragment length polymorphisms in the VP2 gene of infectious bursal disease viruses from outside the United States. Avian Dis. 43:310-314.

Jackwood, D. J. and S. E. Sommer. 2002. Identification of infectious bursal disease virus quasispecies in commercial vaccines and field isolates of this double-stranded RNA virus. Virology 304:105-113.

Jackwood, D. J., S. E. Sommer, and H. V. Knoblich. 2001. Amino acid comparison of infectious bursal disease viruses placed in the same or different molecular groups by RT/PCR-RFLP. Avian Dis. 45:330-339.

Jackwood, D. J., B. D. Spalding, and S. E. Sommer. 2003. Real-time reverse transcriptase-polymerase chain reaction detection and analysis of nucleotide sequences coding for a neutralizing epitope on infectious bursal disease viruses. Avian Dis. 47:738-744.

Jeurissen, S. H., E. M. Janse, P. R. Lehrbach, E. E. Haddad, A. Avakian, and C. E. Whitfill. 1998. The working mechanism of an immune complex vaccine that protects chickens against infectious bursal disease. Immunology 95:494-500.

Juul-Madsen, H. R., O. L. Nielsen, T. Krogh-Maibom, C. M. Rontved, T. S. Dalgaard, N. Bumstead, and P. H. Jorgensen. 2002. Major histocompatibility complex-linked immune response of young chickens vaccinated with an attenuated live infectious bursal disease virus vaccine followed by an infection. Poult. Sci. 81:649-656.

Kibenge, F. S. and V. Dhama. 1997. Evidence that virion-associated VP1 of avibirnaviruses contains viral RNA sequences. Arch. Virol. 142:1227-1236.

Kibenge, F. S., A. S. Dhillon, and R. G. Russell. 1988. Biochemistry and immunology of infectious bursal disease virus. J. Gen. Virol. 69 ( Pt 8):1757-1775.

Kibenge, F. S., B. Qian, J. R. Cleghorn, and C. K. Martin. 1997. Infectious bursal disease virus polyprotein processing does not involve cellular proteases. Arch. Virol. 142:2401-2419.

Kim, I. J., M. Gagic, and J. M. Sharma. 1999. Recovery of antibody-producing ability and lymphocyte repopulation of bursal follicles in chickens exposed to infectious bursal disease virus. Avian Dis. 43:401-413. 
Kim, I. J., S. K. You, H. Kim, H. Y. Yeh, and J. M. Sharma. 2000. Characteristics of bursal T lymphocytes induced by infectious bursal disease virus. J. Virol. 74:88848892.

Kim, S. J., H. W. Sung, J. H. Han, D. Jackwood, and H. M. Kwon. 2004. Protection against very virulent infectious bursal disease virus in chickens immunized with DNA vaccines. Vet. Microbiol. 101:39-51.

Kwon, H. M. and S. J. Kim. 2004. Sequence analysis of the variable VP2 gene of infectious bursal disease viruses passaged in Vero cells. Virus Genes 28:285-291.

Lasher, H. N. and V. S. Davis. 1997. History of infectious bursal disease in the U.S.A.-the first two decades. Avian Dis. 41:11-19.

Le, S.-Y., J.-H. Chen, N. Sonenberg, and V. J. Mainzel, Jr.. 1993. Conserved tertiary structural elements in the 5 ' nontranslated region of cardiovirus, aphthovirus and hepatitis A virus RNAs. Nucleic Acids Res. 21:2445-2451.

Lejal, N., B. Da Costa, J. C. Huet, and B. Delmas. 2000. Role of Ser-652 and Lys-692 in the protease activity of infectious bursal disease virus VP4 and identification of its substrate cleavage sites. J. Gen. Virol. 81:983-992.

Lewis, P. J. and L. A. Babiuk. 1999. DNA vaccines: a review. Adv. Virus Res. 54:129188.

Li, J., Y. Huang, X. Liang, M. Lu, L. Li, L. Yu, and R. Deng. 2003. Plasmid DNA encoding antigens of infectious bursal disease viruses induce protective immune responses in chickens: factors influencing efficacy. Virus Res. 98:63-74.

Li, J., X. Liang, Y. Huang, S. Meng, R. Xie, R. Deng, and L. Yu. 2004. Enhancement of the immunogenicity of DNA vaccine against infectious bursal disease virus by codelivery with plasmid encoding chicken interleukin 2. Virology 329:89-100.

Lim, H. Y. and M. L. Ng. 1999. A different mode of entry by dengue-2 neutralisation escape mutant virus. Arch. Virol. 144:989-995.

Lin, Z., A. Kato, Y. Otaki, T. Nakamura, E. Sasmaz, and S. Ueda. 1993. Sequence comparisons of a highly virulent infectious bursal disease virus prevalent in Japan. Avian Dis. 37:315-323.

Liu, M. and V. N. Vakharia. 2004. VP1 protein of infectious bursal disease virus modulates the virulence in vivo. Virology 330:62-73. 
Lojkic, I., Z. Bidin, and B. Pokric. 2003. Differentiation of infectious bursal disease viruses isolated in Croatia. Avian Dis. 47:59-65.

Lombardo, E., A. Maraver, I. Espinosa, A. Fernandez-Arias, and J. F. Rodriguez. 2000. VP5, the nonstructural polypeptide of infectious bursal disease virus, accumulates within the host plasma membrane and induces cell lysis. Virology 277:345-357.

Lukert, P. D. and Saif, Y. M. 1997. Infectious Bursal Disease, p. 721-738. In Calnek, B. W., Barnes, J. H., Beard, C. W., McDougald, L. R., and Saif, Y. M. (eds.), Diseases of Poultry. Iowa State University Press.

Maas, R. A., S. Venema, H. L. Oei, J. M. A. Pol, I. J. Claasen, and A. ter Huurne. 2001. Efficacy of inactivated infectious bursal disease (IBD) vaccines: comparison serology with protection of progeny chickens against IBD virus strains of varying virulence. Avian Pathol. 30:345-354.

Maraver, A., A. Ona, F. Abaitua, D. Gonzalez, R. Clemente, J. A. Ruiz-Diaz, J. R. Caston, F. Pazos, and J. F. Rodriguez. 2003. The oligomerization domain of VP3, the scaffolding protein of infectious bursal disease virus, plays a critical role in capsid assembly. J. Virol. 77:6438-6449.

Martinez-Torrecuadrada, J. L., B. Lazaro, J. F. Rodriguez, and J. I. Casal. 2000. Antigenic properties and diagnostic potential of baculovirus-expressed infectious bursal disease virus proteins VPX and VP3. Clin. Diagn. Lab Immunol. 7:645-651.

Martinez-Torrecuadrada, J. L., N. Saubi, A. Pages-MantE, J. R. Caston, E. Espuna, and J. I. Casal. 2003. Structure-dependent efficacy of infectious bursal disease virus (IBDV) recombinant vaccines. Vaccine 21:3342-3350.

McFerran, J. B., M. S. McNulty, E. R. McKillop, T. J. Connor, R. M. McCracken, D. S. Collins, and G. M. Allan. 1980. Isolation and serological studies with infectious bursal disease viruses from fowl,turkeys, and ducks: demonstration of a second serotype. Avian Pathol. 9:395-403.

McNulty, M. S., G. M. Allan, and J. B. McFerran. 1979. Isolation of infectious bursal disease virus from turkeys. Avian Pathol. 8:205-212.

McNulty, M. S. and Y. M. Saif. 1988. Antigenic relationship of non-serotype 1 turkey infectious bursal disease viruses from the United States and United Kingdom. Avian Dis. $32: 374-375$. 
Moody, A., S. Sellers, and N. Bumstead. 2000. Measuring infectious bursal disease virus RNA in blood by multiplex real-time quantitative RT-PCR. J. Virol. Methods 85:55-64.

Moradian, A., J. Thorsen, and R. J. Julian. 1990. Single and combined infections of specific-pathogen-free chickens with infectious bursal disease virus and an intestinal isolate of reovirus. Avian Dis. 34:63-72.

Muller, H., M. R. Islam, and R. Raue. 2003. Research on infectious bursal disease--the past, the present and the future. Vet. Microbiol. 97:153-165.

Muller, H. and R. Nitschke. 1987. The two segments of the infectious bursal disease virus genome are circularized by a 90,000-Da protein. Virology 159:174-177.

Muller, H., C. Scholtissek, and H. Becht. 1979. The genome of infectious bursal disease virus consists of two segments of double-stranded RNA. J. Virol. 31:584589 .

Mundt, E. 1999. Tissue culture infectivity of different strains of infectious bursal disease virus is determined by distinct amino acids in VP2. J. Gen. Virol. 80 ( Pt 8):2067-2076.

Mundt, E. and H. Muller. 1995. Complete nucleotide sequences of 5'- and 3'-noncoding regions of both genome segments of different strains of infectious bursal disease virus. Virology 209:10-18.

Nieper, H. and H. Muller. 1996. Susceptibility of chicken lymphoid cells to infectious bursal disease virus does not correlate with the presence of specific binding sites. J. Gen. Virol. 77 ( Pt 6):1229-1237.

Ogawa, M., T. Yamaguchi, A. Setiyono, T. Ho, H. Matsuda, S. Furusawa, H. Fukushi, and K. Hirai. 1998. Some characteristics of a cellular receptor for virulent infectious bursal disease virus by using flow cytometry. Arch. Virol. 143:2327-2341.

Ona, A., D. Luque, F. Abaitua, A. Maraver, J. R. Caston, and J. F. Rodriguez. 2004. The C-terminal domain of the pVP2 precursor is essential for the interaction between VP2 and VP3, the capsid polypeptides of infectious bursal disease virus. Virology 322:135-142.

Oppling, V., H. Muller, and H. Becht. 1991a. Heterogeneity of the antigenic site responsible for the induction of neutralizing antibodies in infectious bursal disease virus. Arch. Virol. 119:211-223. 
Oppling, V., H. Muller, and H. Becht. 1991b. The structural polypeptide VP3 of infectious bursal disease virus carries group- and serotype-specific epitopes. J. Gen. Virol. 72 ( Pt 9):2275-2278.

Owoade, A. A., M. N. Mulders, J. Kohnen, W. Ammerlaan, and C. P. Muller. 2004. High sequence diversity in infectious bursal disease virus serotype 1 in poultry and turkey suggests West-African origin of very virulent strains. Arch. Virol. 149:653672 .

Parkhurst, R. T. 1964. On-the-farm studies of Gumboro Disease in broilers. Avian Dis. 584-596.

Parthiban, M. and V. Thiagarajan. 2002. The value of tissue imprint hybridization for rapid detection of infectious bursal disease virus from field outbreaks. Trop. Anim Health Prod. 34:391-398.

Pilipenko, E. V., S. V. Maslova, A. N. Sinyakov, and V. I. Agol. 1992. Towards identification of cis-acting elements involved in the replication of enterovirus and rhinovirus RNAs: a proposal for the existence of tRNA-like terminal structures. Nucleic Acids Res. 20:1739-1745.

Ragland, W. L., R. Novak, J. El Attrache, V. Savic, and K. Ester. 2002. Chicken anemia virus and infectious bursal disease virus interfere with transcription of chicken IFN-alpha and IFN-gamma mRNA. J. Interferon Cytokine Res. 22:437-441.

Raj, G. D., A. Thangavelu, S. Elankumaran, A. Koteeswaran, and A. T. Venugopalan. 1994. Quantitative counter-immunoelectrophoresis for estimation of antibodies to infectious bursal disease virus. Vet. Res. Commun. 18:289-293.

Raue, R. and H. Muller. 2001. Detection and quantification of IBDV by Reatl-Time PCR. 271-277-.

Rautenschlein, S., H. Y. Yeh, M. K. Njenga, and J. M. Sharma. 2002. Role of intrabursal $\mathrm{T}$ cells in infectious bursal disease virus (IBDV) infection: $\mathrm{T}$ cells promote viral clearance but delay follicular recovery. Arch. Virol. 147:285-304.

Rautenschlein, S., H. Y. Yeh, and J. M. Sharma. 2003. Comparative immunopathogenesis of mild, intermediate, and virulent strains of classic infectious bursal disease virus. Avian Dis. 47:66-78.

Rodenberg, J., J. M. Sharma, S. W. Belzer, R. M. Nordgren, and S. Naqi. 1994. Flow cytometric analysis of $\mathrm{B}$ cell and $\mathrm{T}$ cell subpopulations in specific-pathogen-free chickens infected with infectious bursal disease virus. Avian Dis. 38:16-21. 
Rodriguez-Chavez, I. R., J. K. Rosenberger, and S. S. Cloud. 2002. Characterization of the antigenic, immunogenic, and pathogenic variation of infectious bursal disease virus due to propagation in different host systems (bursa, embryo, and cell culture). II. Antigenicity at the epitope level. Avian Pathol. 31:473-483.

Saif, Y. M. 1998. Infectious bursal disease and hemorrhagic enteritis. Poult. Sci. 77:1186-1189.

Sanchez, A. B. and J. F. Rodriguez. 1999. Proteolytic processing in infectious bursal disease virus: identification of the polyprotein cleavage sites by site-directed mutagenesis. Virology 262:190-199.

Sapats, S. I. and J. Ignjatovic. 2000. Antigenic and sequence heterogeneity of infectious bursal disease virus strains isolated in Australia. Arch. Virol. 145:773-785.

Saravanan, P., S. Kumar, and J. M. Kataria. 2004. Use of multiple antigenic peptides related to antigenic determinants of infectious bursal disease virus (IBDV) for detection of anti-IBDV-specific antibody in ELISA--quantitative comparison with native antigen for their use in serodiagnosis. J. Immunol. Methods 293:61-70.

Schnitzler, D., F. Bernstein, H. Muller, and H. Becht. 1993. The genetic basis for the antigenicity of the VP2 protein of the infectious bursal disease virus. J. Gen. Virol. 74 ( Pt 8):1563-1571.

Scott, A. N., M. S. McNulty, and D. Todd. 2001. Characterisation of a chicken anaemia virus variant population that resists neutralisation with a group-specific monoclonal antibody. Arch. Virol. 146:713-728.

Setiyono, A., T. Hayashi, T. Yamaguchi, H. Fukushi, and K. Hirai. 2001. Detection of cell membrane proteins that interact with virulent infectious bursal disease virus. J. Vet. Med. Sci. 63:219-221.

Sharma, J. M., J. E. Dohms, and A. L. Metz. 1989. Comparative pathogenesis of serotype 1 and variant serotype 1 isolates of infectious bursal disease virus and their effect on humoral and cellular immune competence of specific-pathogen-free chickens. Avian Dis. 33:112-124.

Sharma, J. M. and T. L. Fredericksen. 1987. Mechanism of T cell immunosuppression by infectious bursal disease virus of chickens. Prog. Clin. Biol. Res. 238:283-294.

Sharma, J. M., I. J. Kim, S. Rautenschlein, and H. Y. Yeh. 2000. Infectious bursal disease virus of chickens: pathogenesis and immunosuppression. Dev. Comp Immunol. 24:223-235. 
Shwed, P. S., P. Dobos, L. A. Cameron, V. N. Vakharia, and R. Duncan. 2002. Birnavirus VP1 proteins form a distinct subgroup of RNA-dependent RNA polymerases lacking a GDD motif. Virology 296:241-250.

Snyder, D. B., D. P. Lana, P. K. Savage, F. S. Yancey, S. A. Mengel, and W. W. Marquardt. 1988. Differentiation of infectious bursal disease viruses directly from infected tissues with neutralizing monoclonal antibodies: evidence of a major antigenic shift in recent field isolates. Avian Dis. 32:535-539.

Snyder, D. B., V. N. Vakharia, and P. K. Savage. 1992. Naturally occurringneutralizing monoclonal antibody escape variants define the epidemiology of infectious bursal disease viruses in the United States. Arch. Virol. 127:89-101.

Spies, U., H. Muller, and H. Becht. 1987. Properties of RNA polymerase activity associated with infectious bursal disease virus and characterization of its reaction products. Virus Res. 8:127-140.

Sun, J. H., P. Lu, Y. X. Yan, X. G. Hua, J. Jiang, and Y. Zhao. 2003. Sequence and analysis of genomic segment A and B of very virulent infectious bursal disease virus isolated from China. J. Vet. Med. B Infect. Dis. Vet. Public Health 50:148-154.

Tacken, M., P. Rottier, A. Gielkens, and B. Peeters. 2000. Interactions in vivo between the proteins of infectious bursal disease virus: capsid protein VP3 interacts with the RNA-dependent RNA polymerase, VP1. 81:209-218.

Tacken, M. G., B. P. Peeters, A. A. Thomas, P. J. Rottier, and H. J. Boot. 2002. Infectious bursal disease virus capsid protein VP3 interacts both with VP1, the RNAdependent RNA polymerase, and with viral double-stranded RNA. J. Virol. 76:11301-11311.

Tacken, M. G., P. A. Van Den Beuken, B. P. Peeters, A. A. Thomas, P. J. Rottier, and H. J. Boot. 2003. Homotypic interactions of the infectious bursal disease virus proteins VP3, pVP2, VP4, and VP5: mapping of the interacting domains. Virology 312:306-319.

Tanimura, N. and J. M. Sharma. 1998. In-situ apoptosis in chickens infected with infectious bursal disease virus. J. Comp Pathol. 118:15-27.

Tiwari, A. K., R. S. Kataria, Indervesh, N. Prasad, and R. Gupta. 2003. Differentiation of infectious bursal disease viruses by restriction enzyme analysis of RT-PCR amplified VP1 gene sequence. Comp Immunol. Microbiol. Infect. Dis. 26:47-53. 
van den Berg, T. P. 2000. Acute infectious bursal disease in poultry: a review. Avian Pathol. 29:175-194.

van den Berg, T. P. and M. Gonze. 1996. Acute infectious bursal disease in poultry: immunological and molecular basis of antigenicity of a highly virulent strain. Avian Pathol. 25:751-769.

van den Berg, T. P., D. Morales, N. Eterradossi, G. Rivallan, D. Toquin, R. Raue, K. Zierenberg, M. F. Zhang, Y. P. Zhu, C. Q. Wang, H. J. Zheng, X. Wang, G. C. Chen, B. L. Lim, and H. Muller. 2004. Assessment of genetic, antigenic and pathotypic criteria for the characterization of IBDV strains. Avian Pathol. 33:470476.

van Loon, A. A., N. de Haas, I. Zeyda, and E. Mundt. 2002. Alteration of amino acids in VP2 of very virulent infectious bursal disease virus results in tissue culture adaptation and attenuation in chickens. J. Gen. Virol. 83:121-129.

von Einem, U. I., A. E. Gorbalenya, H. Schirrmeier, S. E. Behrens, T. Letzel, and E. Mundt. 2004. VP1 of infectious bursal disease virus is an RNA-dependent RNA polymerase. J. Gen. Virol. 85:2221-2229.

Wang, X. M., X. W. Zeng, H. L. Gao, C. Y. Fu, and P. Wei. 2004. Changes in VP2 gene during the attenuation of very virulent infectious bursal disease virus strain Gx isolated in China. Avian Dis. 48:77-83.

Wood, G. W., J. C. Muskett, and D. H. Thornton. 1983. Use of inactivated oil emulsion infectious bursal disease vaccines in breeder chickens to prevent immunosuppression in progeny chicks. Res. Vet. Sci. 35:114-115.

Wyeth, P. J. 1975. Effect of infectious bursal disease on the response of chickens to $\mathrm{S}$ typhimurium and E coli infections. Vet. Rec. 96:238-243.

Wyeth, P. J. and N. Chettle. 1982. Comparison of the efficacy of four inactivated infectious bursal disease oil emulsion vaccines. Vet. Rec. 110:359-361.

Yamaguchi, T., M. Ogawa, Y. Inoshima, M. Miyoshi, H. Fukushi, and K. Hirai. 1996. Identification of sequence changes responsible for the attenuation of highly virulent infectious bursal disease virus. Virology 223:219-223.

Yao, K. and V. N. Vakharia. 2001. Induction of apoptosis in vitro by the 17-kDa nonstructural protein of infectious bursal disease virus: possible role in viral pathogenesis. Virology 285:50-58. 
Yu, W. and J. L. Leibowitz. 1995. A conserved motif at the 3' end of mouse hepatitis virus genomic RNA required for host protein binding and viral RNA replication. Virology 214:128-138. 


\section{CAMPYLOBACTER JEJUNI}

\section{Brief historic overview}

At the beginning of the $20^{\text {th }}$ century, infections by Campylobacter were reported in farm animals. At that time, the etiological agent reported was Vibrio fetus and it was causing septic abortions in sheep and cattle. In 1947, Vibrio fetus was reported to cause a septic abortion in a woman, and for more than a decade it was believed that the agent was rare opportunistic, invasive and able to infect mainly debilitated hosts. In 1957, Campylobacter species were found to be responsible for causing diarrhea in humans. In 1963, Sebald and Veron proposed for the first time the name Campylobacter to differentiate this genus from the Vibrio species.

Improvements in the isolation techniques for this pathogen during the 1970's have made possible the identification of Campylobacter as the cause of human gastrointestinal disease in the early 1980 's. In the late 1980's, Campylobacter infections were recognized as one of the major bacterial causes of gastroenteritis in humans. 


\section{Campylobacter general characteristics}

Campylobacter jejuni has been identified the major cause of gastrointestinal infections in developed countries. This infectious agent is a Gram-negative bacterium with a curved or spiral shape, measuring from $0.2-0.5 \mu \mathrm{m}$ wide and $0.5-5 \mu \mathrm{m}$ long. Bacteria in the genus Campylobacter have unipolar or bipolar flagella at one or both ends of the cells which confers motility to the bacterium (Vandamme, 2000).

Campylobacter jejuni is a very fastidious agent. It is microareophilic, with a respiratory type of metabolism, requires $3-15 \%$ oxygen and $3-5 \%$ carbon dioxide and it is nonsporeforming. They grow best at $42{ }^{\circ} \mathrm{C}$ and it takes around $72-96 \mathrm{~h}$ for primary isolation of the agent. The mol\% $\mathrm{G}+\mathrm{C}$ of its DNA varies from 30-38. The C. jejuni genome has several hypervariable regions that may be important for the agent's survival in the host. In addition, these genomic regions have been used in epidemiological studies to identify possible sources of infection (Vandamme, 2000).

\section{C. jejuni reservoirs and transmission in poultry}

Disinfecting and cleaning processes in the poultry houses have minimal influence to prevent colonization in chickens. The main reservoir of $C$. jejuni is poultry but the pathogen has also been associated with many other sources such as wild, domestic and farm animals (Hald and Madsen, 1997; Weber, 1985; Sahin et al., 2002), water (Arvanitidou et al., 1995), insects (Gregory et al., 1997) and rodents (Kapperud et al., 1993), which points to its ubiquitous nature. 
Horizontal transmission of Campylobacter from the environment has been reported as the main source of this pathogen in poultry. Possible environmental sources include old litter, untreated water, farm personnel, equipments, domestic pets, wildlife species, houseflies, insects, etc. However, none of these sources are directly associated with Campylobacter infection in poultry, which indicates that Campylobacter transmission is a complex conjunction of several factors in the poultry farm (Sahin et al., 2002).

Several studies have investigated the possibility that Campylobacter can be transmitted vertically, but the general consensus is that this pathogen is mainly transmitted horizontally. However, there is some evidence that vertical transmission may occur from breeder flocks to broiler farms through the egg (Sahin et al., 2002). Campylobacter can survive in the egg yolk even in the presence of maternal antibodies (Sahin et al., 2001). In addition, this pathogen has been isolated from the ovaries and oviducts of healthy chicken hens (Jacobs-Reitsma, 1997; Camarda et al., 2000). However, the role of the infected reproductive tract in contamination of the eggs is not known.

\section{Colonization in poultry}

Once C. jejuni reaches the intestines of the chicken, it is directed towards the mucous layer of the crypts, with no gross lesions or invasion of the intestinal epithelium. In contrast, in mammals, C. jejuni is more aggressive, invasive and causes pathologic changes in the intestinal cells. 
Several factors are known to contribute to Campylobacter colonization. Among them is the dose of the inoculum (Shanker et al., 1988). However, the minimum dose required for colonization depends on other factors such as age of the chicken, C. jejuni strain (Kaino et al., 1988) and route of challenge (Shanker et al., 1988). Some investigations have reported an association of a $65 \mathrm{kDa}$ protein with the colonizing strain. Additionally, some other factors may be related to colonization such as flagella (Nachamkin et al., 1993), heat shock protein (Konkel et al., 1998), phospholipase A , among others. The age of the birds affects Campylobacter colonization; chickens between 2-5 weeks of age are more susceptible to the pathogen when compared to young chicks (Kaino et al., 1988). Also, colonization can be affected by the genetic lineage of the chickens (Stern et al., 1990).

Once the first birds of the flock are infected, the pathogen spreads rapidly throughout the entire flock. The chickens will be colonized for their entire lives, which creates a problem at the slaughtering plant (Sahin et al., 2002), as cross-contamination of carcasses at the processing plant may occur. In addition, although colonization occurs mainly in the cecal and cloacal crypts (Beery et al., 1988; Meinersmann et al., 1991), the bacterium can also be isolated from the small intestines, gizzard, liver, spleen and gall bladder (Kaino et al., 1988; Morishita et al., 1997; Achen et al., 1998; Young et al., 1999), increasing the chances of contamination during the slaughtering process.

Biosecurity measures on poultry farms decreases the prevalence of Campylobacter (Sahin et al., 2002). It is estimated that up to $100 \%$ of the commercial 
broilers at slaughter age are contaminated with C. jejuni (Jacobs-Reitsma, 1995).

Campylobacter is rarely isolated in chickens between 2-3 weeks of age. It has been speculated that this event could be due to the presence of maternal antibodies, agerelated differences in the intestines, such as competitive microbiota and specific receptors, and also variations in management practices. The better understanding of this fact can assist in the development of strategies to control this pathogen in its primary niche.

\section{Clinical signs and transmission to humans}

The transmission of $C$. jejuni to humans has been related mainly to consumption of raw or undercooked poultry, which is the leading cause of sporadic infections in humans. In some cases, outbreaks have different epidemiological characteristics are associated to consumption of raw milk. Other sources of sporadic infections include drinking untreated water, traveling overseas, contact to pets, etc.

In the United States, it is estimated that 2.1-2.4 million cases of human campylobacteriosis occur every year. Clinical signs vary from mild symptoms with a watery, non-bloody and non-inflammatory diarrhea that can last up to 5 days, to a bloody diarrhea with fever and abdominal cramps (Coker et al., 2002). Usually in developing countries the disease is less severe, probably due constant exposure to the pathogen leads to some level of immunity. Common symptoms in these regions are watery stool, fever, abdominal pain, vomiting, dehydration and presence of fecal leukocytes (Coker et al., 
2002). About $1 \%$ of the patients develop reactive arthritis, which starts 7 to 10 days after the beginning of the symptoms. It has been observed that $C$. jejuni can be associated with an autoimmune disorder of the peripheral nervous system designated Guillain-Barré syndrome (Nachamkin et al., 1998). The condition is characterized by flaccid paralysis and weakness that is usually symmetrical, evolving over a period of several days or more (Nachamkin et al., 1998). It appears to be more severe in developing countries, although there is no data in the literature to confirm this hypothesis. Death is not common and it is estimated that 120-360 people die per year in the US due to infection by Campylobacter (Skirrow and Blaser, 1992).

\section{Prevention and Control}

C. jejuni infection is associated mainly with consumption of undercooked or raw poultry meat. Cross-contamination can occur during the preparation of food; therefore, the proper cooking of poultry meat can reduce the risk of human infection, but not eliminate it. Contamination during the slaughter process would require modifications in the entire process, which is not feasible. Control measures taken during the pre-harvest stage appear to have a better chance of being more effective against this pathogen. With this idea in mind, several control measures are being taken. Biosecurity measures such as cleaning and disinfecting poultry houses between flocks and also applying a standard hygiene protocol to the farm employees proved to reduce $50 \%$ of Campylobacter infection in broilers (Gibbens et al., 2001). However, strict on-farm control of hygiene is 
difficult (van de Giessen et al., 1998). All-in, all-out system of all poultry houses was suggested to limit Campylobacter dissemination between consecutive flocks (Berndtson et al., 1996). A safe source of drinking water is very important, as cows and other farm animals have been reported to harbor this microorganism (Sahin et al., 2002) and therefore can contaminate the water source.

The use of probiotics has been proposed to reduce $C$. jejuni colonization in chickens by competitive exclusion. The principle of this method consists of a competition of the bacteria for nutrients in the intestines which should decrease the number and eliminate other pathogens such as Salmonella sp.. When probiotics were administered in chickens during the three first days of life, a reduction of $70 \%$ in the frequency of $C$. jejuni shedding and a $27 \%$ reduction in jejunal colonization was observed when compared to the control groups (Morishita et al., 1997). Conversely, other experiments reported that the use of probiotics had no effect in Campylobacter colonization (Aho et al., 1992). These inconsistencies may be due the different combinations of competitive agents, which may be difficult to control in bulk production (Mead et al., 1996). Thus it may be difficult to obtain good results with the use of this method under field conditions.

Effective vaccines against Campylobacter in broiler chickens, although ideal, have not been developed. However, several possibilities have been pointed out, such as vaccination of the parents flock to induce passive protection in the offspring (Cawthraw et al., 1994; Sahin et al., 2001). However, it is not known if maternal antibodies will confer protection against this pathogen. In addition, subunit or killed vaccines using 
protein from the flagellae have been proposed, but they conferred only partial protection (Widders et al., 1996). Oral live vaccines have been speculated as another option to prevent $C$. jejuni colonization in chickens. The current available data is still preliminary. The use of chicken lineages that are resistant to Campylobacter infection has been proposed. One study indicated that C. jejuni colonization can be influenced by the chicken lineage (Stern et al., 1990). However, the applicability of this finding to the field conditions is questionable. 


\section{REFERENCES}

Achen, M., T. Y. Morishita, and E. C. Ley. 1998. Shedding and colonization of Campylobacter jejuni in broilers from day-of-hatch to slaughter age. Avian Dis. 42:732-737.

Aho, M., L. Nuotio, E. Nurmi, and T. Kiiskinen. 1992. Competitive exclusion of campylobacters from poultry with K-bacteria and Broilact. Int. J. Food Microbiol. 15:265-275.

Arvanitidou, M., G. A. Stathopoulos, T. C. Constantinidis, and V. Katsouyannopoulos. 1995. The occurrence of Salmonella, Campylobacter and Yersinia spp. in river and lake waters. Microbiol. Res. 150:153-158.

Beery, J. T., M. B. Hugdahl, and M. P. Doyle. 1988. Colonization of gastrointestinal tracts of chicks by Campylobacter jejuni. Appl. Environ. Microbiol. 54:2365-2370.

Berndtson, E., M. L. Danielsson-Tham, and A. Engvall. 1996. Campylobacter incidence on a chicken farm and the spread of Campylobacter during the slaughter process. Int. J. Food Microbiol. 32:35-47.

Camarda, A., D. G. Newell, R. Nasti, and G. Di Modugnoa. 2000. Genotyping Campylobacter jejuni strains isolated from the gut and oviduct of laying hens. Avian Dis. 44:907-912.

Cawthraw, S., R. Ayling, P. Nuijten, T. Wassenaar, and D. G. Newell. 1994. Isotype, specificity, and kinetics of systemic and mucosal antibodies to Campylobacter jejuni antigens, including flagellin, during experimental oral infections of chickens. Avian Dis. 38:341-349.

Coker, A. O., R. D. Isokpehi, B. N. Thomas, K. O. Amisu, and C. L. Obi. 2002. Human campylobacteriosis in developing countries. Emerg. Infect. Dis. 8:237-244. 
Gibbens, J. C., S. J. Pascoe, S. J. Evans, R. H. Davies, and A. R. Sayers. 2001. A trial of biosecurity as a means to control Campylobacter infection of broiler chickens. Prev. Vet. Med. 48:85-99.

Gregory, E., H. Barnhart, D. W. Dreesen, N. J. Stern, and J. L. Corn. 1997. Epidemiological study of Campylobacter spp. in broilers: source, time of colonization, and prevalence. Avian Dis. 41:890-898.

Hald, B. and M. Madsen. 1997. Healthy puppies and kittens as carriers of Campylobacter spp., with special reference to Campylobacter upsaliensis. J. Clin. Microbiol. 35:3351-3352.

Jacobs-Reitsma, W. F. 1995. Campylobacter bacteria in breeder flocks. Avian Dis. 39:355-359.

Jacobs-Reitsma, W. F. 1997. Aspects of epidemiology of Campylobacter in poultry. Vet. Q. 19:113-117.

Kaino, K., H. Hayashidani, K. Kaneko, and M. Ogawa. 1988. Intestinal colonization of Campylobacter jejuni in chickens. Nippon Juigaku. Zasshi 50:489-494.

Kapperud, G., E. Skjerve, L. Vik, K. Hauge, A. Lysaker, I. Aalmen, S. M. Ostroff, and M. Potter. 1993. Epidemiological investigation of risk factors for campylobacter colonization in Norwegian broiler flocks. Epidemiol. Infect. 111:245255.

Konkel, M. E., B. J. Kim, J. D. Klena, C. R. Young, and R. Ziprin. 1998. Characterization of the thermal stress response of Campylobacter jejuni. Infect. Immun. 66:3666-3672.

Mead, G. C., M. J. Scott, T. J. Humphrey, and K. McAlpine. 1996. Observations on the control of Campylobacter jejuni infection of poultry by "competitive exclusion". Avian Pathol. 25:69-79.

Meinersmann, R. J., W. E. Rigsby, N. J. Stern, L. C. Kelley, J. E. Hill, and M. P. Doyle. 1991. Comparative study of colonizing and noncolonizing Campylobacter jejuni. Am. J. Vet. Res. 52:1518-1522.

Morishita, T. Y., P. P. Aye, B. S. Harr, C. W. Cobb, and J. R. Clifford. 1997. Evaluation of an avian-specific probiotic to reduce the colonization and shedding of Campylobacter jejuni in broilers. Avian Dis. 41:850-855. 
Nachamkin, I., B. M. Allos, and T. Ho. 1998. Campylobacter species and GuillainBarre syndrome. Clin. Microbiol. Rev. 11:555-567.

Nachamkin, I., X. H. Yang, and N. J. Stern. 1993. Role of Campylobacter jejuni flagella as colonization factors for three-day-old chicks: analysis with flagellar mutants. Appl. Environ. Microbiol. 59:1269-1273.

Sahin, O., T. Y. Morishita, and Q. Zhang. 2002. Campylobacter colonization in poultry: sources of infection and modes of transmission. Anim Health Res. Rev. 3:95-105.

Sahin, O., Q. Zhang, J. C. Meitzler, B. S. Harr, T. Y. Morishita, and R. Mohan. 2001. Prevalence, antigenic specificity, and bactericidal activity of poultry antiCampylobacter maternal antibodies. Appl. Environ. Microbiol. 67:3951-3957.

Shanker, S., A. Lee, and T. C. Sorrell. 1988. Experimental colonization of broiler chicks with Campylobacter jejuni. Epidemiol. Infect. 100:27-34.

Skirrow, M. B. and Blaser, M. J. 1992. Clinical and Epidemiological Considerations, p. 3-8. In Nachamkin, I., Blaser, M. J., and Tompkins, L. S. (eds.), Campylobacter jejuni - current status and future trends. American Society for Microbiology.

Stern, N. J., R. J. Meinersmann, N. A. Cox, J. S. Bailey, and L. C. Blankenship. 1990. Influence of host lineage on cecal colonization by Campylobacter jejuni in chickens. Avian Dis. 34:602-606.

van de Giessen, A. W., J. J. Tilburg, W. S. Ritmeester, and P. J. van der. 1998. Reduction of campylobacter infections in broiler flocks by application of hygiene measures. Epidemiol. Infect. 121:57-66.

Vandamme, P. 2000. Taxonomy of the family Campylobacteraceae, p. 3-26. In Nachamkin, I. and Blaser, M. J. (eds.), Campylobacter. American Society for Microbiology.

Weber, A. 1985. [Occurrence of Campylobacter jejuni in animals and its significance for the human]. Tierarztl. Prax. 13:151-157.

Widders, P. R., R. Perry, W. I. Muir, A. J. Husband, and K. A. Long. 1996. Immunisation of chickens to reduce intestinal colonisation with Campylobacter jejuni. Br. Poult. Sci. 37:765-778.

Young, C. R., R. L. Ziprin, M. E. Hume, and L. H. Stanker. 1999. Dose response and organ invasion of day-of-hatch Leghorn chicks by different isolates of Campylobacter jejuni. Avian Dis. 43:763-767. 


\section{CHAPTER 2}

\section{REAL-TIME RT-PCR ANALYSIS OF TWO EPITOPE REGIONS ENCODED BY THE VP2 GENE OF INFECTIOUS BURSAL DISEASE VIRUSES}

Summary. Infectious bursal disease virus (IBDV) causes an immunosuppressive disease in chickens and leads to severe economic losses in the poultry industry. Vaccination may not be effective if there is exposure of the vaccinated flock to a different antigenic subtype, which reinforces the importance of identification of new IBDV variants. The virus outer capsid is constituted of VP2, in which the major neutralizing epitopes are located. Forty-eight bursa samples collected from IBDV infected commercial broiler flocks in the US were analyzed by real-time RT-PCR using probes designed for two epitope regions of VP2 denominated minor peak 1 and peak B. It was observed that 23, 48 and 44 samples tested with the minor peak probes Del-E, STC and F15, respectively, had a lower melting temperature (Tm) than expected. Furthermore, 44, 41 and 48 samples tested with the Del-E, STC and F15 peak B probes respectively, had a lower Tm compared to the control, which indicates the presence of one or more nucleotide mutations in the samples. 
This fact was confirmed by nucleotide sequencing which also demonstrated that most mutations resulted in amino acid substitutions. Real-time RT-PCR can be a useful tool to assist in the development of more effective vaccination strategies. 


\section{INTRODUCTION}

Infectious bursal disease (IBD) or Gumboro disease is a highly infectious viral illness of young chickens. It leads to severe economic losses worldwide due to a high rate of morbidity and mortality in an acute form or as a consequence of a severe immunosuppression (Muller et al., 2003). The virus is present in $95 \%$ of the member countries of the OIE (Eterradossi, 1995) which denotes a failure of efficacy in the current strategies for prevention and control of this infection.

Infectious bursal disease virus (IBDV) belongs to the Birnaviridae family and its genome consists of two segments of double-stranded RNA designated A and B. Segment $\mathrm{B}$ is smaller and codifies VP1, which has RNA dependent RNA polymerase and capping enzyme activities. Segment A has two open reading frames (ORF). The smaller ORF partially overlaps a larger ORF and encodes VP5, a non-structural protein not essential for virus replication but considered to play a role in releasing virus particles from the cell. The larger ORF is monocystronic and encodes a polyprotein that is cotranslationally processed into the major structural proteins: VP4, VP3 and VP2. VP4 is a protease that shares common features with the bacterial lon proteases (Muller et al., 2003); VP3 forms the inner part of the capsid and contains the structural group specific antigen; VP2 is encoded by a variable sequence region of the genome and constitutes the antigenic epitopes in the outer capsid responsible for eliciting neutralizing antibodies (Bayliss et al., 1990). Mutations in this region may lead to antigenic drift, which can be responsible 
for the emergence of new IBDV variants in the US (van den Berg, 2000). In addition, VP2 is a hydrophobic and conformational dependent protein. It has hydrophilic regions at each terminus, denominated antigenic peaks A and B which span aa 210 to 225 and aa 312 to 324, respectively (Heine et al., 1991). Two smaller hydrophilic areas of the VP2 variable domain, denominated minor peak 1 (aa 249 to 254) and minor peak 2 (aa 279 to 290) are also responsible for IBDV antigenicity (van den Berg and Gonze, 1996). Mutations in some specific amino acids in the hypervariable region have been associated with differences in virus antigenicity (aa 254 (D) or (N)), and in virus attenuation (aa 253 $(\mathrm{Q} \rightarrow \mathrm{H})$, aa $279(\mathrm{~N} \rightarrow \mathrm{T})$, aa $284(\mathrm{~A} \rightarrow \mathrm{T}))($ Vakharia et al., 1994; Kwon and Kim, 2004).

Prevention and control of IBDV requires good biosafety practices and vaccination. Usually the parent flock is vaccinated and this confers passive protection to the offspring through neutralizing antibodies. Nevertheless, the vaccine may not be effective if there is exposure to high titers of virus or to a heterologous antigenic subtype (Ismail and Saif, 1991). Due the low degree of protection offered by vaccination with heterologous antigenic subtypes, it would be helpful to select an appropriate antigenic subtype for vaccination based on the antigenic subtype present in the flock's environment. Diagnostic approaches that are able to infer the presence of new antigenic subtypes are necessary to assist in the development of strategies for prevention and control of IBDV. A previous study has used real-time RT-PCR for diagnosis and identification of nucleotide sequences that encode a major neutralizing epitope on VP2 of IBDV vaccine strains (Jackwood et al., 2003). In the present study we used real-time RT- 
PCR to analyze nucleotide sequences of IBDV samples that encode two important antigenic regions: minor peak 1 and hydrophilic peak B. This approach may assist in a more accurate identification of IBDV subtypes and thus help in the development of effective vaccination strategies against this important pathogen.

\section{MATERIALS AND METHODS}

\section{Samples}

Forty-eight bursa samples from IBDV positive commercial chicken flocks in the U.S. were sent to our laboratory and used in these experiments. The flock history and vaccination schedule were unknown except that all flocks were experiencing problems typical of immune suppression.

\section{Viral RNA extraction}

The bursa samples were homogenized in TNE buffer $(10 \mathrm{mM}$ Tris- $\mathrm{HCl}, \mathrm{pH} 8.0$, $100 \mathrm{mM} \mathrm{NaCl}, 1 \mathrm{mM}$ EDTA) and then frozen and thawed 3 times. An $800 \mu 1$ volume of this suspension was extracted with an equal volume of chloroform, followed by incubation of a $500 \mu 1$ volume of the supernatant for $1 \mathrm{hr}$ at $37^{\circ} \mathrm{C}$ with $1.0 \mathrm{mg} / \mathrm{ml}$ proteinase K (Sigma Chemical Co., St. Louis, MO) and 0.5\% sodium dodecyl sulfate (Sigma Chemical Co.). Next, the sample was extracted with an equal volume of acid phenol, pH 4.3 (AMRESCO, Solon, $\mathrm{OH}$ ) and $400 \mu 1$ of the supernatant was extracted with 
the same volume of chloroform-isoamyl alcohol (24:1). Subsequently, the RNA was precipitated with $3 \mathrm{M}$ sodium acetate and ethanol and was kept at $-20^{\circ} \mathrm{C}$ for at least $24 \mathrm{hs}$. Then the samples were centrifuged at $13,000 \times \mathrm{g}$ dried and suspended in $100 \mu 1$ of $90 \%$ dimethyl sulfoxide (Sigma Chemical Co.).

\section{Real-Time RT-PCR}

All samples were tested at least 2 times and the standard deviation of the Tm was calculated. The complete protocol was described previously (Jackwood and Sommer, 2002a). Real-time RT-PCR was conducted with a LightCycler instrument (Roche Diagnostics, Mannhein, Germany). The viral RNA was amplified using a LightCycler RNA amplification kit - hybridization probes (Roche; Molecular Biochemicals, Alameda, CA). Each reaction contained $4 \mu 1$ SX RT-PCR reaction mix, $4.5 \mathrm{mM} \mathrm{MgCl}, 0.25 \mu \mathrm{M}$ of each IBDV primer, $0.2 \mu \mathrm{M}$ of each probe, $0.5 \mu \mathrm{l}$ viral $\mathrm{RNA}$, and sterile $\mathrm{H}_{2} \mathrm{O}$ was added to the reaction. The final reaction volume was $20 \mu 1$. The primers used amplified a 743-bp sequence region of the VP2 gene (Jackwood and Sommer, 1998).

In order to detect the PCR products, a two probe system was used. The first probe was labeled at the 3' end with fluorescein isothiocyanate (FITC) and it was denominated mutation probe (BioChem, Salt Lake City, UT). The second probe or anchor probe (BioChem) was located downstream and was labeled at the 5'end with either Red 640 or Red 705 fluorophores. The mutation and anchor probes were separated from each other by one base. When these probes were hybridized to the PCR product, the acceptor dyes 
were adjacent to and excited by fluorescein. Fluorescence resonance energy transfer (FRET) occurred and was detected by the LightCycler instrument. Probes were complementary to Del-E, STC and F15 strains (Tables 2.1, 2.2). The probes designed to the minor peak region were designated DEMP (Del-E), STMP (STC) and F15MP (F15). Each reaction was performed using a positive control, which was the homologous match for the respective probe.

Two sets of probes were used in the same reaction: one set was designed to hybridize to minor peak 1 and the other to the peak B region of the VP2 gene. Since the two fluorophores (Red 640 and Red 705) had different emission spectra, it was possible to distinguish between signals from each probe set.

The LightCycler instrument was programmed as follows: Reverse transcriptase incubation at $55^{\circ} \mathrm{C}$ for $7 \mathrm{~min}$ followed by a denaturation step at $95^{\circ} \mathrm{C}$ for $5 \mathrm{~min}$. The amplification step was comprised of 40 cycles of $95{ }^{\circ} \mathrm{C}$ for $1 \mathrm{sec}, 62{ }^{\circ} \mathrm{C}$ for $10 \mathrm{sec}$ and 72 ${ }^{\circ} \mathrm{C}$ for $30 \mathrm{sec}$. Subsequently, the reaction was cooled to $35^{\circ} \mathrm{C}$ and then slowly heated to 95 ${ }^{\circ} \mathrm{C}$. The loss of fluorescence that occurred during this temperature increase was used to determine the melting temperatures $(\mathrm{Tm})$ of the mutation probes at minor peak and peak B.

\section{Data analysis}

The data analysis was performed as described (Jackwood and Sommer, 2002a). The fluorescence was analyzed in fluorimeter channels 2 and $3(\mathrm{~F} 2 / \mathrm{F} 3)$. The F2 channel 
detected the fluorescence emitted by the Red 640 probe, while the F3 channel detected the fluorescence released by the Red 705 probe. The light cycler instrument was previously calibrated with a color calibration test that generated a color compensation file which neutralized the background crosstalk between the two channels. The melting temperature was established based on the loss of fluorescence that occurred as the mutation probe was denaturated from the target DNA. The results were displayed in a graph as the first negative derivative $(-d[\mathrm{~F} 2 / \mathrm{F} 3])$ vs. temperature change $(d \mathrm{~T})$. The predicted melting temperatures of the probes were determined with the TM Utility 1.5 from Idaho Technologies Inc. (Salt Lake City, UT).

\section{Sequencing}

From a total of forty-eight samples tested, only thirty-four could be sequenced, probably due a poor quality of the PCR product. The sequencing results were submitted to Genbank and the accession numbers are from AY963110 to AY963143. The viral RNA extracted from the samples was subjected to RT-PCR using the same primers and procedures as previously described (Jackwood and Sommer, 1997). The primers were designed to conserved regions that flanked a $743 \mathrm{bp}$ fragment of the IBDV VP2 gene. Their sequences are: Primer \#1, 5'-TACCACATCTGAGACCCG-3' and Primer \#2, 5'AGTTTCTGTATTAGGCCC-3'. Briefly, the RT-PCR reaction was conducted using the GeneAmp RNA PCR kit (Perkin Elmer, Roche Molecular Systems, Inc., Branchsburg, NJ). Following the RT reaction at $42{ }^{\circ} \mathrm{C}$ for $1 \mathrm{hr}$, the PCR reaction consisted of 30 cycles 
at $95{ }^{\circ} \mathrm{C}$ for $2 \mathrm{~min}, 53{ }^{\circ} \mathrm{C}$ for $1 \mathrm{~min}$ and $72{ }^{\circ} \mathrm{C}$ for $2 \mathrm{~min}$. After that, the samples were incubated at $72{ }^{\circ} \mathrm{C}$ for $7 \mathrm{~min}$. The resulting PCR products were prepared for sequencing using the GeneClean Spin Kit (Q-BIOgene INC., Vista, CA) as previously described (Jackwood et al., 2001). DNA sequencing was done at the University of Wisconsin Biotechnology Center, Madison, Wisconsin, using BigDye Terminator technology with Applied Biosystems 3700 automated DNA sequencer. The nucleotide sequences were downloaded using Chromas (Technelysium Pty Ltd., Queensland, Australia) and analyzed using Omega software (Oxford molecular, Campbell, California).

\section{RESULTS}

Forty-eight IBDV positive bursa samples from commercial broiler flocks in the US were analyzed by real-time RT-PCR with two sets of probes complementary to nucleotide sequences that encode the antigenic regions minor peak 1 and peak B of VP2. The probes were designed based on an antigenic variant strain (Del-E), a classic strain (STC) and a field strain (F15); therefore there were two sets of probes for each strain which were tested in the same reaction. A lower melting temperature (Tm) of the sample when compared with the control signified the presence of one or more mutations in the target region.

From a total of 47 IBDV positive samples tested by real-time PCR using the DelE minor peak probe (DEMP) (Fig. 2.2), 23 had a lower Tm than expected (Fig. 2.1). 
From these, 14 were sequenced and it was observed that all of them had from one to four mutations.

Eleven samples had mutations that lead to at least one amino acid change and the most frequent mutation was located in the amino acid position $254(\mathrm{~S} \rightarrow \mathrm{N})$. The samples and the corresponding mutations are listed in Table 2.3. When the samples were analyzed with the Del-E peak B probe (Del-E) (Fig.2.3), 44 had lower melting temperatures than expected (Fig. 2.1) and from these, 34 were sequenced and had from 1 to 5 mutations. Twenty samples had amino acids substitutions with the most common located in amino acid position $323(\mathrm{E} \rightarrow \mathrm{D})$ (Table 2.4).

The forty-eight IBDV positive samples tested with the STC minor peak probe (STMP) (Fig.2.4) had a lower Tm than expected (Fig.2.1). From these, 34 were sequenced and had from 2 to 6 mutations which lead to at least one amino acid substitution. The most common amino acid changes were located in positions 249 $(\mathrm{Q} \rightarrow \mathrm{K})$ and $254(\mathrm{G} \rightarrow \mathrm{S})$ (Table 2.5). When the results with the peak B probe were analyzed, it was observed that of 44 samples tested, 41 had a lower Tm than expected (Fig.2.1, 2.5). From these, 34 samples were sequenced and they had from 1 to 6 mutations and most of these lead to at least one amino acid change. The most common substitutions were located in amino acid positions $318(\mathrm{G} \rightarrow \mathrm{D}$ and $\mathrm{G} \rightarrow \mathrm{N})$ and 323 $(\mathrm{D} \rightarrow \mathrm{E})$ (Table 2.6).

The forty-four samples tested using the F15 minor peak probe (F15MP) had a lower Tm when compared to the control (Fig.2.1, 2.6). From these, 31 were sequenced 
and it was observed that they had from 1 to 6 mutations all of which lead to amino acid substitutions. The most common changes were located in position $252(\mathrm{I} \rightarrow \mathrm{V})$ and 254 $(\mathrm{N} \rightarrow \mathrm{S})$ (Table 2.7). Forty-eight samples were analyzed with the F15 peak B probe (F15) and all of them had a lower Tm than expected (Fig.2.1, 2.7). From these, 31 samples were sequenced. They had from 1 to 4 mutations and 23 samples had amino acid substitutions distributed mainly in positions $323(\mathrm{D} \rightarrow \mathrm{E})$ and $318(\mathrm{D} \rightarrow \mathrm{N}, \mathrm{D} \rightarrow \mathrm{S}, \mathrm{D} \rightarrow \mathrm{G})$ (Table 2.8).

\section{DISCUSSION}

IBDV is a poultry pathogen responsible for substantial economic losses in the broiler industry. The virus can cause an acute disease in chickens which leads to high morbidity and mortality in susceptible flocks. In addition, the virus induced immunosuppression increases the susceptibility against other pathogens and decreases vaccination efficacy, which is a major disease control measure in this industry. Despite all efforts with improved biosafety practices and vaccination, the virus is still pandemic. One of the most frequent problems in the field is the decreased vaccination efficacy due to the use of vaccines antigenically non-synonymous to the strain present in the flock's environment. In this case, the virus can break through maternal antibody protection and cause the disease. Therefore, approaches that are able to detect new IBDV variants may play an important role in developing strategies for IBDV control.

In this study, we analyzed 48 IBDV positive samples using real-time RT-PCR with two sets of probes designed based on regions encoding the antigenic epitopes in 
minor peak 1 and peak B of three different IBDV strains: Del-E, STC and F15. These strains belong to different antigenic groups, denominated variant, classic and an antigenically uncharacterized field strain, respectively. Mutations in the amino acid sequence of an unknown virus, when compared to Del-E, STC and F15 may correspond to antigenic differences that could affect vaccination efficacy. For instance, if a lower melting temperature than expected is observed when a sample is tested with probes designed to two different antigenic regions of a classical strain, this demonstrates one or more nucleotide mutations and could be indicative of amino acid changes. This would suggest that the use of a commercial vaccine based on a classic strain would not be effective in the flock tested. Further studies are necessary to confirm this assumption. Many samples had lower than expected melting temperatures, which indicate high genetic variability among IBDV samples and suggests a high mutability rate for this virus in the sample population tested. However, it is good to emphasize that we tested a small number of samples that originated from flocks with a history of IBDV infection. Thus, it is possible that we would observe different results with an unbiased sample population.

The nucleotide sequences of 34 samples were determined and we observed that, depending on the probe employed, the samples had from 1 to 6 mutations. All samples with nucleotide mutations had a lower Tm than expected except samples AL 177 and GA215. Also, one sample (GA17) with no nucleotide mutations had a lower Tm when compared to the control. Additionally, the sample FL 55 displayed Tms that were not consistent with the number of mutations in the sample. We speculate that this was caused due the presence of quasispecies in the samples (Jackwood and Sommer, 2002a), which 
could have been sequenced instead of the dominant virus detected in the real-time RTPCR or vice-versa. This may have impaired the sequencing results, as the real-time RTPCR outcomes were very consistent after several repetitions. When the samples were analyzed with the minor peak probes of the three different IBDV strains, we observed amino acid mutations in all positions except for positions 250 (T) and 255 (L). Mutations in amino acid position $253(\mathrm{Q} \rightarrow \mathrm{H})$ have been reported to be related to attenuation in cell culture (Kwon and Kim, 2004; Mundt, 1999). The samples analyzed with the peak B probes had mutations in all amino acid positions, except for $319(\mathrm{G})$ and $320(\mathrm{Q})$ which were conserved in all samples.

Most of the nucleotide mutations in both epitope regions resulted in amino acid substitutions and also in different amino acid groups; as for instance one of the most frequent mutations in aa position $249(\mathrm{Q} \rightarrow \mathrm{K})$ resulted in a change from an amide to a basic group. This fact supports our hypothesis that these mutations could signify antigenic changes in the samples tested as they may result in conformational changes at the epitope level. However, as mentioned previously, further studies are necessary to confirm this hypothesis.

This new application of the Real-time RT-PCR technique proved to be a powerful tool for diagnosis and identification of IBDV. However, when the sample tested differs from the probe employed, it may be necessary to further identify nucleotide mutations and more importantly possible amino acid substitutions through sequencing. 
Real-time RT-PCR has been used in several studies such as identification of IBDV quasispecies (Jackwood and Sommer, 2002a), IBDV in broilers and proventriculitis (Pantin-Jackwood and Brown, 2003), real-time RT-PCR based on genome segment B for the detection of IBDV (Raue and Mazaheri, 2003), real-time RTPCR for detection and analysis of nucleotide sequences coding for an epitope of IBDV (Jackwood et al., 2003) and others (Raue and Muller, 2001; Moody et al., 2000) . In the present study, we adapted this technique to analyze two important antigenic regions of this virus, which may assist in the identification of newly emerging antigenic variants. Real-time RT-PCR is relatively simple to perform, economically feasible and provides very fast results, mainly when compared to the commonly used methodologies for characterization of IBDV samples such as antigen capture ELISA and RT-PCR-RFLP. Consequently, this approach may assist in the development of more effective vaccination strategies which may improve the control of this disease.

\section{ACKNOWLEDGMENTS}

We would like to thank Susan Sommer-Wagner for her technical support. This work was funded in part by funds appropriated to the Ohio Agricultural Research and Development Center and by grant \#491 from the U.S. Poultry and Egg Association, Tucker, Georgia. USA. 


\section{CONCLUSION}

The high mutation rate of RNA viruses and the high selection pressure generated by intensive vaccination of birds for disease control can lead to the emergence of viruses with new properties allowing them to persist in immune populations. These mutations have led to antigenic variation and changes in the virulence of IBDV strains.

Current field conditions have indicated that it may be necessary to use new approaches to control IBDV, as the virus is still endemic despite existing control measures. The field conditions are changing which creates a challenging situation and favors the emergence of new variants. For instance, poultry production has adapted to increased market demand with dense populations turning over very fast. Dense populations of the host species create a favorable environment for mutable viruses. In addition, the widespread use of vaccines increases the selective pressure on these pathogens; therefore it promotes the survival of mutants that diverge from the commercial vaccine strains. The geographic distribution of the poultry farms also contributes for the presence of geographically localized variants. Modifications in the host play an important role in the current field conditions. The birds are being adapted to the necessities of the market, which demands productivity. Because of this, birds suffer

physiological stress probably due the rapid growth which depletes the innate and adaptive immune responses. This leads to the assumption that these birds are more susceptible to infection and disease. The conjunction of all these factors point to the idea that the measures for controlling IBDV should be adapted to specific situations in the field. For 
example, if a flock presents symptoms of IBDV infection even after the usual commercial vaccination, it is reasonable to state that an autogenous vaccine would be an option, as it would offer a homologous response to the antigen which may lead to an adequate immune response in the birds, as IBDV does not cross-react very effectively between different antigenic subtypes. However, this option has some counterpoints as these vaccines are inactivated and the use of adjuvants and additional boosters may be necessary. The use of autogenous vaccines as an option should be carefully considered in regions in which IBDV is causing problems despite the standard control measures employed. With this idea in mind, approaches that are able to identify and characterize newly emerging IBDV strains as soon as they appear can be used as a major tool to combat this disease. Consequently, the new version of real-time RT-PCR we proposed in our study can fulfill these expectations, as it is not only able to identify new genetic variants, but also compares them to vaccine strains. The nucleotide sequences of two major antigenic regions were tested. The results suggest it is reasonable to assume that this test can infer the presence of antigenic differences among the samples tested. Obviously the results obtained with this test can not say with $100 \%$ certainty that there is a new variant strain in the field. However, the results can give us an important insight of why the current vaccination scheme is not working and what vaccine might be more adequate. With a few palpable options on the horizon, and with current vaccination strategies not working very well in many circumstances, the best approach may be to try to improve the current control strategy. 
Real-Time RT-PCR proved to be a suitable approach with the advantages of being fast, relatively easy to be performed and economically feasible, mainly when compared with other diagnostic tools currently available. 


\section{REFERENCES}

Bayliss, C. D., Spies, U., Shaw, K., Peters, R. W., Papageorgiou, A., Muller, H., Boursnell, M. E. 1990. A comparison of the sequences of segment A of four infectious bursal disease virus strains and identification of a variable region in VP2. J.Gen.Virol. 71, 1303-1312.

Eterradossi, N. 1995. Progress in the diagnosis and prophylaxis of Infectious Bursal Disease in poultry. Comprehensive reports on technical items presented to the International Comittee or to regional Commissions, pp. 75-82. Paris: Office International des Epizooties.

Heine, H. G., Haritou, M., Failla, P., Fahey, K., Azad, A. 1991. Sequence analysis and expression of the host-protective immunogen VP2 of a variant strain of infectious bursal disease virus which can circumvent vaccination with standard type I strains. J.Gen.Virol. 72, 1835-1843.

Ismail, N. M. and Saif, Y. M. 1991. Immunogenicity of infectious bursal disease viruses in chickens. Avian Dis. 35, 460-469.

Jackwood, D. J. and Sommer, S. E. 1997. Restriction fragment length polymorphisms in the VP2 gene of infectious bursal disease viruses. Avian Dis. 41, 627-637.

Jackwood, D. J. and Sommer, S. E. 1998. Genetic heterogeneity in the VP2 gene of infectious bursal disease viruses detected in commercially reared chickens. Avian Dis. $42,321-339$.

Jackwood, D. J. and Sommer, S. E. 2002. Identification of infectious bursal disease virus quasispecies in commercial vaccines and field isolates of this double-stranded RNA virus. Virology 304, 105-113.

Jackwood, D. J., Sommer, S. E., Knoblich, H. V. 2001. Amino acid comparison of infectious bursal disease viruses placed in the same or different molecular groups by RT/PCR-RFLP. Avian Dis. 45, 330-339. 
Jackwood, D. J., Spalding, B. D., Sommer, S. E. 2003. Real-time reverse transcriptasepolymerase chain reaction detection and analysis of nucleotide sequences coding for a neutralizing epitope on infectious bursal disease viruses. Avian Dis. 47, 738-744.

Kwon, H. M. and Kim, S. J. 2004. Sequence analysis of the variable VP2 gene of infectious bursal disease viruses passaged in Vero cells. Virus Genes 28, 285-291.

Moody, A., Sellers, S., Bumstead, N. 2000. Measuring infectious bursal disease virus RNA in blood by multiplex real-time quantitative RT-PCR. J.Virol.Methods 85, 5564.

Muller, H., Islam, M. R., Raue, R. 2003. Research on infectious bursal disease--the past, the present and the future. Vet.Microbiol. 97, 153-165.

Mundt, E. 1999. Tissue culture infectivity of different strains of infectious bursal disease virus is determined by distinct amino acids in VP2. J.Gen.Virol. 80, 2067-2076.

Pantin-Jackwood, M. J. and Brown, T. P. 2003. Infectious bursal disease virus and proventriculitis in broiler chickens. Avian Dis. 47, 681-690.

Raue, R. and Mazaheri, A. 2003. Real-time RT-PCR based on genome segment B for the detection of infectious bursal disese virus. Archiv fur Geflugelkunde 67, 22-27.

Raue, R., and Müller, H. 2001. Detection and quantification of IBDV by real-time RTPCR. In: Proc. $2^{\text {nd }}$ International Symposium on Infectious Bursal Disease and Chicken Infectious Anaemia. Rauischholzhausen, Germany. pp. 271-277.

Vakharia, V. N., He, J., Ahamed, B., Snyder, D. B. 1994. Molecular basis of antigenic variation in infectious bursal disease virus. Virus Res. 31, 265-273.

van den Berg, T. P. 2000. Acute infectious bursal disease in poultry: a review. Avian Pathol. 29, 175-194.

van den Berg, T. P., Gonze, M., Morales, D. and Meulemans, G. 1996. Acute infectious bursal disease virus in poultry: immunological and molecular basis of antigenicity of a highly virulent strain. Avian Pathol. 25, 751-769. 


\begin{tabular}{llc}
\hline Probes & \multicolumn{1}{c}{ Sequence } & Tm $\left({ }^{\circ} \mathrm{C}\right)^{\mathrm{a}}$ \\
DEMP & Mutation probe: 5'-CAAAACAAGCGTCCAAAGCCTTG-FITC-3' & 63.8 \\
& Anchor probe: 5'-Red 705-CTGGGCGCCACCATCTACCTTATAGGCTTTG-3' & 71.1 \\
STMP & Mutation probe: 5'-TCAAACAAGCGTCCAAGGTCTTG-FITC-3' & 63.8 \\
& Anchor probe: 5'-Red 705-CTGGGCGCCACCATCTACTTTATAGGCTTTG-3' & 69.8 \\
F15MP & Mutation probe: 5'-CAAAACAAGCATCCAAAACCTTG-FITC-3' & 59.8 \\
& Anchor probe:5'-Red 705-CTGGGCGCCACCATCTACCTTATAGGCTTCG-3' & 72.2 \\
\hline
\end{tabular}

Table 2.1. Mutation and anchor probe nucleotide sequences that are complementary to the minor peak region of the VP2 gene.

\begin{tabular}{llc}
\hline Probes & \multicolumn{1}{c}{ Sequence } & Tm $\left({ }^{\circ} \mathrm{C}\right)^{\mathrm{a}}$ \\
Del-E & \multicolumn{1}{c}{${ }^{\mathrm{b}}$} & Mutation probe: 5'-GTGATGGTCAGGCAGGGGAACAG-FITC-3' \\
& Anchor probe: 5'-Red 640-TGTCATGGTCGGCAAGTGGGAGCC-3' & 71.0 \\
STC $^{\mathrm{b}}$ & Mutation probe: 5'-GTGGTGGCCAGGCAGGGGATCAG-FITC-3' & 71.4 \\
& Anchor probe: 5'-Red 640-TGTCATGGTCGGCAAGTGGGAGCCTAGCAGTG-3' & 75.0 \\
F15 & Mutation probe: 5'-GCGATGGTCAGGCAGGGGACCAG-FITC-3' & 71.3 \\
& Anchor probe: 5'-Red 640-TGTCATGGTCGGCAAGTGGGAGCCTAGCAGTG-3' & 75.0 \\
\hline
\end{tabular}

${ }^{a}$ Theoretical melting temperature determined using the TM utility 1.5 (Idaho Technologies, Inc.).
b Probes have been previously published in Jackwood and Sommer, 2002 and Jackwood et al., 2003.

Table 2.2. Mutation and Anchor probe nucleotide sequences that are complementary to the peak B region of the VP2 gene. 


\begin{tabular}{|c|c|c|c|c|}
\hline Samples & Nucleotide sequence & $T m^{a}$ & Mut. $^{b}$ & aa changes ${ }^{c}$ \\
\hline DEL-E ${ }^{\mathbf{d}}$ & CAAAACAAGCGTCCAAAGCCTTG & $61.3 \pm 0.66^{\mathrm{e}}$ & & K T S V Q S L \\
\hline AL186 & CAAAACAAGCGTCCAAAGCCTTG & $62.6 \pm 0.56$ & 0 & K T S V Q S L \\
\hline AR84 & CAAAACAAGCGTCCAAAGCCTTG & $63.5 \pm 0.94$ & 0 & K T S V Q S L \\
\hline GA146 & CAAAACAAGCGTCCAAAGCCTTG & $62.7 \pm 0.05$ & 0 & K T S V Q S L \\
\hline GA147 & CAAAACAAGCGTCCAAAGCCTTG & $63.1 \pm 0.16$ & 0 & K T S V Q S L \\
\hline GA17 & CAAAACAAGCGTCCAAAGCCTTG & $55.8 \pm 1.65$ & 0 & K T S V Q S L \\
\hline GA198 & CAAAACAAGCGTCCAAAGCCTTG & $61.6 \pm 0.16$ & 0 & K T S V Q S L \\
\hline GA205 & CAAAACAAGCGTCCAAAGCCTTG & $62.3 \pm 0.90$ & 0 & K T S V Q S L \\
\hline GA206 & CAAAACAAGCGTCCAAAGCCTTG & $62.9 \pm 0.11$ & 0 & K T S V Q S L \\
\hline GA208 & CAAAACAAGCGTCCAAAGCCTTG & $63.2 \pm 0.34$ & 0 & K T S V Q S L \\
\hline GA214 & CAAAACAAGCGTCCAAAGCCTTG & $62.7 \pm 1.25$ & 0 & K T S V Q S L \\
\hline GA35 & CAAAACAAGCGTCCAAAGCCTTG & $62.3 \pm 0.06$ & 0 & K T S V Q S L \\
\hline GA36 & CAAAACAAGCGTCCAAAGCCTTG & $62.6 \pm 0.60$ & 0 & K T S V Q S L \\
\hline GA94 & CAAAACAAGCGTCCAAAGCCTTG & $62.4 \pm 1.31$ & 0 & K T S V Q S L \\
\hline GA95 & CAAAACAAGCGTCCAAAGCCTTG & $63.2 \pm 0.44$ & 0 & K T S V Q S L \\
\hline GA97 & CAAAACAAGCGTCCAAAGCCTTG & $62.8 \pm 0.33$ & 0 & K T S V Q S L \\
\hline NC109 & CAAAACAAGCGTCCAAAGCCTTG & $62.9 \pm 0.31$ & 0 & K T S V Q S L \\
\hline NC20 & CAAAACAAGCGTCCAAAGCCTTG & $62.7 \pm 0.38$ & 0 & K T S V Q S L \\
\hline $\mathrm{NC} 21$ & CAAAACAAGCGTCCAAAGCCTTG & $62.8 \pm 0.44$ & 0 & K T S V Q S L \\
\hline NC56 & CAAAACAAGCGTCCAAAGCCTTG & $62.5 \pm 0.28$ & 0 & K T S V Q S L \\
\hline AL177 & CAAAACAAGCGTCCAAAACCTTG & $62.5 \pm 0.71$ & 1 & K T S V Q N L \\
\hline AR115 & CAAAACAAGCGTCCAAAACCTTG & $56.6 \pm 0.33$ & 1 & K T S V Q N L \\
\hline AR78 & CAAAACAAGCGTCCAAAACCTTG & $56.2 \pm 0.57$ & 1 & K T S V Q N L \\
\hline FL55 & CAAAACAAGCGTCCAAAACCTTG & $53.0 \pm 0.47$ & 1 & K T S V Q N L \\
\hline GA215 & CAAAACAAGCGTCCAAAGTCTTG & $62.3 \pm 0.17$ & 1 & K T S V Q S L \\
\hline GA34 & CAAAACAAGCGTCGAAAGCCTTG & $53.2 \pm 0.45$ & 1 & K T S V E S L \\
\hline MO196 & CAAAACCAGCGTCCAAAGCCTTG & $55.8 \pm 0.11$ & 1 & K T S V Q S L \\
\hline NC58 & CAAGACAAGCGTCCAAAGCCTTG & $57.3 \pm 0.76$ & 1 & K T S V Q S L \\
\hline NC93 & TAAAACAAGCGTCCAAAGCCTTG & $60.3 \pm 1.79$ & 1 & K T S V Q S L \\
\hline GA11 & TAAAACAAGCATCCAAAGCCTTG & $55.7 \pm 0.38$ & 2 & K T S I Q S L \\
\hline AR113 & TAAAACAAGCGTCCAAAACCTTG & $55.2 \pm 0.00$ & 2 & K T S V Q N L \\
\hline MS218 & TAAAACAAGCGTCCAAAACCTTG & $55.1 \pm 1.24$ & 2 & K T S V Q N L \\
\hline MS200 & СААААСАААСАТССАААGCСТТG & $50.7 \pm 1.28$ & 2 & K T N I Q S L \\
\hline MS201 & CAAAACGAGCGTCCAAAACCTTG & $48.7 \pm 0.89$ & 2 & K T S V Q N L \\
\hline $\mathrm{NC} 14$ & TCAAACAAGCGTCCACGGCCTTG & $52.1 \pm 0.18$ & 4 & Q T S V H G L \\
\hline
\end{tabular}

${ }^{a}$ Melting temperature (average of at least 2 different reactions) \pm standard deviation.

${ }^{\mathbf{b}}$ Number of nucleotide substitutions.

${ }^{\mathbf{c}}$ Amino acids spam the positions 249 to 255 and substitutions are in bold type.

${ }^{\mathrm{d}}$ Homologous match of the DEMP probe.

e Sample was tested 16 times $(n=16)$.

Table 2.3. Nucleotide sequence comparison of DEMP probe (minor peak 1) with sequenced samples. 


\begin{tabular}{|c|c|c|c|c|}
\hline Samples & Nucleotide sequence & $T m^{a}$ & Mut. $^{b}$ & aa changes $^{c}$ \\
\hline Del-E & GTGATGGTCAGGCAGGGGAACAG & $66.4 \pm 0.99^{\mathrm{e}}$ & & D G Q A GE Q \\
\hline GA17 & GTGATGGTCAGGCAGGGGAACAG & $63.0 \pm 0.44$ & 0 & D G Q A GE Q \\
\hline GA35 & GTGATGGTCAGGCAGGGGATCAG & $63.2 \pm 0.16$ & 1 & D G Q A G D Q \\
\hline GA94 & GTGATGGTCAGGCAGGGGATCAG & $62.8 \pm 1.14$ & 1 & D G Q A G D Q \\
\hline GA95 & GTGATGGTCAGGCAGGGGATCAG & $63.0 \pm 0.58$ & 1 & D G Q A G D Q \\
\hline GA97 & GTGATGGTCAGGCAGGGGATCAG & $63.2 \pm 0.38$ & 1 & D G Q A G D Q \\
\hline GA146 & GTGATGGTCAGGCAGGGGATCAG & $63.4 \pm 0.48$ & 1 & D G Q A G D Q \\
\hline GA147 & GTGATGGTCAGGCAGGGGATCAG & $64.1 \pm 1.67$ & 1 & D G Q A G D Q \\
\hline GA208 & GTGATGGTCAGGCTGGGGAACAG & $62.6 \pm 0.43$ & 1 & D G Q A G E Q \\
\hline GA215 & GTGATGGTCAGGCAGGGGATCAG & $62.2 \pm 0.92$ & 1 & D G Q A G D Q \\
\hline NC20 & GCGATGGTCAGGCAGGGGAACAG & $63.7 \pm 0.11$ & 1 & D G Q A GE Q \\
\hline $\mathrm{NC} 21$ & GCGATGGTCAGGCAGGGGAACAG & $63.9 \pm 0.00$ & 1 & D G Q A GE Q \\
\hline NC58 & GCGATGGTCAGGCAGGGGAACAG & $65.7 \pm 0.56$ & 1 & D G Q A G E Q \\
\hline NC93 & GTGATGGTCAGGCAGGGGATCAG & $63.3 \pm 0.16$ & 1 & D G Q A G D Q \\
\hline NC109 & GCGATGGTCAGGCAGGGGAACAG & $65.5 \pm 0.35$ & 1 & D G Q A G E Q \\
\hline AL177 & GTGATGGTCAGGCAGAGGATCAG & $57.8 \pm 0.04$ & 2 & D G Q A E D Q \\
\hline AR78 & GCGATGGTCAGGCAGGGGAGCAG & $59.9 \pm 0.88$ & 2 & D G Q A G E Q \\
\hline AR115 & GCGATGGTCAGGCAGGGGAGCAG & $59.3 \pm 0.99$ & 2 & D G Q A GE Q \\
\hline FL55 & GCGATGGTCAGGCAGGGGAGCAG & $59.3 \pm 0.16$ & 2 & D G Q A G E Q \\
\hline GA11 & GTGATGGTCAGGCAGGGGAGCAA & $62.0 \pm 0.11$ & 2 & D G Q AGE Q \\
\hline GA34 & GTGGTGGTCAGGCAGGGGATCAG & $57.5 \pm 2.57$ & 2 & G G Q AG D Q \\
\hline GA206 & GTGATGGTCAGGCAGGGGAGCAA & $49.2 \pm 3.19$ & 2 & D G Q AGE Q \\
\hline $\mathrm{NC} 14$ & GTGGTGGTCAGGCAGGGGATCAG & $57.7 \pm 0.28$ & 2 & G G Q AG D Q \\
\hline NC56 & GCGATGGTCAGGCAGGGGAGCAG & $59.7 \pm 1.15$ & 2 & D G Q A G E Q \\
\hline MS200 & GGGATGGTCAGGCAGAGGACCAG & $55.3 \pm 0.27$ & 3 & D G Q AE D Q \\
\hline AL186 & GCAATGGTCAGGAAGGGGACCAG & $49.9 \pm 0.33$ & 4 & N G Q E G D Q \\
\hline GA198 & GCAATGGTCAGGAAGGGGATCAG & $46.0 \pm 0.27$ & 4 & N G Q E G D Q \\
\hline GA214 & AAGATGGTCAGGCAGGGGAGCAA & $59.1 \pm 1.01$ & 4 & D G Q A G E Q \\
\hline MO196 & GTAGTGGTCAGGAAGGGGACCAG & ND & 4 & S G Q E G D Q \\
\hline MS201 & GCAATGGTCAGGCAGAGGACCAG & $55.0 \pm 0.89$ & 4 & N G Q A E D Q \\
\hline AR84 & GCAATGGTCAGGCTGAGGATCAG & $45.4 \pm 0.05$ & 5 & N G Q A E D Q \\
\hline AR113 & GCAATGGACAGGCAGAGGACCAG & $48.0 \pm 0.16$ & 5 & N G Q A G D Q \\
\hline GA36 & GCAATGGTCAGGCAGAGGATCTG & $48.9 \pm 0.93$ & 5 & N G Q A E D L \\
\hline GA205 & GCAATGGTCAGGCAGAGGATCTG & $49.1 \pm 1.68$ & 5 & N G Q A E D L \\
\hline MS218 & GCAATGGACAGGCAGAGGACCAG & $48.3 \pm 0.96$ & 5 & N G Q A E D Q \\
\hline
\end{tabular}

${ }^{a}$ Melting temperature (average of at least 2 different reactions) \pm standard deviation.

${ }^{\text {b }}$ Number of nucleotide substitutions.

${ }^{c}$ Amino acids spam the positions 318 to 324 and substitutions are in bold type.

${ }^{\mathrm{d}}$ Homologous match of the DEL-E probe.

${ }^{\mathrm{e}}$ Sample was tested 15 times $(\mathrm{n}=15)$.

ND- not determined

Table 2.4. Nucleotide sequence comparison of Del-E probe (peak B) with sequenced samples. 


\begin{tabular}{|c|c|c|c|c|}
\hline Samples & Nucleotide sequence & $\overline{T m^{a}}$ & Mut. $^{b}$ & aa changes $^{c}$ \\
\hline STC $^{d}$ & TCAAACAAGCGTCCAAGGTCTTG & $63.8 \pm 0.87^{\mathrm{e}}$ & & Q T S V Q G L \\
\hline $\mathrm{NC} 14$ & TCAAACAAGCGTCCACGGCCTTG & $56.4 \pm 0.16$ & 2 & Q T S V H G L \\
\hline GA215 & CAAAACAAGCGTCCAAAGTCTTG & $54.7 \pm 1.00$ & 3 & K T S V Q G L \\
\hline NC93 & TAAAACAAGCGTCCAAAGCCTTG & $50.2 \pm 0.53$ & 3 & K T S V Q S L \\
\hline AL186 & CAAAACAAGCGTCCAAAGCCTTG & $50.0 \pm 0.06$ & 4 & K T S V Q S L \\
\hline AR113 & TAAAACAAGCGTCCAAAACCTTG & $44.8 \pm 0.79$ & 4 & K T S V Q N L \\
\hline AR84 & CAAAACAAGCGTCCAAAGCCTTG & $50.9 \pm 0.31$ & 4 & K T S V Q S L \\
\hline GA11 & TAAAACAAGCATCCAAAGCCTTG & $45.2 \pm 0.71$ & 4 & K T S I Q S L \\
\hline GA146 & CAAAACAAGCGTCCAAAGCCTTG & $49.5 \pm 0.06$ & 4 & K T S V Q S L \\
\hline GA147 & CAАAACAAGCGTCCAAAGCCTTG & $49.4 \pm 0.34$ & 4 & K T S V Q S L \\
\hline GA17 & CAAAACAAGCGTCCAAAGCCTTG & $51.4 \pm 0.79$ & 4 & K T S V Q S L \\
\hline GA198 & CAAAACAAGCGTCCAAAGCCTTG & $50.0 \pm 0.39$ & 4 & K T S V Q S L \\
\hline GA205 & CAAAACAAGCGTCCAAAGCCTTG & $50.0 \pm 0.55$ & 4 & K T S V Q S L \\
\hline GA206 & CAAAACAAGCGTCCAAAGCCTTG & $51.2 \pm 0.28$ & 4 & K T S V Q S L \\
\hline GA208 & CAAAACAAGCGTCCAAAGCCTTG & $49.6 \pm 0.50$ & 4 & K T S V Q S L \\
\hline GA214 & CAAAACAAGCGTCCAAAGCCTTG & $51.0 \pm 0.36$ & 4 & K T S V Q S L \\
\hline GA35 & CAAAACAAGCGTCCAAAGCCTTG & $50.3 \pm 0.28$ & 4 & K T S V Q S L \\
\hline GA36 & CAAAACAAGCGTCCAAAGCCTTG & $50.3 \pm 0.33$ & 4 & K T S V Q S L \\
\hline GA94 & CAAAACAAGCGTCCAAAGCCTTG & $51.2 \pm 0.28$ & 4 & K T S V Q S L \\
\hline GA95 & CAAAACAAGCGTCCAAAGCCTTG & $50.8 \pm 0.76$ & 4 & K T S V Q S L \\
\hline GA97 & CAAAACAAGCGTCCAAAGCCTTG & $50.7 \pm 0.66$ & 4 & K T S V Q S L \\
\hline MS218 & TAAAACAAGCGTCCAAAACCTTG & $44.9 \pm 0.39$ & 4 & K T S V Q N L \\
\hline NC109 & CAAAACAAGCGTCCAAAGCCTTG & $50.3 \pm 0.41$ & 4 & K T S V Q S L \\
\hline NC20 & CAAAACAAGCGTCCAAAGCCTTG & $50.2 \pm 0.40$ & 4 & K T S V Q S L \\
\hline NC21 & CAAAACAAGCGTCCAAAGCCTTG & $50.7 \pm 0.68$ & 4 & K T S V Q S L \\
\hline NC56 & CAAAACAAGCGTCCAAAGCCTTG & $50.0 \pm 0.07$ & 4 & K T S V Q S L \\
\hline AL177 & CAАAACAAGCGTCCAАAАCСТTG & $50.5 \pm 0.56$ & 5 & K T S V Q N L \\
\hline AR115 & CAAAACAAGCGTCCAAAACCTTG & $44.6 \pm 0.65$ & 5 & K T S V Q N L \\
\hline AR78 & CAAAACAAGCGTCCAAAACCTTG & $44.5 \pm 0.05$ & 5 & K T S V Q N L \\
\hline FL55 & САAАACAAGCGTCCAАAАССТTG & $57.5 \pm 1.56$ & 5 & K T S V Q N L \\
\hline GA34 & CAAAACAAGCGTCGAAAGCCTTG & $39.8 \pm 1.05$ & 5 & K T S V E S L \\
\hline MO196 & CAAAACCAGCGTCCAAAGCCTTG & $46.1 \pm 0.11$ & 5 & K T S V Q S L \\
\hline NC58 & CAAGACAAGCGTCCAAAGCCTTG & $48.0 \pm 0.11$ & 5 & K T S V Q S L \\
\hline MS200 & СААААСАААСАТССАААGССТТG & $38.3 \pm 0.78$ & 6 & K T N I Q S L \\
\hline MS201 & CAAAACGAGCGTCCAAAACCTTG & $36.7 \pm 0.56$ & 6 & K T S V Q N L \\
\hline
\end{tabular}

${ }^{a}$ Melting temperature (average of at least 2 different reactions) \pm standard deviation.

${ }^{\mathbf{b}}$ Number of nucleotide substitutions.

${ }^{\mathbf{c}}$ Amino acids spam the positions 249 to 255 and substitutions are in bold type.

${ }^{\mathbf{d}}$ Homologous match of the STMP probe.

${ }^{\mathbf{e}}$ Sample was tested 13 times $(\mathrm{n}=13)$.

Table 2.5. Nucleotide comparison of STMP probe (minor peak 1) with sequenced samples. 


\begin{tabular}{|c|c|c|c|c|}
\hline Samples & Nucleotide sequence & $\mathbf{T m}^{\mathrm{a}}$ & Mut. $^{b}$ & aa changes $^{c}$ \\
\hline STC $^{d}$ & GTGGTGGCCAGGCAGGGGATCAG & $69.12 \pm 0.84^{\mathrm{e}}$ & & G G Q A G D Q \\
\hline GA34 & GTGGTGGTCAGGCAGGGGATCAG & $62.03 \pm 0.17$ & 1 & G G Q A G D Q \\
\hline $\mathrm{NC} 14$ & GTGGTGGTCAGGCAGGGGATCAG & $62.34 \pm 0.83$ & 1 & G G Q A G D Q \\
\hline GA35 & GTGATGGTCAGGCAGGGGATCAG & $53.07 \pm 1.23$ & 2 & D G Q A G D Q \\
\hline GA94 & GTGATGGTCAGGCAGGGGATCAG & $55.04 \pm 0.34$ & 2 & D G Q A G D Q \\
\hline GA95 & GTGATGGTCAGGCAGGGGATCAG & $55.85 \pm 0.16$ & 2 & D G Q A G D Q \\
\hline GA97 & GTGATGGTCAGGCAGGGGATCAG & $55.55 \pm 0.06$ & 2 & D G Q A G D Q \\
\hline GA146 & GTGATGGTCAGGCAGGGGATCAG & $56.38 \pm 2.99$ & 2 & D G Q A G D Q \\
\hline GA147 & GTGATGGTCAGGCAGGGGATCAG & $57.44 \pm 3.28$ & 2 & D G Q A G D Q \\
\hline GA215 & GTGATGGTCAGGCAGGGGATCAG & $59.33 \pm 0.17$ & 2 & D G Q A G D Q \\
\hline NC93 & GTGATGGTCAGGCAGGGGATCAG & $55.43 \pm 0.00$ & 2 & D G Q A G D Q \\
\hline GA17 & GTGATGGTCAGGCAGGGGAACAG & $50.91 \pm 0.39$ & 3 & D G Q A G E Q \\
\hline AL177 & GTGATGGTCAGGCAGAGGATCAG & $53.23 \pm 0.63$ & 3 & D G Q A G E Q \\
\hline GA208 & GTGATGGTCAGGCTGGGGAACAG & $45.83 \pm 0.73$ & 4 & D G Q A G E Q \\
\hline $\mathrm{NC} 20$ & GCGATGGTCAGGCAGGGGAACAG & $48.35 \pm 0.22$ & 4 & D G Q A G E Q \\
\hline NC21 & GCGATGGTCAGGCAGGGGAACAG & $48.58 \pm 0.11$ & 4 & D G Q A G E Q \\
\hline NC58 & GCGATGGTCAGGCAGGGGAACAG & $46.51 \pm 3.38$ & 4 & D G Q A G E Q \\
\hline NC109 & GCGATGGTCAGGCAGGGGAACAG & $49.02 \pm 0.39$ & 4 & D G Q A G E Q \\
\hline AR78 & GCGATGGTCAGGCAGGGGAGCAG & $48.23 \pm 0.06$ & 4 & D G Q A G E Q \\
\hline AR115 & GCGATGGTCAGGCAGGGGAGCAG & $48.66 \pm 0.23$ & 4 & D G Q A G E Q \\
\hline FL55 & GCGATGGTCAGGCAGGGGAGCAG & $69.84 \pm 0.89$ & 4 & D G Q A G E Q \\
\hline GA11 & GTGATGGTCAGGCAGGGGAGCAA & $48.53 \pm 0.48$ & 4 & D G Q A G E Q \\
\hline GA206 & GTGATGGTCAGGCAGGGGAGCAA & $47.98 \pm 1.37$ & 4 & D G Q A G E Q \\
\hline NC56 & GCGATGGTCAGGCAGGGGAGCAG & $47.72 \pm 1.11$ & 4 & D G Q A G E Q \\
\hline MO196 & GTAGTGGTCAGGAAGGGGACCAG & $44.19 \pm 0.35$ & 4 & S G Q E GE Q \\
\hline MS200 & GGGATGGTCAGGCAGAGGACCAG & $47.68 \pm 0.28$ & 5 & D G Q A E D Q \\
\hline GA198 & GCAATGGTCAGGAAGGGGATCAG & $42.03 \pm 0.75$ & 5 & N G Q E G D Q \\
\hline AL186 & GCAATGGTCAGGAAGGGGACCAG & $38.48 \pm 0.59$ & 6 & N G Q E G D Q \\
\hline GA214 & AAGATGGTCAGGCAGGGGAGCAA & $44.97 \pm 0.35$ & 6 & D G Q A G E Q \\
\hline MS201 & GCAATGGTCAGGCAGAGGACCAG & $44.91 \pm 1.87$ & 6 & N G Q A E D Q \\
\hline AR84 & GCAATGGTCAGGCTGAGGATCAG & $41.38 \pm 0.95$ & 6 & N G Q A E D Q \\
\hline AR113 & GCAATGGACAGGCAGAGGACCAG & $43.59 \pm 0.38$ & 6 & N G Q A E D Q \\
\hline GA36 & GCAATGGTCAGGCAGAGGATCTG & $41.81 \pm 0.89$ & 6 & N G Q A E D Q \\
\hline GA205 & GCAATGGTCAGGCAGAGGATCTG & $44.79 \pm 0.18$ & 6 & N G Q A E D Q \\
\hline MS218 & GCAATGGACAGGCAGAGGACCAG & $43.32 \pm 0.38$ & 6 & N G Q A E D Q \\
\hline
\end{tabular}

${ }^{a}$ Melting temperature (average of at least 2 different reactions) \pm standard deviation.

${ }^{\mathbf{b}}$ Number of nucleotide substitutions.

c Amino acids spam the positions 318 to 324 and substitutions are in bold type.

${ }^{\mathrm{d}}$ Homologous match of the STC probe.

${ }^{\mathrm{e}}$ Sample was tested 15 times $(\mathrm{n}=15)$.

Table 2.6. Nucleotide sequence comparison of STC probe (peak B) with sequenced samples. 


\begin{tabular}{|c|c|c|c|c|}
\hline Samples & Nucleotide sequence & $T \mathbf{m}^{\mathrm{a}}$ & Mut. $^{b}$ & aa changes $^{\mathrm{c}}$ \\
\hline $\mathrm{F} 15^{\mathrm{d}^{\mathrm{t}}}$ & САAАACAAGCATCCAАAАCСТTG & $59.8 \pm 0.89^{\mathrm{e}}$ & & K T S I Q N L \\
\hline AR78 & CAAAACAAGCGTCCAAAACCTTG & $50.3 \pm 0.76$ & 1 & K T S V Q N L \\
\hline AR115 & CAAAACAAGCGTCCAAAACCTTG & $50.6 \pm 0.34$ & 1 & K T S V Q N L \\
\hline AL177 & CAAAACAAGCGTCCAAAACCTTG & $50.1 \pm 0.08$ & 1 & K T S V Q N L \\
\hline FL55 & CAAAACAAGCGTCCAAAACCTTG & ND & 1 & K T S V Q N L \\
\hline AL186 & CAAAACAAGCGTCCAAAGCCTTG & $42.9 \pm 0.16$ & 2 & K T S V Q S L \\
\hline AR84 & CAAAACAAGCGTCCAAAGCCTTG & $43.6 \pm 0.80$ & 2 & K T S V Q S L \\
\hline AR113 & TAAAACAAGCGTCCAAAACCTTG & $48.6 \pm 0.16$ & 2 & K T S V Q N L \\
\hline GA11 & TAAAACAAGCATCCAAAGCCTTG & $49.4 \pm 0.89$ & 2 & K T S I Q S L \\
\hline GA17 & CAAAACAAGCGTCCAAAGCCTTG & $43.9 \pm 0.56$ & 2 & K T S V Q S L \\
\hline GA34 & CAAAACAAGCGTCGAAAGCCTTG & ND & 3 & K T S VE S L \\
\hline GA35 & CAAAACAAGCGTCCAAAGCCTTG & $44.0 \pm 0.38$ & 2 & K T S V Q S L \\
\hline GA36 & CAAAACAAGCGTCCAAAGCCTTG & $43.7 \pm 0.64$ & 2 & K T S V Q S L \\
\hline GA94 & CAAAACAAGCGTCCAAAGCCTTG & $43.2 \pm 0.22$ & 2 & K T S V Q S L \\
\hline GA95 & CAAAACAAGCGTCCAAAGCCTTG & $43.1 \pm 0.16$ & 2 & K T S V Q S L \\
\hline GA97 & CAAAACAAGCGTCCAAAGCCTTG & $43.1 \pm 0.06$ & 2 & K T S V Q S L \\
\hline GA146 & CAAAACAAGCGTCCAAAGCCTTG & $43.4 \pm 0.09$ & 2 & K T S V Q S L \\
\hline GA147 & CAAAACAAGCGTCCAAAGCCTTG & $43.0 \pm 0.04$ & 2 & K T S V Q S L \\
\hline GA198 & CAAAACAAGCGTCCAAAGCCTTG & $42.7 \pm 0.05$ & 2 & K T S V Q S L \\
\hline GA205 & CAAAACAAGCGTCCAAAGCCTTG & $42.8 \pm 0.22$ & 2 & K T S V Q S L \\
\hline GA206 & CAAAACAAGCGTCCAAAGCCTTG & $44.4 \pm 0.40$ & 2 & K T S V Q S L \\
\hline GA208 & CAAAACAAGCGTCCAAAGCCTTG & $42.7 \pm 0.05$ & 2 & K T S V Q S L \\
\hline GA214 & CAAAACAAGCGTCCAAAGCCTTG & $43.5 \pm 0.17$ & 2 & K T S V Q S L \\
\hline MS200 & CAAAACAAACATCCAAAGCCTTG & $44.6 \pm 0.41$ & 2 & K T N I Q S L \\
\hline MS201 & CAAAACGAGCGTCCAAAACCTTG & $41.7 \pm 0.47$ & 2 & K T S V Q N L \\
\hline MS218 & TAAAACAAGCGTCCAAAACCTTG & $49.6 \pm 0.50$ & 2 & K T S V Q N L \\
\hline $\mathrm{NC} 20$ & CAAAACAAGCGTCCAAAGCCTTG & $43.7 \pm 0.41$ & 2 & K T S V Q S L \\
\hline $\mathrm{NC} 21$ & CAAAACAAGCGTCCAAAGCCTTG & $43.8 \pm 0.69$ & 2 & K T S V Q S L \\
\hline NC56 & CAAAACAAGCGTCCAAAGCCTTG & $43.6 \pm 0.34$ & 2 & K T S V Q S L \\
\hline NC109 & CAAAACAAGCGTCCAAAGCCTTG & $36.7 \pm 0.00$ & 2 & K T S V Q S L \\
\hline GA215 & CAAAACAAGCGTCCAAAGTCTTG & $37.5 \pm 0.78$ & 3 & K T S V Q S L \\
\hline MO196 & CAAAACCAGCGTCCAAAGCCTTG & $39.1 \pm 0.06$ & 3 & K T S V Q S L \\
\hline NC58 & CAAGACAAGCGTCCAAAGCCTTG & $37.1 \pm 0.78$ & 3 & K T S V Q S L \\
\hline NC93 & TAAAACAAGCGTCCAAAGCCTTG & $40.5 \pm 0.01$ & 3 & K T S V Q S L \\
\hline $\mathrm{NC} 14$ & TCAAACAAGCGTCCACGGCCTTG & ND & 6 & Q T S V HG L \\
\hline
\end{tabular}

${ }^{a}$ Melting temperature (average of at least 2 different reactions) \pm standard deviation.

${ }^{\mathbf{b}}$ Number of nucleotide substitutions.

${ }^{\mathbf{c}}$ Amino acids spam the positions 249 to 255 and substitutions are in bold type.

${ }^{\mathbf{d}}$ Homologous match of the F15MP probe.

e Sample was tested 16 times $(\mathrm{n}=16)$.

ND- not determined.

Table 2.7. Nucleotide sequence comparison of F15MP probe (minor peak 1) with sequenced samples. 


\begin{tabular}{|c|c|c|c|c|}
\hline $\begin{array}{l}\text { Samples } \\
\text { F } 15^{\mathrm{d}}\end{array}$ & Nucleotide sequence & $\operatorname{Tm}_{68} \mathbf{T m}^{\mathbf{a}}$ & Mut. $^{b}$ & $\begin{array}{c}\text { aa changes }^{\mathbf{c}} \\
\text { D G O A G D O }\end{array}$ \\
\hline NC20 & GCGATGGTCAGGCAGGGGAACAG & $\begin{array}{r}00.0 \pm 1.00 \\
63.5 \pm 1.21\end{array}$ & 1 & D GQA GE Q \\
\hline $\mathrm{NC} 21$ & GCGATGGTCAGGCAGGGGAACAG & $63.3 \pm 1.26$ & 1 & D G Q A G EQ \\
\hline NC58 & GCGATGGTCAGGCAGGGGAACAG & $63.2 \pm 0.75$ & 1 & D G Q A G E Q \\
\hline NC109 & GCGATGGTCAGGCAGGGGAACAG & $55.8 \pm 0.46$ & 1 & D G Q A GE Q \\
\hline AR78 & GCGATGGTCAGGCAGGGGAGCAG & $62.7 \pm 0.38$ & 1 & D G Q A G E Q \\
\hline AR115 & GCGATGGTCAGGCAGGGGAGCAG & $63.4 \pm 0.45$ & 1 & D G Q A G E Q \\
\hline FL55 & GCGATGGTCAGGCAGGGGAGCAG & $50.9 \pm 0.84$ & 1 & D G Q A G E Q \\
\hline NC56 & GCGATGGTCAGGCAGGGGAGCAG & $63.3 \pm 0.64$ & 1 & D GQA GE Q \\
\hline GA34 & GTGGTGGTCAGGCAGGGGATCAG & $54.8 \pm 0.89$ & 2 & G G Q A G D Q \\
\hline GA35 & GTGATGGTCAGGCAGGGGATCAG & $57.8 \pm 1.57$ & 2 & D G Q A G D Q \\
\hline GA94 & GTGATGGTCAGGCAGGGGATCAG & $55.0 \pm 0.03$ & 2 & D G Q A G D Q \\
\hline GA95 & GTGATGGTCAGGCAGGGGATCAG & $54.8 \pm 0.25$ & 2 & D G Q A G DQ \\
\hline GA97 & GTGATGGTCAGGCAGGGGATCAG & $55.2 \pm 0.11$ & 2 & D G Q A G DQ \\
\hline GA146 & GTGATGGTCAGGCAGGGGATCAG & $54.6 \pm 0.73$ & 2 & D G Q A G D Q \\
\hline GA147 & GTGATGGTCAGGCAGGGGATCAG & $56.0 \pm 0.11$ & 2 & D G Q A G D Q \\
\hline GA215 & GTGATGGTCAGGCAGGGGATCAG & $55.0 \pm 1.13$ & 2 & D G Q A G DQ \\
\hline NC93 & GTGATGGTCAGGCAGGGGATCAG & $55.6 \pm 0.66$ & 2 & D G Q A G DQ \\
\hline GA17 & GTGATGGTCAGGCAGGGGAACAG & $56.2 \pm 0.83$ & 2 & D G Q A G E Q \\
\hline AL177 & GTGATGGTCAGGCAGAGGATCAG & $53.9 \pm 0.06$ & 2 & D G Q A E D Q \\
\hline MS200 & GGGATGGTCAGGCAGAGGACCAG & $61.0 \pm 0.27$ & 2 & D G Q A E D Q \\
\hline AL186 & GCAATGGTCAGGAAGGGGACCAG & $54.1 \pm 0.00$ & 2 & NGQE G D Q \\
\hline MS201 & GCAATGGTCAGGCAGAGGACCAG & ND & 2 & N G Q A E D Q \\
\hline $\mathrm{NC} 14$ & GTGGTGGTCAGGCAGGGGATCAG & $55.0 \pm 0.61$ & 3 & G GQA G D Q \\
\hline GA208 & GTGATGGTCAGGCTGGGGAACAG & $50.4 \pm 0.06$ & 3 & D G Q A G E Q \\
\hline GA11 & GTGATGGTCAGGCAGGGGAGCAA & $56.7 \pm 1.05$ & 3 & D G Q A G E Q \\
\hline GA206 & GTGATGGTCAGGCAGGGGAGCAA & ND & 3 & D G Q A G E Q \\
\hline GA198 & GCAATGGTCAGGAAGGGGATCAG & $46.1 \pm 0.11$ & 3 & NGQE G D Q \\
\hline AR113 & GCAATGGACAGGCAGAGGACCAG & $52.5 \pm 1.01$ & 3 & NGQ A E D Q \\
\hline MS218 & GCAATGGACAGGCAGAGGACCAG & $53.9 \pm 0.11$ & 3 & N G Q A E D Q \\
\hline MO196 & GTAGTGGTCAGGAAGGGGACCAG & $51.7 \pm 0.44$ & 4 & S G Q A G D Q \\
\hline GA214 & AAGATGGTCAGGCAGGGGAGCAA & ND & 4 & D G Q A G E Q \\
\hline AR84 & GCAATGGTCAGGCTGAGGATCAG & $46.2 \pm 1.14$ & 4 & $\mathbf{N} G$ Q A E D Q \\
\hline GA36 & GCAATGGTCAGGCAGAGGATCTG & $51.3 \pm 1.13$ & 4 & N G Q A E D L \\
\hline GA205 & GCAATGGTCAGGCAGAGGATCTG & $49.6 \pm 0.22$ & 4 & N G Q A E D L \\
\hline
\end{tabular}

${ }^{\text {a }}$ Melting temperature (average of at least 2 different reactions) \pm standard deviation.

${ }^{\mathbf{b}}$ Number of nucleotide substitutions.

c Amino acids spam the positions 318 to 324 and substitutions are in bold type.

${ }^{\mathrm{d}}$ Homologous match of the F15 probe.

${ }^{\text {e }}$ Sample was tested 14 times $(\mathrm{n}=14)$.

Table 2.8. Nucleotide sequence comparison of F15 probe (peak B) with sequenced samples. 
Figure 2.1. Melting temperature (Tm) results in degrees Celsius obtained using probes after real-time RT-PCR reaction. Each reaction was tested with a positive control (homologous virus) which was a perfect nucleotide match for the tested probe and based on that a horizontal threshold bar was drawn. Samples with a similar Tm when compared to the control were considered to not have nucleotide mutations. IBDV samples in each graph are in the same order and the state of origin is stated in the $\mathrm{X}$ axis. Error bars represents the standard deviation of the sample Tm. 
Figure 2.1.
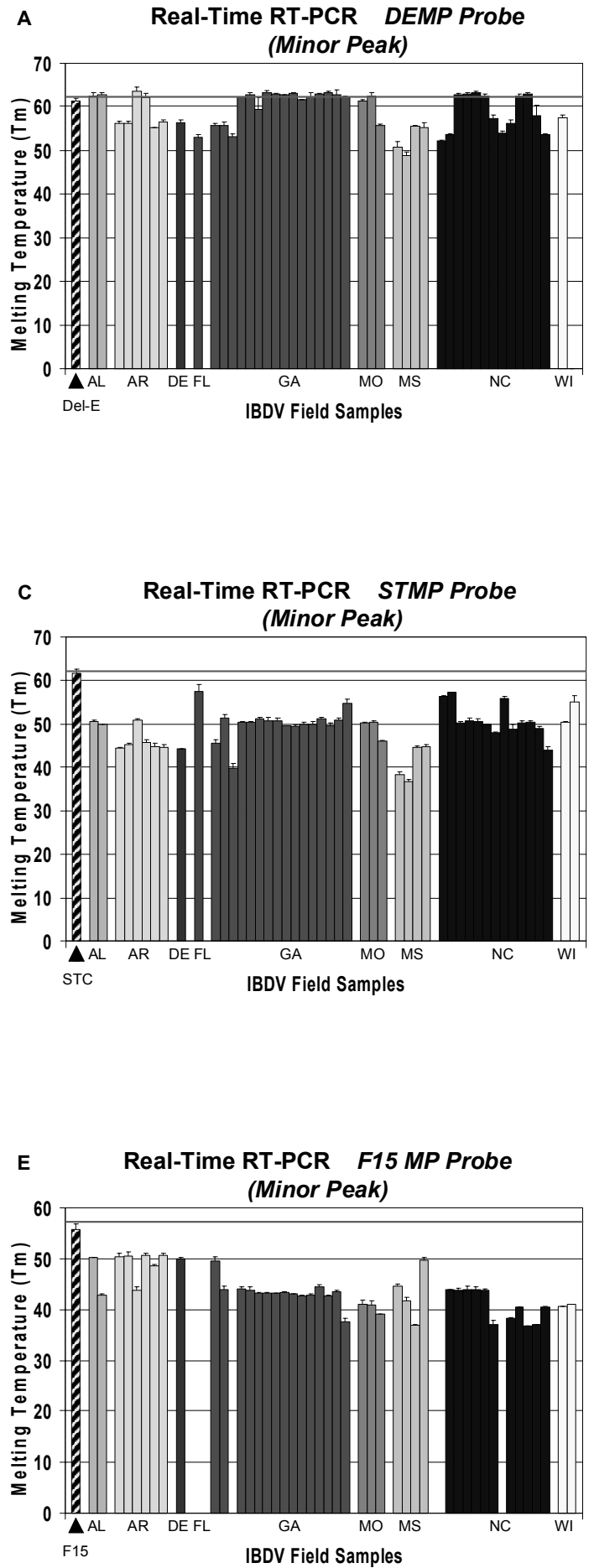

B Real-Time RT-PCR Del-E Probe (Peak B)

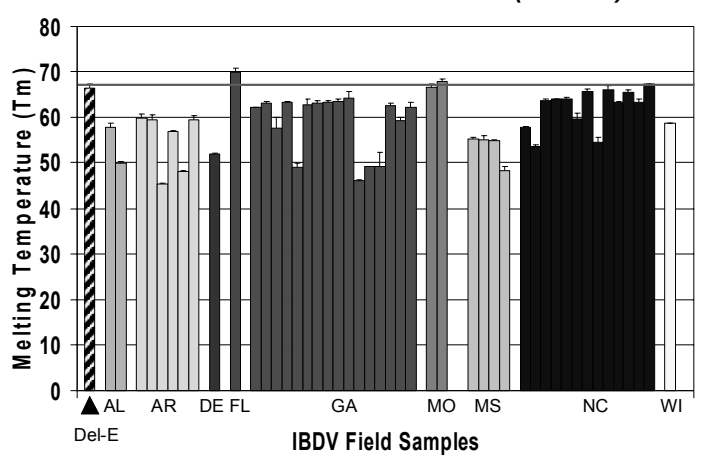

D Real-Time RT-PCR STC Probe (Peak B)

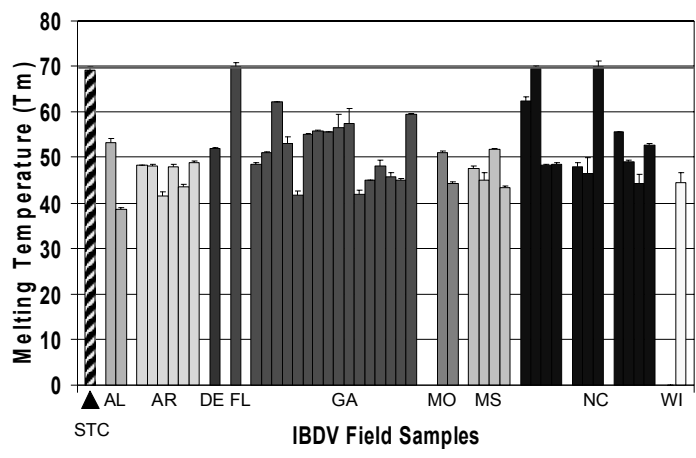

F Real-Time RT-PCR F15 Probe (Peak B)

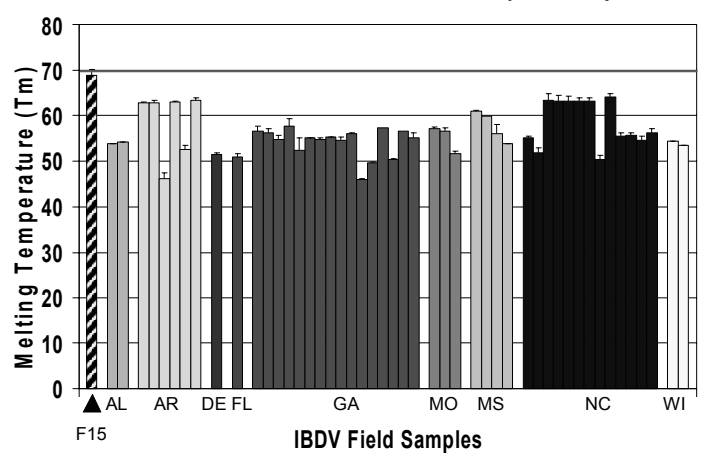




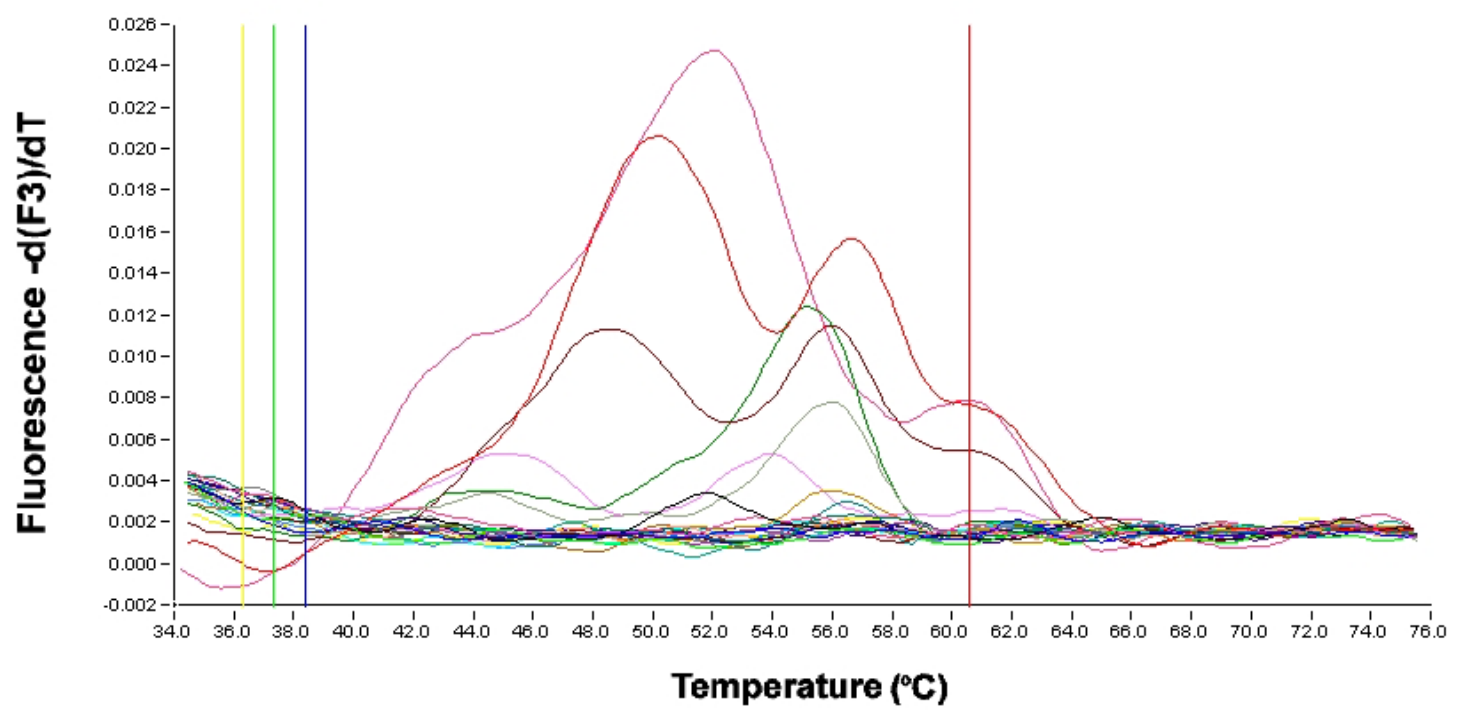

Digital Filter: Enabled Calculation Method: Polynomial

Degrees to Average: $9.0 \quad$ Red cursor $\mathrm{Tm}=60.5772 \quad$ Yellow cursor $\mathrm{Tm}=36.3141 \quad$ Green cursor $\mathrm{Tm}=37.3461$

Red cursor on the positive control of the reaction which has a Tm of 60.57 (control homologous to the probe tested).

Fig. 2.2. Real-time RT-PCR melting curves of samples tested with the DEMP probe (minor peak probe). 


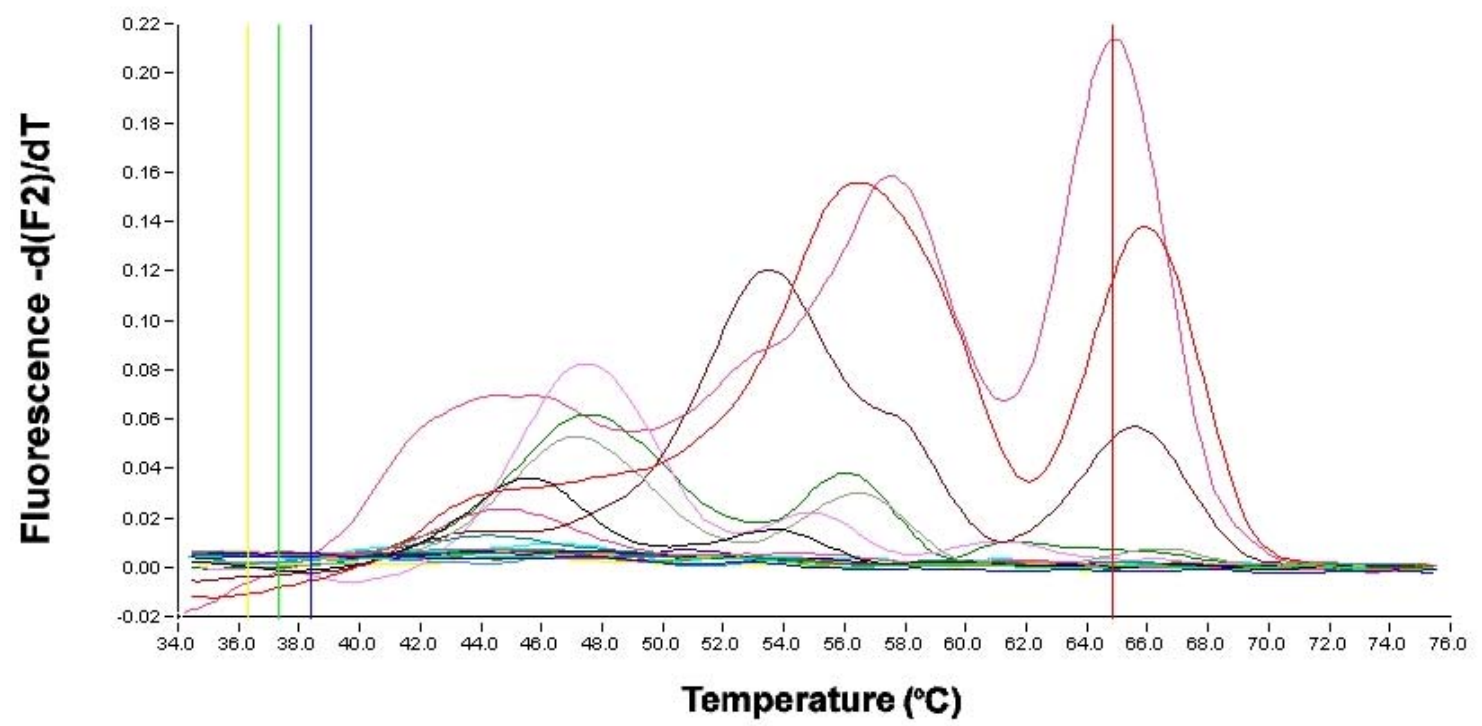

Digital Filter: Enabled
Calculation Method: Polynomial
Degrees to Average: $9.0 \quad$ Red cursor $\mathrm{Tm}=64.8532 \quad$ Yellow cursor $\mathrm{Tm}=36.3141 \quad$ Green cursor $\mathrm{Tm}=37.3461$

Red cursor on the positive control of the reaction which has a Tm of 64.85 (control homologous to the probe tested).

Fig. 2.3. Real-time RT-PCR melting curves of samples tested with the Del-E probe (peak B probe). 


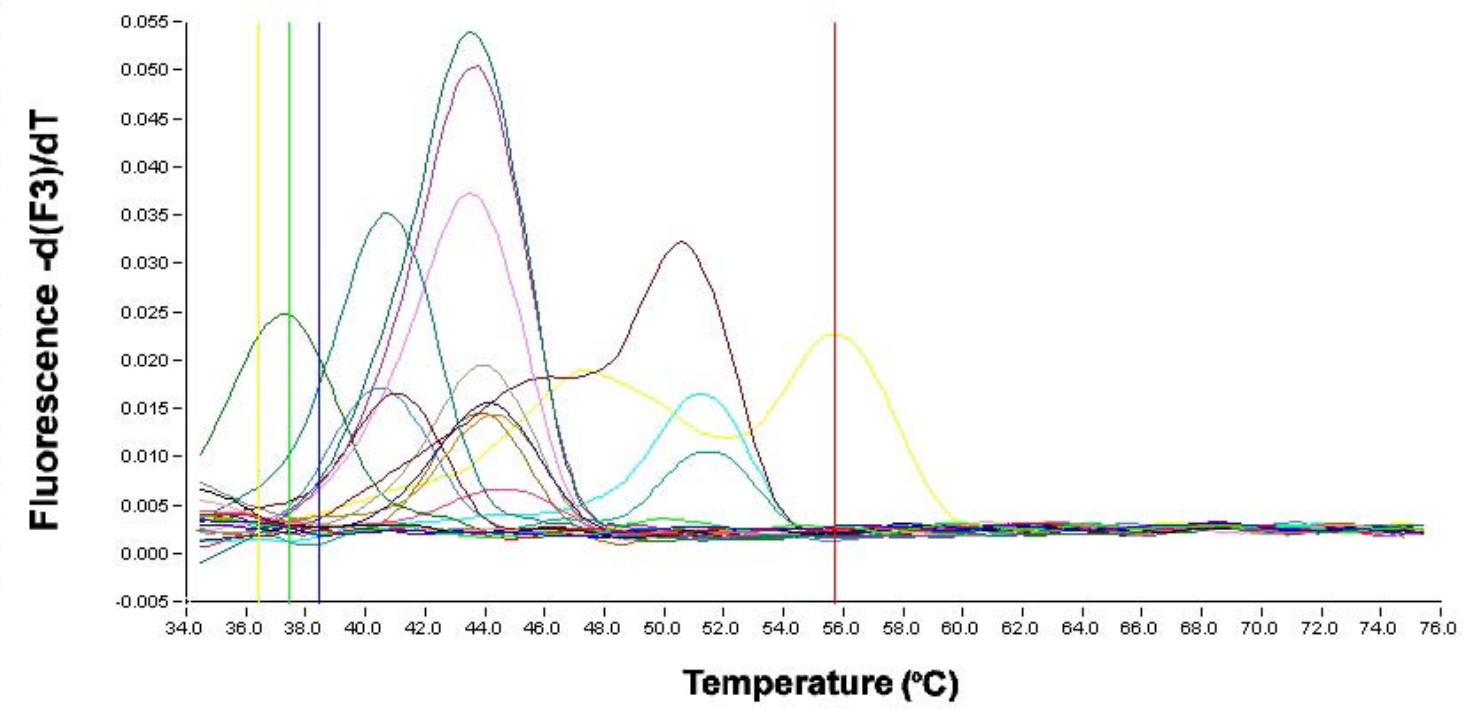

Digital Filter: Enabled

Calculation Method: Polynomial

Degrees to Average: 9.0

Red cursor $T m=55.7410$

Yellow cursor $\mathrm{Tm}=36.4265$

Green cursor $\mathrm{Tm}=37.4523$

Red cursor on the positive control of the reaction which has a Tm of 55.74 (control homologous to the probe tested).

Fig.2.4. Real-time RT-PCR melting curves of samples tested with F15MP (minor peak probe). 

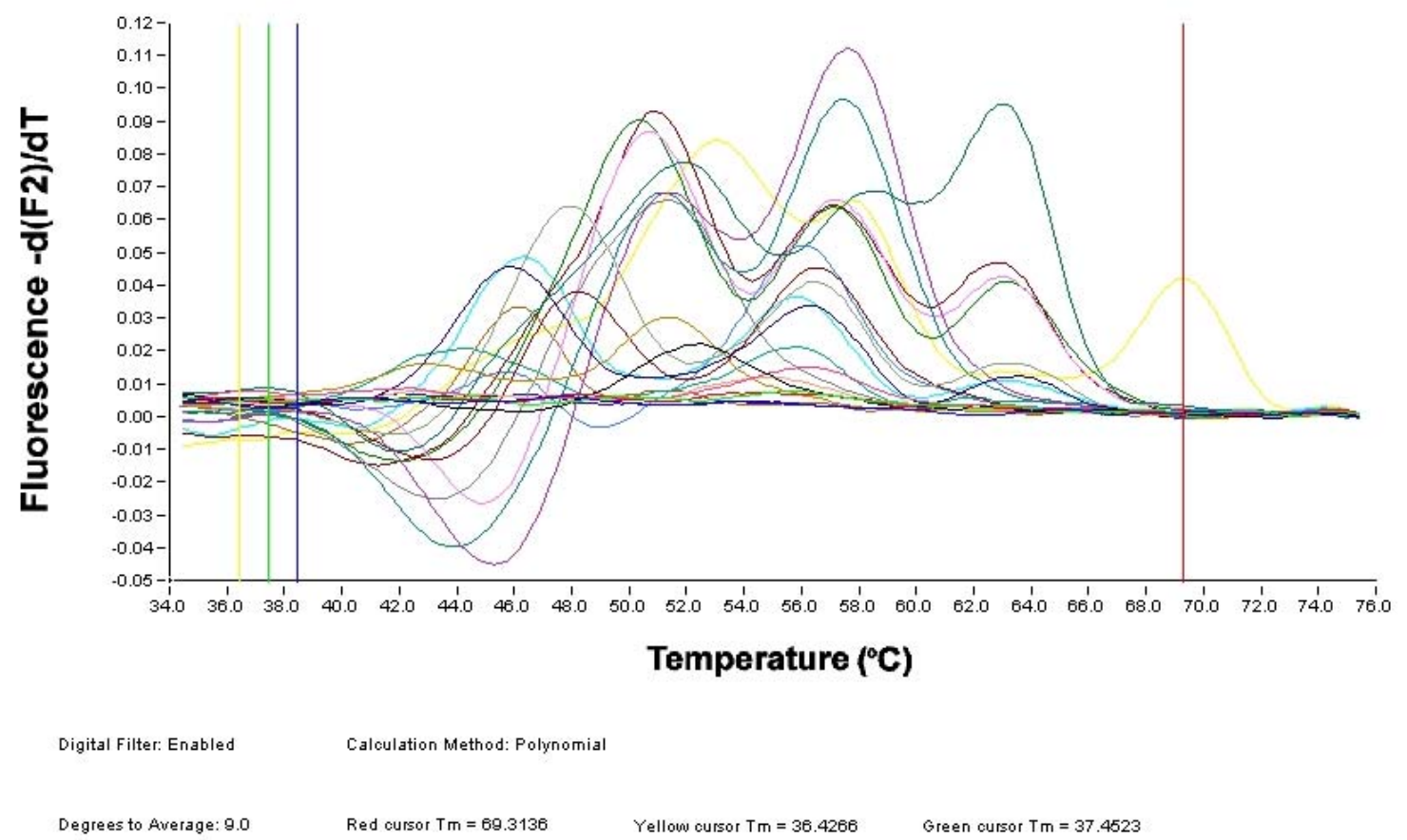

Red cursor on the positive control of the reaction which has a Tm of 69.31 (control homologous to the probe tested).

Fig. 2.5. Real-time RT-PCR melting curves of samples tested with F15 (peak B probe). 


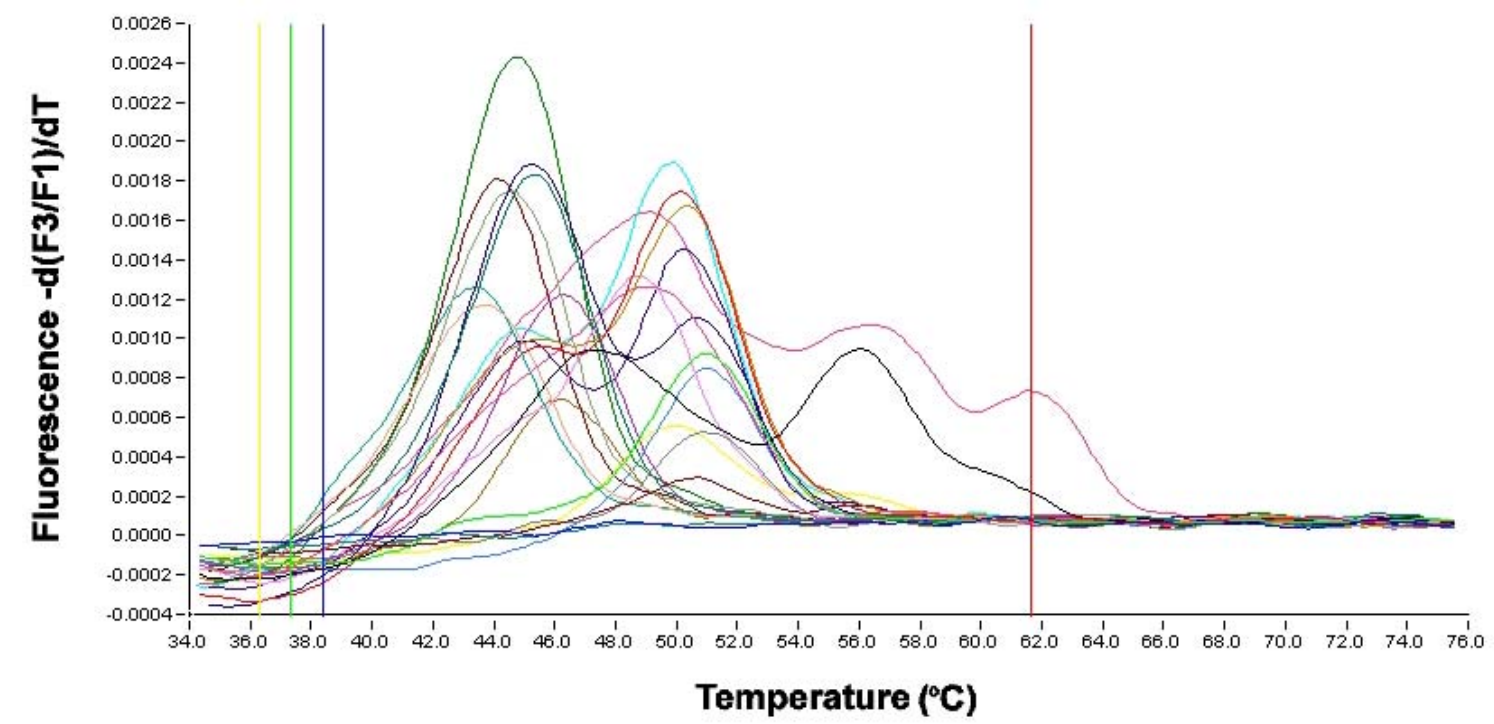

Digital Filter: Enabled

Calculation Method: Polynomial

Degrees to Average: 9.0

Red cursor $\mathrm{Tm}=61.6535$

Yellow cursor $\mathrm{Tm}=36.3141$

Green cursor $\mathrm{Tm}=37.3461$

Red cursor on the positive control of the reaction which has a Tm of 61.65 (control homologous to the probe tested).

Fig. 2.6. Real-time RT-PCR melting curves of samples tested with STMP (minor peak probe). 


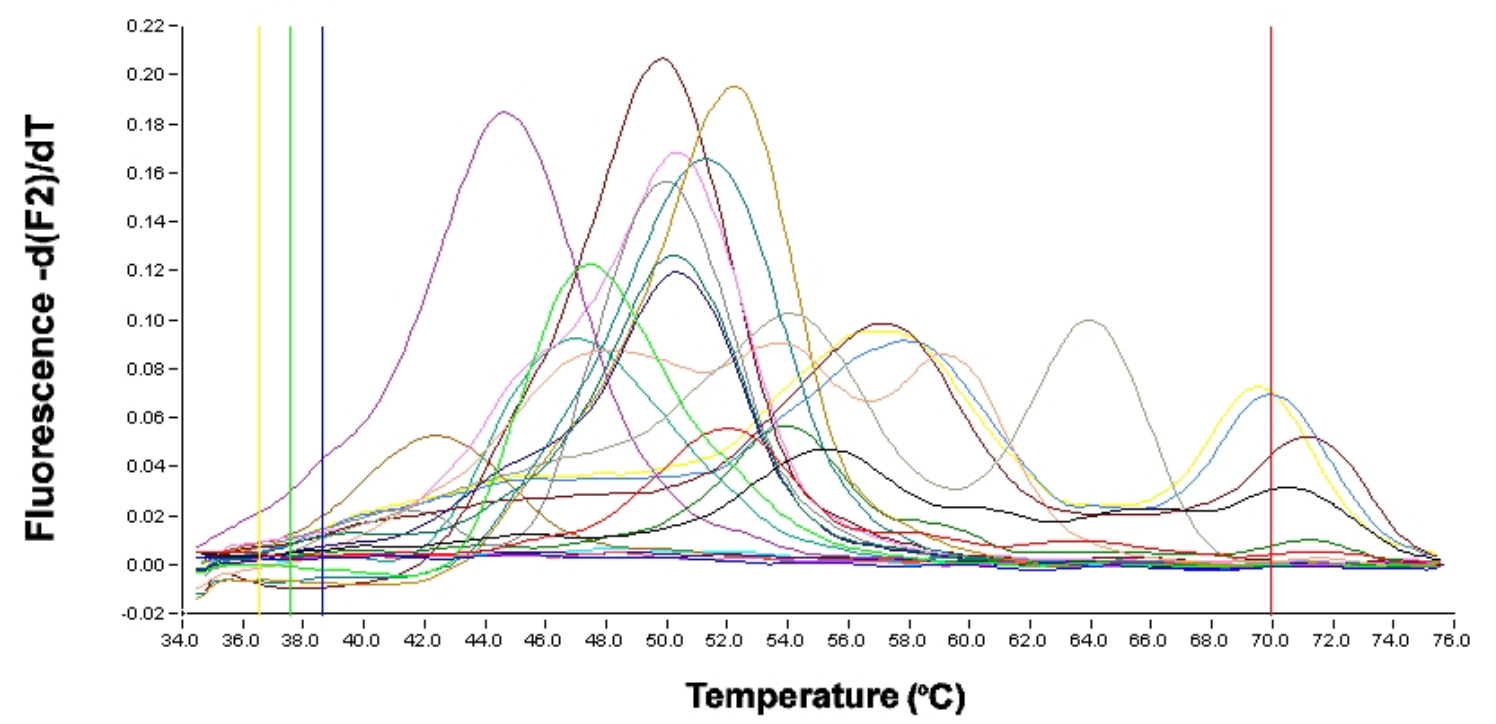

Digital Filter: Enabled Calculation Method: Polynomial

Degrees to Average: $9.0 \quad$ Red cursor $\mathrm{Tm}=69.9376 \quad$ Yellow cursor $\mathrm{Tm}=36.5578 \quad$ Green cursor $\mathrm{Tm}=37.5867$

Red cursor on the positive control of the reaction which has a Tm of 69.93 (control homologous to the probe tested).

Fig. 2.7. Real-time RT-PCR melting curves of samples tested with STC (peak B probe). 


\section{CHAPTER 3}

\section{ANALYSIS OF INFECTIOUS BURSAL DISEASE VIRUS-INDUCED IMMUNOSUPPRESSION AND CAMPYLOBACTER JEJUNI COLONIZATION AND SHEDDING IN CHICKENS}

Summary. Infectious bursal disease virus leads to an immunosuppressive disease in young chickens. The disease is endemic despite the intensive vaccination programs currently used. Previous studies have demonstrated that IBDV infection increases the susceptibility to other pathogens such as Salmonella spp. and E. coli. A study was designed to analyze a possible correlation between IBDV induced-immunosuppression and Campylobacter jejuni colonization and shedding in chickens. Six experiments were performed with specific pathogen free chickens raised under controlled conditions and they were denominated A, B, C, D, E and F. Experiments A, B, C and D had three groups: an inoculated control, a $C$. jejuni (S3B strain) group (inoculated with $C$. jejuni only) and a third group inoculated with IBDV and C. jejuni (S3B strain). In these 4 
experiments, the chickens were inoculated with the virus in the $3^{\text {rd }}$ day of life.

Experiments E and F had 5 groups: one control, two C. jejuni groups inoculated with different doses of ATTC33291, and two C. jejuni + IBDV groups which were inoculated with varying doses of $C$. jejuni (ATTC33291) and with the IBDV strain Del-E. The chickens from both experiments were inoculated with the Del-E strain on the $7^{\text {th }}$ day of age. Birds were euthanized at two times each week and intestinal contents were collected from the cloaca, cecum and small intestines. The samples were cultured in appropriate media and subsequently submitted to PCR. Additionally, bursa samples were collected at each necropsy and the bursa/body weight ratio of each bird was calculated. Bursa samples were submitted to RNA extraction followed by real-time RT-PCR. The results demonstrated a prolonged shedding and significantly higher numbers of $C$. jejuni in the groups inoculated with $C$. jejuni and IBDV, which indicates that IBDV induced immunosuppression exacerbated C. jejuni colonization and shedding in chickens. 


\section{INTRODUCTION}

Infectious bursal disease virus (IBDV) induces immunosuppression in susceptible chickens infected during the first three weeks of life which may last during their lifetime. The chickens do not present any clinical signs, although they develop a subclinical infection characterized by microscopic lesions at the bursa of Fabricius. In chickens between 3 and 6 weeks old, the virus causes an acute disease characterized by anorexia, depression, ruffled feathers, prostration and eventually death (Saif, 1998). Both subclinical infection and acute disease lead to major economic losses in the poultry industry due to impaired growth, mortality, excessive condemnation of carcasses, increased susceptibility against other infectious agents such as Salmonella species, interference with vaccination efficacy and decreased feed conversion and hatchability (Kibenge et al., 1988; Bautista et al., 2004; Sharma et al., 2000). Consequently, IBDV is considered one of the most important viral pathogens of commercial poultry.

The disease is considered endemic and has considerable socio-economic importance at the international level as it is present in $95 \%$ of the OIE Member Countries. This is probably because some of the virus characteristics such as high resistance to environmental conditions and also the genetic instability of the virsl genome which impairs biosecurity measures and vaccination efficacy (van den Berg, 2000).

The mechanism of IBDV induced-immunossupression in chickens is still not well understood, but is directly related to the destruction of the lymphoid tissues in the bursa 
of Fabricius. The target cell of the virus is an $\operatorname{IgM}^{+} \mathrm{B}$ cell, causing a cytolytic infection, which leads to impairment of antibody production. The immunosuppression is possibly caused by a conjunction of several factors including virus induced apoptosis and necrosis of macrophages and B lymphocytes (Sharma et al., 2000). In addition, although IBDV does not replicate in $\mathrm{T}$ cells, lymphocytolysis of $\mathrm{T}$-helper cells and activation of suppressor $\mathrm{T}$ cells occur, which may also be involved in IBDV induced immunosuppression (Sharma et al., 1994; Sharma and Lee, 1983).

Despite the current vaccination programs used, commercial chicken flocks experience recurring losses due to IBDV induced immunosuppression. In addition, the chickens become more susceptible to pathogens transmissible to humans such as $E$. coli and Salmonella species (Wyeth, 1975; Bautista et al., 2004). In this report, a possible correlation between Campylobacter jejuni colonization and shedding in chickens and IBDV induced immunosuppression is investigated. 


\section{MATERIAL AND METHODS}

\section{Experimental design}

\section{Chickens}

Six experiments (A, B, C, D, E, and F) were performed using specific pathogen free leghorn chickens (SPAFAS, Storrs, CT) free of antibodies against IBDV and Campylobacter spp.. They were maintained in positive pressure containment units with slatted floors and HEPA-filtered intake and exhaust air and fed with pelleted food and distilled autoclaved water ad libitum. The experiments A, B, C and D consisted of three groups: a control/non-inoculated group (group 1), a Campylobacter jejuni group (group 2), which was inoculated with the $C$. jejuni strain S3B and a third group (group 3) which was inoculated with the variant IBDV strain Del-E, and the C. jejuni strain S3B. The experiments $\mathrm{E}$ and $\mathrm{F}$ consisted of 5 groups each: one group 1 (control), groups 2 and 3 (C. jejuni group inoculated with the ATCC33291 strain - American Type Culture Collection, Rockville, Md.), and groups 4 and 5 which were inoculated with both $C$. jejuni (strain ATCC33291) and IBDV (Del-E strain).

\section{Virus Inoculation}

The chickens were inoculated with $50 \mu 1$ of a bursa homogenate containing approximately $10^{3} 50 \%$ end-point egg infectious doses $\left(\mathrm{EID}_{50}\right)$ of the Del-E IBDV strain via the ocular-nasal route in varying times. Chickens from experiments A and B were 
inoculated on the $3^{\text {rd }}$ day of life and chickens from experiments C, D, E and F on the $7^{\text {th }}$ day of life.

\section{C. jejuni inoculation}

Chickens were inoculated via oral gavage with $C$. jejuni in varying dosages and time of inoculation. In experiment $\mathrm{A}, 10^{3} \mathrm{CFU} /$ chicken was administered. In experiment B, each bird from both groups was inoculated with $3.2 \times 10^{4} \mathrm{CFU} /$ chicken. In both experiments $C$. jejuni was administered at 7 days after the virus inoculation. In experiment $\mathrm{C}$ the birds were inoculated with $10^{4} \mathrm{CFU} /$ chicken and in experiment D $10^{6}$ CFU/chicken. In both experiments (C and D) C. jejuni was administered at 14 days after the virus inoculation. Experiments $\mathrm{E}$ and $\mathrm{F}$ consisted of 5 groups each. In experiment E, groups 2 and 4 were inoculated with $C$. jejuni dosages of $10^{3} \mathrm{CFU} / \mathrm{chicken}$ and groups 3 and 5 were inoculated with $10^{5} \mathrm{CFU} /$ chicken. In experiments $\mathrm{E}$ and $\mathrm{F}$, C. jejuni was inoculated 14 and 15 days, respectively, after the administration of the virus.

\section{Sample collection}

Bursa samples from each bird were harvested during necropsy at different times according to the experiment. The bursa and the body weight of each bird were determined. Based on that, a bursa/body ratio was calculated (bursa weight/body weight $\mathrm{x}$ 1000). Usually, 2 to 5 birds were euthanized at 7 days of age (A, B) or 14 days of age (C, D, E, F). After that, the birds were euthanized twice a week, with an interval between 
necropsies of 3 or 4 days during a period of 4 weeks. At each collection time, intestinal contents were collected with a swab from the small intestine, cecum and cloaca, cultured and submitted to PCR (Kathryn Subler thesis).

\section{Viral RNA extraction}

The bursa samples were homogenized in TNE buffer (1:2) (10mM Tris-HCl, $\mathrm{pH}$ 8.0, $100 \mathrm{mM} \mathrm{NaCl}, 1 \mathrm{mM}$ EDTA) and then frozen and thawed 3 times. An $800 \mu 1$ volume of this suspension was extracted with an equal volume of chloroform, followed by incubation of a $500 \mu 1$ volume of the supernatant for $1 \mathrm{hr}$ at $37^{\circ} \mathrm{C}$ with $1.0 \mathrm{mg} / \mathrm{ml}$ proteinase K (Sigma Chemical Co., St. Louis, MO) and $0.5 \%$ sodium dodecyl sulfate (Sigma Chemical Co.). Next, the sample was extracted with an equal volume of acid phenol, pH 4.3 (AMRESCO, Solon, $\mathrm{OH}$ ) and $400 \mu 1$ of the supernatant was extracted with the same volume of chloroform-isoamyl alcohol (24:1). Subsequently, the RNA was precipitated with $3 \mathrm{M}$ sodium acetate and ethanol and was kept at $-20^{\circ} \mathrm{C}$ for at least $24 \mathrm{~h}$. Then the samples were centrifuged at 13,000 $\mathrm{x} g$ dried and suspended in $100 \mu 1$ of $90 \%$ dimethyl sulfoxide (Sigma Chemical Co.).

\section{Real-time RT-PCR}

Real-time RT-PCR was conducted with a LightCycler instrument (Roche Diagnostics, Mannhein, Germany). The viral RNA was amplified using a LightCycler RNA amplification kit - hybridization probes (Roche; Molecular Biochemicals, Alameda, 
CA). Each reaction contained $4 \mu 1$ XX RT-PCR reaction mix, $4.5 \mathrm{mM} \mathrm{MgCl}_{2}, 0.25 \mu \mathrm{M}$ of each IBDV primer, $0.2 \mu \mathrm{M}$ of each probe, $0.5 \mu \mathrm{l}$ viral RNA, and sterile $\mathrm{H}_{2} \mathrm{O}$ was added to the reaction. The final reaction volume was $20 \mu 1$. The primers used amplified a 743-bp sequence region of the VP2 gene (Jackwood and Sommer, 1998).

In order to detect the PCR products, a two probe system was used. The first probe was labeled at the 3' end with fluorescein isothiocyanate (FITC) and it was denominated mutation probe (BioChem, Salt Lake City, UT). The second probe or anchor probe (BioChem) was located downstream and was labeled at the 5'end with a Red 640 fluorophore. The mutation and anchor probes were separated from each other by one base. When these probes were hybridized to the PCR product, the acceptor dyes were adjacent to and excited by fluorescein. Fluorescence resonance energy transfer (FRET) occurred and was detected by the LightCycler instrument. The probes were complementary to the Del-E strain and had the following nucleotide sequence: mutation probe: 5'-GTGATGGTCAGGCAGGGGAACAG-FITC-3' (Tm: 67.2) and anchor probe: 5'-Red 640-TGTCATGGTCGGCAAGTGGGAGCC-3' (Tm: 71.0). If the sample tested is a homologous match for the mutation probe, no changes in the Tm are observed. However, shifts in the Tm occur when a sample has one or more mutations.

\section{Statistical analysis}

The bursa-body weight ratios difference among groups was calculated using a one-way analysis of variance (ANOVA) and Fisher's test in Minitab 14 software (Minitab, Inc., State College, PA). 


\section{RESULTS}

In order to determine a possible correlation between IBDV induced immunosuppression and $C$. jejuni colonization in chickens, 5 experiments were performed with SPF chickens. IBDV was inoculated either at the 7 th or the 14 th day of the bird's life. C. jejuni was administered to the chickens in several dosages at different times.

The bursa-body weight (BBW) ratio was calculated for each bird in all five experiments. It was observed that, in most cases, the BBW ratios of the IBDV infected groups were significantly lower than the control (Group 1) and the $C$. jejuni groups, and this occurred in all experiments (Tables 3.1 to 3.6). Additionally, it was observed that all bursa samples from the groups inoculated with IBDV and $C$. jejuni were positive for the viral RNA when analyzed by real-time RT-PCR, and displayed the expected Tm (Fig.3.1). This virus RNA could be detected till the last day of collection (data not shown). On the other hand, bursa samples from the controls and C. jejuni groups of all six experiments were negative for viral RNA using real time RT-PCR.

Intestinal contents were collected from the cecum, cloaca and small intestines of the chickens. Subsequently, the samples were cultured and quantified in appropriate culture media. If colonies that were suspected to be $C$. jejuni were detected, they were submitted to PCR to confirm that they belonged to the genus Campylobacter. It was observed that $C$. jejuni was present in significantly higher numbers in chickens from the 
groups inoculated with $C$. jejuni and IBDV. In addition, a prolonged detection of $C$. jejuni in this group was observed when compared to the groups inoculated with C. jejuni only (Kathryn Subler thesis). 


\section{DISCUSSION}

Infectious bursal disease virus is an important pathogen in the poultry industry as it causes large economic losses due the acute disease and the virus-induced immunosuppression. The virus is endemic worldwide which indicates the lack of efficacy in controlling this infection (Muller et al., 2003). C. jejuni is a food borne pathogen that is responsible for causing human gastroenteritis mainly in developed countries. It is estimated that $C$. jejuni causes 2.1-2.4 million cases per year in the US (Blaser, 1997). The bacterium is able to colonize the chicken's gut very effectively and up to $100 \%$ of broilers at slaughter age may carry this bacterium (Jacobs-Reitsma, 1995). Consumption of undercooked poultry is considered the major source of $C$. jejuni infection in humans (Friedman et al., 2004).

The epidemiology of $C$. jejuni on the farm is not very well understood, but the general consensus is that several factors are responsible to the highly effective dissemination of this human pathogen to poultry flocks (Sahin et al., 2002). Our results indicated that IBDV induced immunosuppression exacerbates $C$. jejuni colonization and shedding in chickens. This finding is supported by previous studies which observed that IBDV increases susceptibility against other food-borne pathogens (Bautista et al., 2004; Wyeth, 1975). These observations support the idea that IBDV may have an indirect impact on food-borne diseases and reinforce the importance of the control of IBDV in commercial flocks. 


\begin{tabular}{cccccccc}
\hline & \multicolumn{6}{c}{ Day of age post-C. jejuni inoculation $^{B}$} \\
\cline { 2 - 7 } Group $^{A}$ & 0 & 3 & 7 & 10 & 14 & 17 & 22 \\
1 & $2.671^{\mathrm{a}}$ & $1.466^{\mathrm{a}}$ & $2.660^{\mathrm{a}}$ & $3.726^{\mathrm{a}}$ & $3.67^{\mathrm{a}}$ & $5.538^{\mathrm{a}}$ & $5.476^{\mathrm{a}}$ \\
2 & $3.342^{\mathrm{a}}$ & $4.438^{\mathrm{b}}$ & $4.384^{\mathrm{b}}$ & $5.028^{\mathrm{b}}$ & $6.166^{\mathrm{b}}$ & $4.543^{\mathrm{a}}$ & $4.825^{\mathrm{a}}$ \\
3 & $0.709^{\mathrm{b}}$ & $1.780^{\mathrm{a}}$ & $1.470^{\mathrm{c}}$ & $1.607^{\mathrm{c}}$ & $1.236^{\mathrm{c}}$ & $1.131^{\mathrm{b}}$ & $1.105^{\mathrm{b}}$
\end{tabular}

${ }^{\mathrm{A}}$ Groups are: 1. Control, 2. C. jejuni $\left(10^{3}\right), 3 . \mathrm{IBDV}+$ C. jejuni $\left(10^{3}\right)$.

${ }^{\mathrm{B}}$ Lower case letters indicate statistically significant differences between groups at each necropsy date.

Table 3.1. Bursa/ body weight ratios from Experiment A.

\begin{tabular}{ccccccccc}
\hline & \multicolumn{7}{c}{ Day of age post-C. jejuni inoculation ${ }^{B}$} \\
Group $^{A}$ & 0 & 3 & 7 & 10 & 14 & 17 & 21 & 24 \\
\cline { 2 - 8 } 1 & $4.216^{\mathrm{a}}$ & $4.544^{\mathrm{a}}$ & $6.100^{\mathrm{a}}$ & $5.881^{\mathrm{a}}$ & $6.433^{\mathrm{a}}$ & $5.928^{\mathrm{a}}$ & $7.048^{\mathrm{a}}$ & $5.844^{\mathrm{a}}$ \\
2 & $3.331^{\mathrm{a}}$ & $3.848^{\mathrm{a}}$ & $4.364^{\mathrm{b}}$ & $4.999^{\mathrm{a}}$ & $5.793^{\mathrm{a}}$ & $5.275^{\mathrm{a}}$ & $6.153^{\mathrm{a}}$ & $5.777^{\mathrm{a}}$ \\
3 & $1.234^{\mathrm{a}}$ & $1.386^{\mathrm{b}}$ & $1.358^{\mathrm{c}}$ & $1.286^{\mathrm{b}}$ & $0.955^{\mathrm{b}}$ & $1.012^{\mathrm{b}}$ & $0.907^{\mathrm{b}}$ & $1.185^{\mathrm{b}}$
\end{tabular}

${ }^{\mathrm{A}}$ Groups are: 1. Control, 2. C. jejuni $\left(3.2 \times 10^{4}\right)$, 3. IBDV + C. jejuni $\left(3.2 \times 10^{4}\right)$.

${ }^{\mathrm{B}}$ Lower case letters indicate statistically significant differences between groups at each necropsy date.

Table 3.2. Bursa/ body weight ratios from Experiment B. 


\begin{tabular}{ccccccccc}
\hline & \multicolumn{7}{c}{ Day of age post-C. jejuni inoculation $^{B}$} \\
\cline { 2 - 8 } Group $^{A}$ & 0 & 3 & 7 & 10 & 14 & 17 & 21 & 24 \\
1 & $6.108^{\mathrm{a}}$ & $5.112^{\mathrm{a}}$ & $2.704^{\mathrm{a}}$ & $3.726^{\mathrm{a}}$ & $3.529^{\mathrm{a}}$ & $5.360^{\mathrm{a}}$ & $4.430^{\mathrm{a}}$ & $5.804^{\mathrm{a}}$ \\
2 & $5.307^{\mathrm{a}}$ & $7.120^{\mathrm{b}}$ & $6.061^{\mathrm{b}}$ & $6.275^{\mathrm{b}}$ & $5.719^{\mathrm{b}}$ & $5.421^{\mathrm{a}}$ & $6.330^{\mathrm{b}}$ & $6.532^{\mathrm{a}}$ \\
3 & $1.491^{\mathrm{b}}$ & $0.925^{\mathrm{c}}$ & $1.396^{\mathrm{a}}$ & $1.192^{\mathrm{c}}$ & $1.347^{\mathrm{c}}$ & $1.136^{\mathrm{b}}$ & $1.024^{\mathrm{c}}$ & $0.949^{\mathrm{b}}$ \\
\hline
\end{tabular}

${ }^{\mathrm{A}}$ Groups are: 1. Control, 2. C. jejuni $\left(10^{4}\right), 3$. IBDV + C. jejuni $\left(10^{4}\right)$.

${ }^{\mathrm{B}}$ Lower case letters indicate statistically significant differences between groups at each necropsy date.

Table 3.3. Bursa/ body weight ratios from Experiment $\mathrm{C}$.

\begin{tabular}{ccccccccc}
\hline & \multicolumn{7}{c}{ Day of age post-C. jejuni inoculation } \\
Group $^{A}$ & 0 & 3 & 7 & 10 & 14 & 17 & 21 & 24 \\
\cline { 2 - 8 } 1 & $5.62^{\mathrm{a}}$ & $5.048^{\mathrm{a}}$ & $5.358^{\mathrm{a}}$ & $5.485^{\mathrm{a}}$ & $6.331^{\mathrm{a}}$ & $5.513^{\mathrm{a}}$ & $5.855^{\mathrm{a}}$ & $5.528^{\mathrm{a}}$ \\
2 & $3.902^{\mathrm{a}}$ & $5.018^{\mathrm{a}}$ & $5.698^{\mathrm{a}}$ & $5.508^{\mathrm{a}}$ & $5.683^{\mathrm{a}}$ & $5.767^{\mathrm{a}}$ & $5.295^{\mathrm{a}}$ & $5.836^{\mathrm{a}}$ \\
3 & $1.310^{\mathrm{b}}$ & $1.299^{\mathrm{b}}$ & $1.243^{\mathrm{b}}$ & $1.067^{\mathrm{b}}$ & $0.842^{\mathrm{b}}$ & $1.175^{\mathrm{b}}$ & $1.180^{\mathrm{b}}$ & $1.048^{\mathrm{b}}$ \\
& & & & & & & & \\
\hline
\end{tabular}

${ }^{\mathrm{A}}$ Groups are: 1. Control, 2. C. jejuni $\left(10^{6}\right), 3$. IBDV + C. jejuni $\left(10^{6}\right)$.

${ }^{\mathrm{B}}$ Lower case letters indicate statistically significant differences between groups at each necropsy date.

Table 3.4. Bursa/ body weight ratios from Experiment D. 


\begin{tabular}{|c|c|c|c|c|c|c|c|c|}
\hline \multirow[b]{2}{*}{ Group $^{A}$} & \multicolumn{8}{|c|}{ Day of age post-Campylobacter jejuni inoculation ${ }^{B}$} \\
\hline & 0 & 6 & 9 & 13 & 16 & 20 & 23 & 27 \\
\hline 1 & $4.705^{\mathrm{a}}$ & $4.498^{\mathrm{a}}$ & $5.577^{\mathrm{a}}$ & $5.008^{\mathrm{a}}$ & $5.646^{\mathrm{a}}$ & $4.962^{\mathrm{a}}$ & $4.483^{\mathrm{a}}$ & $3.706^{\mathrm{a}}$ \\
\hline 2 & $4.163^{\mathrm{a}}$ & $4.723^{\mathrm{a}}$ & $5.921^{\mathrm{a}}$ & $4.471^{\mathrm{a}}$ & $5.097^{\mathrm{a}}$ & $5.372^{\mathrm{a}}$ & $3.482^{\mathrm{a}}$ & $4.179^{\mathrm{a}}$ \\
\hline 3 & $4.098^{\mathrm{a}}$ & $5.000^{\mathrm{a}}$ & $5.373^{\mathrm{a}}$ & $6.289^{\mathrm{a}}$ & $5.745^{\mathrm{a}}$ & $4.415^{\mathrm{a}}$ & $4.973^{\mathrm{a}}$ & $4.550^{\mathrm{a}}$ \\
\hline 4 & $1.132^{b}$ & $1.132^{b}$ & $0.832^{\mathrm{b}}$ & $1.000^{\mathrm{b}}$ & $1.212^{\mathrm{b}}$ & $1.434^{\mathrm{b}}$ & $1.327^{b}$ & $1.693^{b}$ \\
\hline 5 & $1.300^{\mathrm{b}}$ & $0.918^{\mathrm{b}}$ & $1.498^{\mathrm{b}}$ & $0.965^{\mathrm{b}}$ & $1.162^{\mathrm{b}}$ & $0.865^{\mathrm{b}}$ & $0.631^{\mathrm{b}}$ & $1.032^{\mathrm{b}}$ \\
\hline $\begin{array}{l}{ }^{\mathrm{A}} \text { Groups a } \\
\left(10^{5}\right) . \\
{ }^{\mathrm{B}} \text { Lower ca }\end{array}$ & $\begin{array}{l}\text { Contı } \\
\text { etters in }\end{array}$ & C. jej & $\left.0^{3}\right), 3$ & $\overline{n i(10}$ & IBDV & $\overline{\text { jejuni }}$ & $\overline{5 . \mathrm{IBD}}$ & $\begin{array}{l}\text { C. jejun } \\
\text { late. }\end{array}$ \\
\hline
\end{tabular}




\begin{tabular}{ccccccccc}
\hline & \multicolumn{7}{c}{ Day of age post-Campylobacter jejuni inoculation ${ }^{B}$} \\
Group $^{A}$ & 0 & 7 & 10 & 14 & 16 & 21 & 24 & 28 \\
\hline 1 & $5.635^{\mathrm{a}}$ & $6.025^{\mathrm{a}}$ & $5.629^{\mathrm{a}}$ & $7.336^{\mathrm{a}}$ & $7.015^{\mathrm{a}}$ & $5.461^{\mathrm{a}}$ & $5.613^{\mathrm{a}}$ & $9.307^{\mathrm{a}}$ \\
2 & $5.049^{\mathrm{a}}$ & $6.157^{\mathrm{a}}$ & $6.318^{\mathrm{a}}$ & $6.048^{\mathrm{a}}$ & $5.188^{\mathrm{b}}$ & $5.424^{\mathrm{a}}$ & $5.983^{\mathrm{a}}$ & $6.935^{\mathrm{b}}$ \\
3 & $5.622^{\mathrm{a}}$ & $4.155^{\mathrm{b}}$ & $6.518^{\mathrm{a}}$ & $6.628^{\mathrm{a}}$ & $6.563^{\mathrm{ab}}$ & $6.313^{\mathrm{a}}$ & $6.841^{\mathrm{a}}$ & $6.268^{\mathrm{b}}$ \\
4 & $1.221^{\mathrm{b}}$ & $1.069^{\mathrm{c}}$ & $0.784^{\mathrm{b}}$ & $1.056^{\mathrm{b}}$ & $0.789^{\mathrm{c}}$ & $1.188^{\mathrm{b}}$ & $1.097^{\mathrm{b}}$ & $1.079^{\mathrm{c}}$ \\
5 & $1.516^{\mathrm{b}}$ & $1.245^{\mathrm{c}}$ & $1.226^{\mathrm{b}}$ & $1.169^{\mathrm{b}}$ & $1.726^{\mathrm{c}}$ & $1.745^{\mathrm{b}}$ & $1.256^{\mathrm{b}}$ & $1.185^{\mathrm{c}}$ \\
\hline & & & & & & & & \\
\hline
\end{tabular}

${ }^{\mathrm{A}}$ Groups are: 1 . Control, 2. C. jejuni $\left(10^{3}\right), 3$. C. jejuni $\left(10^{5}\right), 4 . \mathrm{IBDV}+C$. jejuni $\left(10^{3}\right), 5 . \mathrm{IBDV}+C$. jejuni $\left(10^{5}\right)$.

${ }^{\mathrm{B}}$ Lower case letters indicate statistically significant differences between groups at each necropsy date.

Table 3.6. Bursa/ body weight ratios from Experiment F. 

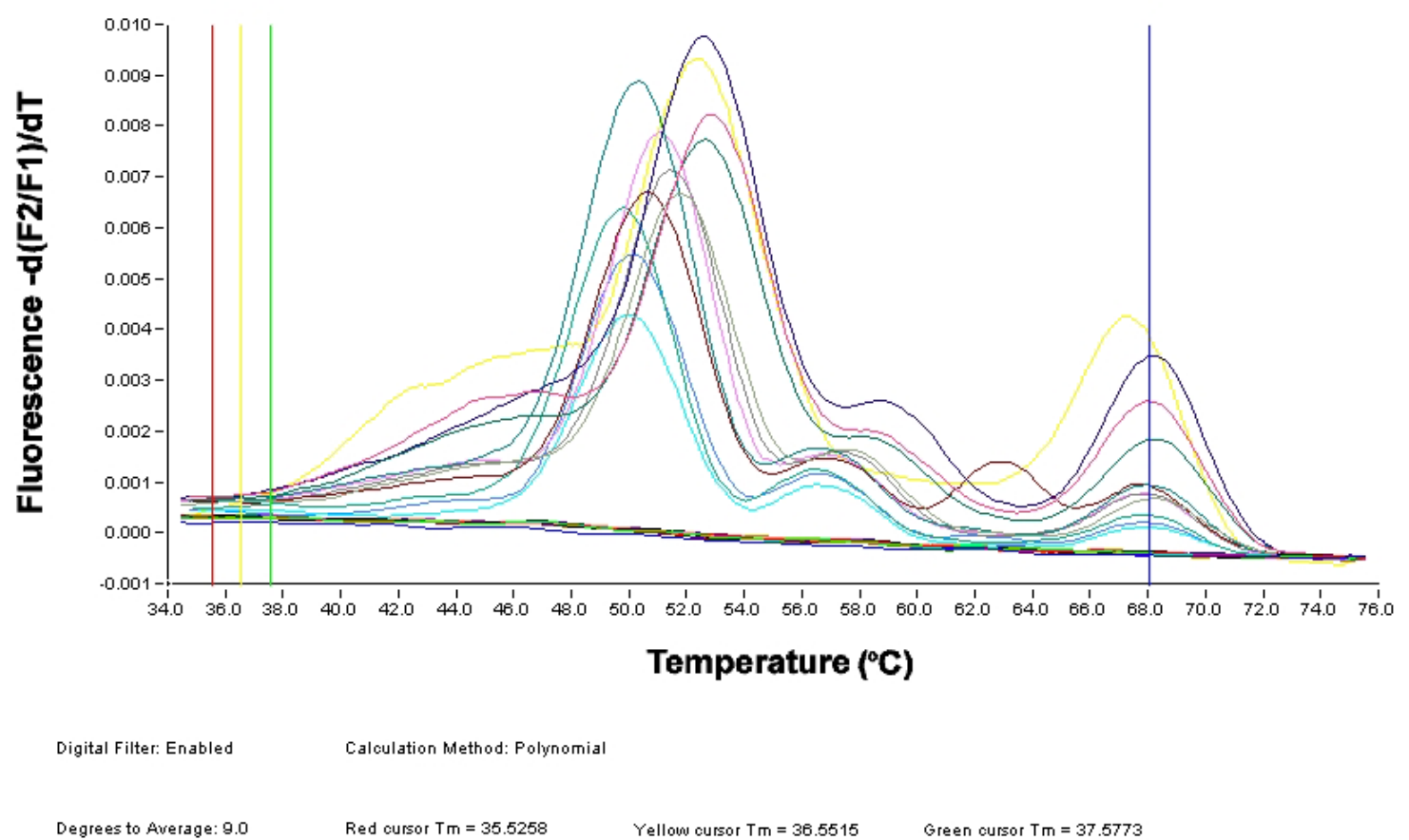

Blue cursor on the expected melting temperatures of bursa samples from the group IBDV+Campylobacter jejuni (perfect match for Del-E probe).

Figure 3.1. Real-time PCR melting curves of bursa samples tested with the Del-E probe. 


\section{REFERENCES}

Bautista, D. A., S. Elankumaran, and R. A. Heckert. 2004. Effect of a variant infectious bursal disease virus (E/Del) on Salmonella typhimurium infection in commercial broiler chickens. Avian Dis. 48:361-369.

Blaser, M. J. 1997. Epidemiologic and clinical features of Campylobacter jejuni infections. J. Infect. Dis. 176 Suppl 2:S103-S105.

Friedman, C. R., R. M. Hoekstra, M. Samuel, R. Marcus, J. Bender, B. Shiferaw, S. Reddy, S. D. Ahuja, D. L. Helfrick, F. Hardnett, M. Carter, B. Anderson, and R. V. Tauxe. 2004. Risk factors for sporadic Campylobacter infection in the United States: A case-control study in FoodNet sites. Clin. Infect. Dis. 38 Suppl 3:S285S296.

Jackwood, D. J. and S. E. Sommer. 1998. Genetic heterogeneity in the VP2 gene of infectious bursal disease viruses detected in commercially reared chickens. Avian Dis. 42:321-339.

Jacobs-Reitsma, W. F. 1995. Campylobacter bacteria in breeder flocks. Avian Dis. 39:355-359.

Kibenge, F. S., A. S. Dhillon, and R. G. Russell. 1988. Biochemistry and immunology of infectious bursal disease virus. J. Gen. Virol. 69 ( Pt 8):1757-1775.

Muller, H., M. R. Islam, and R. Raue. 2003. Research on infectious bursal disease - the past, the present and the future. Vet. Microbiol. 97:153-165.

Sahin, O., T. Y. Morishita, and Q. Zhang. 2002. Campylobacter colonization in poultry: sources of infection and modes of transmission. Anim Health Res. Rev. 3:95-105.

Saif, Y. M. 1998. Infectious bursal disease and hemorrhagic enteritis. Poult. Sci. 77:1186-1189. 
Sharma, J. M., K. Karaca, and T. Pertile. 1994. Virus-induced immunosuppression in chickens. Poult. Sci. 73:1082-1086.

Sharma, J. M., I. J. Kim, S. Rautenschlein, and H. Y. Yeh. 2000. Infectious bursal disease virus of chickens: pathogenesis and immunosuppression. Dev. Comp Immunol. 24:223-235.

Sharma, J. M. and L. F. Lee. 1983. Effect of infectious bursal disease on natural killer cell activity and mitogenic response of chicken lymphoid cells: role of adherent cells in cellular immune suppression. Infect. Immun. 42:747-754.

van den Berg, T. P. 2000. Acute infectious bursal disease in poultry: a review. Avian Pathol. 29:175-194.

Wyeth, P. J. 1975. Effect of infectious bursal disease on the response of chickens to S typhimurium and E coli infections. Vet. Rec. 96:238-243. 


\section{BIBLIOGRAPHY}

Abdel-Alim, G., M. H. Awaad, and Y. M. Saif. 2003. Characterization of Egyptian field strains of infectious bursal disease virus. Avian Dis. 47:1452-1457.

Abdel-Alim, G. A. and Y. M. Saif. 2001. Immunogenicity and antigenicity of very virulent strains of infectious bursal disease viruses. Avian Dis. 45:92-101.

Achen, M., T. Y. Morishita, and E. C. Ley. 1998. Shedding and colonization of Campylobacter jejuni in broilers from day-of-hatch to slaughter age. Avian Dis. 42:732-737.

Aho, M., L. Nuotio, E. Nurmi, and T. Kiiskinen. 1992. Competitive exclusion of campylobacters from poultry with K-bacteria and Broilact. Int. J. Food Microbiol. 15:265-275.

Anzola, J. B., Z. Xu, T. Asamizu, and D. L. Nuss. 1987. Segment specific inverted repeats found adjected to conserved terminal sequences in wound tumor virus genome and defective interfering RNAs. Proc. Natl. Acad. Sci. U. S. A 84:8305-.

Arvanitidou, M., G. A. Stathopoulos, T. C. Constantinidis, and V. Katsouyannopoulos. 1995. The occurrence of Salmonella, Campylobacter and Yersinia spp. in river and lake waters. Microbiol. Res. 150:153-158.

Azad, A. A., M. N. Jagadish, M. A. Brown, and P. J. Hudson. 1987. Deletion mapping and expression in Escherichia coli of the large genomic segment of a birnavirus. Virology 161:145-152.

Bais, M. V., R. S. Kataria, A. K. Tiwari, K. N. Viswas, A. V. Reddy, and N. Prasad. 2004. Sequence analysis of an Indian field isolate of infectious bursal disease virus shows six unique amino acid changes in the VP1 gene. Vet. Res. Commun. 28:641646. 
Banda, A., P. Villegas, and J. El Attrache. 2003. Molecular characterization of infectious bursal disease virus from commercial poultry in the United States and Latin America. Avian Dis. 47:87-95.

Banda, A., P. Villegas, and J. El Attrache. 2004. Heteroduplex mobility assay for genotyping infectious bursal disease virus. Avian Dis. 48:851-862.

Bautista, D. A., S. Elankumaran, and R. A. Heckert. 2004. Effect of a variant infectious bursal disease virus (E/Del) on Salmonella typhimurium infection in commercial broiler chickens. Avian Dis. 48:361-369.

Bayliss, C. D., U. Spies, K. Shaw, R. W. Peters, A. Papageorgiou, H. Muller, and M. E. Boursnell. 1990. A comparison of the sequences of segment A of four infectious bursal disease virus strains and identification of a variable region in VP2. J. Gen. Virol. 71 ( Pt 6):1303-1312.

Beery, J. T., M. B. Hugdahl, and M. P. Doyle. 1988. Colonization of gastrointestinal tracts of chicks by Campylobacter jejuni. Appl. Environ. Microbiol. 54:2365-2370.

Benton, W. J., M. S. Cover, and J. K. Rosenberger. 1967. Studies on the transmission of the infectious bursal agent (IBA) of chickens. Avian Dis. 11:430-438.

Berndtson, E., M. L. Danielsson-Tham, and A. Engvall. 1996. Campylobacter incidence on a chicken farm and the spread of Campylobacter during the slaughter process. Int. J. Food Microbiol. 32:35-47.

Blackhall, J., Fuentes A, and Magnusson G. 1996. Genetic stability of a porcine rotavirus RNA segment during repeated plaque isolation. Virology 225:181-190.

Blaser, M. J. 1997. Epidemiologic and clinical features of Campylobacter jejuni infections. J. Infect. Dis. 176 Suppl 2:S103-S105.

Boot, H. J. and S. B. Pritz-Verschuren. 2004. Modifications of the 3'-UTR stem-loop of infectious bursal disease virus are allowed without influencing replication or virulence. Nucleic Acids Res. 32:211-222.

Boot, H. J., A. A. ter Huurne, A. J. Hoekman, B. P. Peeters, and A. L. Gielkens. 2000. Rescue of very virulent and mosaic infectious bursal disease virus from cloned cDNA: VP2 is not the sole determinant of the very virulent phenotype. J. Virol. 74:6701-6711.

Brandt, M., K. Yao, M. Liu, R. A. Heckert, and V. N. Vakharia. 2001. Molecular determinants of virulence, cell tropism, and pathogenic phenotype of infectious bursal disease virus. J. Virol. 75:11974-11982. 
Brown, M. D., P. Green, and M. A. Skinner. 1994. VP2 sequences of recent European 'very virulent' isolates of infectious bursal disease virus are closely related to each other but are distinct from those of 'classical' strains. J. Gen. Virol. 75 ( Pt 3):675680 .

Camarda, A., D. G. Newell, R. Nasti, and G. Di Modugnoa. 2000. Genotyping Campylobacter jejuni strains isolated from the gut and oviduct of laying hens. Avian Dis. 44:907-912.

Cao, Y. C., W. S. Yeung, M. Law, Y. Z. Bi, F. C. Leung, and B. L. Lim. 1998. Molecular characterization of seven Chinese isolates of infectious bursal disease virus: classical, very virulent, and variant strains. Avian Dis. 42:340-351.

Caston, J. R., J. L. Martinez-Torrecuadrada, A. Maraver, E. Lombardo, J. F. Rodriguez, J. I. Casal, and J. L. Carrascosa. 2001. C terminus of infectious bursal disease virus major capsid protein VP2 is involved in definition of the T number for capsid assembly. J. Virol. 75:10815-10828.

Caterina, K. M., Frasca S Jr, T. Girshick, and M. I. Khan. 2004. Development of a multiplex PCR for detection of avian adenovirus, avian reovirus, infectious bursal disease virus, and chicken anemia virus. Mol. Cell Probes 18:293-298.

Cawthraw, S., R. Ayling, P. Nuijten, T. Wassenaar, and D. G. Newell. 1994. Isotype, specificity, and kinetics of systemic and mucosal antibodies to Campylobacter jejuni antigens, including flagellin, during experimental oral infections of chickens. Avian Dis. $38: 341-349$.

Chang, H. C., T. L. Lin, and C. C. Wu. 2001. DNA-mediated vaccination against infectious bursal disease in chickens. Vaccine 20:328-335.

Chettle, N. J. and P. J. Wyeth. 1989. Failure of maternally derived infectious bursal disease antibodies to serotypes 1 and 2 to protect against heterologous virus. Br. Vet. J. 145:165-169.

Chevalier, C., J. Lepault, B. Da Costa, and B. Delmas. 2004. The last C-terminal residue of VP3, glutamic acid 257, controls capsid assembly of infectious bursal disease virus. J. Virol. 78:3296-3303.

Chevalier, C., J. Lepault, I. Erk, B. Da Costa, and B. Delmas. 2002. The maturation process of pVP2 requires assembly of infectious bursal disease virus capsids. J. Virol. 76:2384-2392.

Coker, A. O., R. D. Isokpehi, B. N. Thomas, K. O. Amisu, and C. L. Obi. 2002. Human campylobacteriosis in developing countries. Emerg. Infect. Dis. 8:237-244. 
Cosgrove, A. S. 1962. An apparently new disease of chickens-Avian Nephrosis. Avian Dis. 6:385-389.

Cui, X., H. S. Nagesha, and I. H. Holmes. 2003. Identification of crucial residues of conformational epitopes on VP2 protein of infectious bursal disease virus by phage display. J. Virol. Methods 109:75-83.

Da Costa, B., C. Chevalier, C. Henry, J. C. Huet, S. Petit, J. Lepault, H. Boot, and B. Delmas. 2002. The capsid of infectious bursal disease virus contains several small peptides arising from the maturation process of pVP2. J. Virol. 76:2393-2402.

Dobos, P. 1993. In vitro guanylylation of infectious pancreatic necrosis virus polypeptide VP1. Virology 193:403-413.

Dobos, P. 1995. Protein-primed RNA synthesis in vitro by the virion-associated RNA polymerase of infectious pancreatic necrosis virus. Virology 208:19-25.

Elankumaran, S., R. A. Heckert, and L. Moura. 2002. Pathogenesis and tissue distribution of a variant strain of infectious bursal disease virus in commercial broiler chickens. Avian Dis. 46:169-176.

Eterradossi, N. 1995. Progress in the diagnosis and prophylaxis of Infectious Bursal Disease in poultry. Comprehensive reports on technical items presented to the International Comittee or to regional Commissions:75-82.

Eterradossi, N., C. Arnauld, F. Tekaia, D. Toquin, H. Le Coq, G. Rivallan, M. Guittet, J. Domenech, T. P. Van Den Berg, and M. A. Skinner. 1999. Antigenic and genetic relationships between European very virulent infectious bursal disease viruses and an early West Africa isolate. Avian Pathol. 28:36-46.

Eterradossi, N., C. Arnauld, D. Toquin, and G. Rivallan. 1998. Critical amino acid changes in VP2 variable domain are associated with typical and atypical antigenicity in very virulent infectious bursal disease viruses. Arch. Virol. 143:1627-1636.

Eterradossi, N., G. Rivallan, D. Toquin, and M. Guittet. 1997. Limited antigenic variation among recent infectious bursal disease virus isolates from France. Arch. Virol. 142:2079-2087.

Fahey, K. J., P. McWaters, M. A. Brown, K. Erny, V. J. Murphy, and D. R. Hewish. 1991. Virus-neutralizing and passively protective monoclonal antibodies to infectious bursal disease virus of chickens. Avian Dis. 35:365-373. 
Fahey, K. J., I. J. O'Donnell, and T. J. Bagust. 1985. Antibody to the 32K structural protein of infectious bursal disease virus neutralizes viral infectivity in vitro and confers protection on young chickens. J. Gen. Virol. 66 ( Pt 12):2693-2702.

Faragher, J. T., W. H. Allan, and P. J. Wyeth. 1974. Immunosuppressive effects of infectious bursal agent on vaccination against Newcastle disease. Vet. Rec. 95:385388.

Fernandez-Arias, A., S. Martinez, and J. F. Rodriguez. 1998. The major antigenic protein of Infectious Bursal Disease Virus, VP2, Is an Apoptotic Inducer. J. Virol. 71:8014-8018.

Friedman, C. R., R. M. Hoekstra, M. Samuel, R. Marcus, J. Bender, B. Shiferaw, S. Reddy, S. D. Ahuja, D. L. Helfrick, F. Hardnett, M. Carter, B. Anderson, and R. V. Tauxe. 2004. Risk factors for sporadic Campylobacter infection in the United States: A case-control study in FoodNet sites. Clin. Infect. Dis. 38 Suppl 3:S285S296.

Giambrone, J. J., J. P. Donahoe, D. L. Dawe, and C. S. Eidson. 1977. Specific suppression of the bursa-dependent immune system of chicks with infectious bursal disease virus. Am. J. Vet. Res. 38:581-583.

Giambrone, J. J., C. S. Eidson, R. K. Page, O. J. Fletcher, B. O. Barger, and S. H. Kleven. 1976. Effect of infectious bursal agent on the response of chickens to Newcastle disease and Marek's disease vaccination. Avian Dis. 20:534-544.

Gibbens, J. C., S. J. Pascoe, S. J. Evans, R. H. Davies, and A. R. Sayers. 2001. A trial of biosecurity as a means to control Campylobacter infection of broiler chickens. Prev. Vet. Med. 48:85-99.

Gough, R. E., S. E. N. Drury, D. d. B. Welchman, J. R. Chitty, and G. E. S. Summerhays. 2002. Isolation of birnavirus and reovirus-like agents from penguins in the United Kingdom. 151:422-424.

Gregory, E., H. Barnhart, D. W. Dreesen, N. J. Stern, and J. L. Corn. 1997. Epidemiological study of Campylobacter spp. in broilers: source, time of colonization, and prevalence. Avian Dis. 41:890-898.

Haddad, E. E., C. E. Whitfill, A. P. Avakian, C. A. Ricks, P. D. Andrews, J. A. Thoma, and P. S. Wakenell. 1997. Efficacy of a novel infectious bursal disease virus immune complex vaccine in broiler chickens. Avian Dis. 41:882-889. 
Hagen, M., T. D. Y. Chung, J. I. Butcher, and M. Krystal. 1994. Recombinant Influenza virus polymerase: Requirement of both $5^{\prime}$ and $3^{\prime}$ viral ends for endonuclease activity. J. Virol. 68:1509-1515.

Hald, B. and M. Madsen. 1997. Healthy puppies and kittens as carriers of Campylobacter spp., with special reference to Campylobacter upsaliensis. J. Clin. Microbiol. 35:3351-3352.

Heine, H. G., M. Haritou, P. Failla, K. Fahey, and A. Azad. 1991. Sequence analysis and expression of the host-protective immunogen VP2 of a variant strain of infectious bursal disease virus which can circumvent vaccination with standard type I strains. J. Gen. Virol. 72 ( Pt 8):1835-1843.

Henderson, K. S. and D. J. Jackwood. 1990. Comparison of the dot blot hybridization assay with antigen detection assays for the diagnosis of infectious bursal disease virus infections. Avian Dis. 34:744-748.

Hirai, K., S. Shimakura, E. Kawamoto, F. Taguchi, S. T. Kim, C. N. Chang, and Y. Iritani. 1974. The immunodepressive effect of infectious bursal disease virus in chickens. Avian Dis. 18:50-57.

Hitchner, S. B. 2004. History of biological control of poultry diseases in the USA. Avian Dis. 48:1-8.

Huang, Z., S. Elankumaran, A. S. Yunus, and S. K. Samal. 2004. A recombinant Newcastle disease virus (NDV) expressing VP2 protein of infectious bursal disease virus (IBDV) protects against NDV and IBDV. J. Virol. 78:10054-10063.

Hudson, P. J., N. M. McKern, B. E. Power, and A. A. Azad. 1986. Genomic structure of the large RNA segment of infectious bursal disease virus. Nucleic Acids Res. 14:5001-5012.

Hulse, D. J. and C. H. Romero. 2004. Partial protection against infectious bursal disease virus through DNA-mediated vaccination with the VP2 capsid protein and chicken IL-2 genes. Vaccine 22:1249-1259.

Ikuta, N., J. El Attrache, P. Villegas, E. M. Garcia, V. R. Lunge, A. S. Fonseca, C. Oliveira, and E. K. Marques. 2001. Molecular characterization of Brazilian infectious bursal disease viruses. Avian Dis. 45:297-306.

Ismail, N. M. and Y. M. Saif. 1991. Immunogenicity of infectious bursal disease viruses in chickens. Avian Dis. 35:460-469. 
Ivanyi, J. 1975. Immunodeficiency in the chicken. II. Production of monomeric IgM following testosterone treatment or infection with Gumboro disease. Immunology 28:1015-1021.

Jackwood, D. H. and Y. M. Saif. 1987. Antigenic diversity of infectious bursal disease viruses. Avian Dis. 31:766-770.

Jackwood, D. J., G. Hanes, and S. H. Miller. 1996a. Infectious bursal disease viral RNA amplification using RT/PCR from bursa tissue following phenol: chloroform inactivation of the virus. Avian Dis. 40:457-460.

Jackwood, D. J., K. S. Henderson, and R. J. Jackwood. 1996b. Enzyme-linked immunosorbent assay-based detection of antibodies to antigenic subtypes of infectious bursal disease viruses of chickens. Clin. Diagn. Lab Immunol. 3:456-463.

Jackwood, D. J. and S. E. Sommer. 1997. Restriction fragment length polymorphisms in the VP2 gene of infectious bursal disease viruses. Avian Dis. 41:627-637.

Jackwood, D. J. and S. E. Sommer. 1998. Genetic heterogeneity in the VP2 gene of infectious bursal disease viruses detected in commercially reared chickens. Avian Dis. 42:321-339.

Jackwood, D. J. and S. E. Sommer. 1999. Restriction fragment length polymorphisms in the VP2 gene of infectious bursal disease viruses from outside the United States. Avian Dis. 43:310-314.

Jackwood, D. J. and S. E. Sommer. 2002a. Identification of infectious bursal disease virus quasispecies in commercial vaccines and field isolates of this double-stranded RNA virus. Virology 304:105-113.

Jackwood, D. J. and S. E. Sommer. 2002b. Virulent vaccine strains of infectious bursal disease virus not distinguishable from wild-type viruses with marker the use of a molecular. Avian Dis. 46:1030-1032.

Jackwood, D. J., S. E. Sommer, and H. V. Knoblich. 2001. Amino acid comparison of infectious bursal disease viruses placed in the same or different molecular groups by RT/PCR-RFLP. Avian Dis. 45:330-339.

Jackwood, D. J., B. D. Spalding, and S. E. Sommer. 2003. Real-time reverse transcriptase-polymerase chain reaction detection and analysis of nucleotide sequences coding for a neutralizing epitope on infectious bursal disease viruses. Avian Dis. 47:738-744.

Jacobs-Reitsma, W. F. 1995. Campylobacter bacteria in breeder flocks. Avian Dis. 39:355-359. 
Jacobs-Reitsma, W. F. 1997. Aspects of epidemiology of Campylobacter in poultry. Vet. Q. 19:113-117.

Jeurissen, S. H., E. M. Janse, P. R. Lehrbach, E. E. Haddad, A. Avakian, and C. E. Whitfill. 1998. The working mechanism of an immune complex vaccine that protects chickens against infectious bursal disease. Immunology 95:494-500.

Juul-Madsen, H. R., O. L. Nielsen, T. Krogh-Maibom, C. M. Rontved, T. S. Dalgaard, N. Bumstead, and P. H. Jorgensen. 2002. Major histocompatibility complex-linked immune response of young chickens vaccinated with an attenuated live infectious bursal disease virus vaccine followed by an infection. Poult. Sci. 81:649-656.

Kaino, K., H. Hayashidani, K. Kaneko, and M. Ogawa. 1988. Intestinal colonization of Campylobacter jejuni in chickens. Nippon Juigaku. Zasshi 50:489-494.

Kapperud, G., E. Skjerve, L. Vik, K. Hauge, A. Lysaker, I. Aalmen, S. M. Ostroff, and M. Potter. 1993. Epidemiological investigation of risk factors for campylobacter colonization in Norwegian broiler flocks. Epidemiol. Infect. 111:245255.

Kibenge, F. S. and V. Dhama. 1997. Evidence that virion-associated VP1 of avibirnaviruses contains viral RNA sequences. Arch. Virol. 142:1227-1236.

Kibenge, F. S., A. S. Dhillon, and R. G. Russell. 1988. Biochemistry and immunology of infectious bursal disease virus. J. Gen. Virol. 69 ( Pt 8):1757-1775.

Kibenge, F. S., B. Qian, J. R. Cleghorn, and C. K. Martin. 1997. Infectious bursal disease virus polyprotein processing does not involve cellular proteases. Arch. Virol. 142:2401-2419.

Kim, I. J., M. Gagic, and J. M. Sharma. 1999. Recovery of antibody-producing ability and lymphocyte repopulation of bursal follicles in chickens exposed to infectious bursal disease virus. Avian Dis. 43:401-413.

Kim, I. J., S. K. You, H. Kim, H. Y. Yeh, and J. M. Sharma. 2000. Characteristics of bursal T lymphocytes induced by infectious bursal disease virus. J. Virol. 74:88848892 .

Kim, S. J., H. W. Sung, J. H. Han, D. Jackwood, and H. M. Kwon. 2004. Protection against very virulent infectious bursal disease virus in chickens immunized with DNA vaccines. Vet. Microbiol. 101:39-51. 
Konkel, M. E., B. J. Kim, J. D. Klena, C. R. Young, and R. Ziprin. 1998. Characterization of the thermal stress response of Campylobacter jejuni. Infect. Immun. 66:3666-3672.

Kwon, H. M. and S. J. Kim. 2004. Sequence analysis of the variable VP2 gene of infectious bursal disease viruses passaged in Vero cells. Virus Genes 28:285-291.

Lasher, H. N. and V. S. Davis. 1997. History of infectious bursal disease in the U.S.A.-the first two decades. Avian Dis. 41:11-19.

Le, S.-Y., J.-H. Chen, N. Sonenberg, and V. J. Mainzel, Jr.. 1993. Conserved tertiary structural elements in the 5 ' nontranslated region of cardiovirus, aphthovirus and hepatitis A virus RNAs. Nucleic Acids Res. 21:2445-2451.

Lejal, N., B. Da Costa, J. C. Huet, and B. Delmas. 2000. Role of Ser-652 and Lys-692 in the protease activity of infectious bursal disease virus VP4 and identification of its substrate cleavage sites. J. Gen. Virol. 81:983-992.

Lewis, P. J. and L. A. Babiuk. 1999. DNA vaccines: a review. Adv. Virus Res. 54:129188.

Li, J., Y. Huang, X. Liang, M. Lu, L. Li, L. Yu, and R. Deng. 2003. Plasmid DNA encoding antigens of infectious bursal disease viruses induce protective immune responses in chickens: factors influencing efficacy. Virus Res. 98:63-74.

Li, J., X. Liang, Y. Huang, S. Meng, R. Xie, R. Deng, and L. Yu. 2004. Enhancement of the immunogenicity of DNA vaccine against infectious bursal disease virus by codelivery with plasmid encoding chicken interleukin 2. Virology 329:89-100.

Lim, H. Y. and M. L. Ng. 1999. A different mode of entry by dengue-2 neutralisation escape mutant virus. Arch. Virol. 144:989-995.

Lin, Z., A. Kato, Y. Otaki, T. Nakamura, E. Sasmaz, and S. Ueda. 1993. Sequence comparisons of a highly virulent infectious bursal disease virus prevalent in Japan. Avian Dis. 37:315-323.

Liu, M. and V. N. Vakharia. 2004. VP1 protein of infectious bursal disease virus modulates the virulence in vivo. Virology 330:62-73.

Lojkic, I., Z. Bidin, and B. Pokric. 2003. Differentiation of infectious bursal disease viruses isolated in Croatia. Avian Dis. 47:59-65. 
Lombardo, E., A. Maraver, I. Espinosa, A. Fernandez-Arias, and J. F. Rodriguez. 2000. VP5, the nonstructural polypeptide of infectious bursal disease virus, accumulates within the host plasma membrane and induces cell lysis. Virology 277:345-357.

Lukert, P. D. and Saif, Y. M. 1997. Infectious Bursal Disease, p. 721-738. In Calnek, B. W., Barnes, J. H., Beard, C. W., McDougald, L. R., and Saif, Y. M. (eds.), Diseases of Poultry. Iowa State University Press.

Maas, R. A., S. Venema, H. L. Oei, J. M. A. Pol, I. J. Claasen, and A. ter Huurne. 2001. Efficacy of inactivated infectious bursal disease (IBD) vaccines: comparison serology with protection of progeny chickens against IBD virus strains of varying virulence. Avian Pathol. 30:345-354.

Maraver, A., A. Ona, F. Abaitua, D. Gonzalez, R. Clemente, J. A. Ruiz-Diaz, J. R. Caston, F. Pazos, and J. F. Rodriguez. 2003. The oligomerization domain of VP3, the scaffolding protein of infectious bursal disease virus, plays a critical role in capsid assembly. J. Virol. 77:6438-6449.

Martinez-Torrecuadrada, J. L., B. Lazaro, J. F. Rodriguez, and J. I. Casal. 2000. Antigenic properties and diagnostic potential of baculovirus-expressed infectious bursal disease virus proteins VPX and VP3. Clin. Diagn. Lab Immunol. 7:645-651.

Martinez-Torrecuadrada, J. L., N. Saubi, A. Pages-MantE, J. R. Caston, E. Espuna, and J. I. Casal. 2003. Structure-dependent efficacy of infectious bursal disease virus (IBDV) recombinant vaccines. Vaccine 21:3342-3350.

McFerran, J. B., M. S. McNulty, E. R. McKillop, T. J. Connor, R. M. McCracken, D. S. Collins, and G. M. Allan. 1980. Isolation and serological studies with infectious bursal disease viruses from fowl,turkeys, and ducks: demonstration of a second serotype. Avian Pathol. 9:395-403.

McNulty, M. S., G. M. Allan, and J. B. McFerran. 1979. Isolation of infectious bursal disease virus from turkeys. Avian Pathol. 8:205-212.

McNulty, M. S. and Y. M. Saif. 1988. Antigenic relationship of non-serotype 1 turkey infectious bursal disease viruses from the United States and United Kingdom. Avian Dis. $32: 374-375$.

Mead, G. C., M. J. Scott, T. J. Humphrey, and K. McAlpine. 1996. Observations on the control of Campylobacter jejuni infection of poultry by "competitive exclusion". Avian Pathol. 25:69-79. 
Meinersmann, R. J., W. E. Rigsby, N. J. Stern, L. C. Kelley, J. E. Hill, and M. P. Doyle. 1991. Comparative study of colonizing and noncolonizing Campylobacter jejuni. Am. J. Vet. Res. 52:1518-1522.

Moody, A., S. Sellers, and N. Bumstead. 2000. Measuring infectious bursal disease virus RNA in blood by multiplex real-time quantitative RT-PCR. J. Virol. Methods 85:55-64.

Moradian, A., J. Thorsen, and R. J. Julian. 1990. Single and combined infections of specific-pathogen-free chickens with infectious bursal disease virus and an intestinal isolate of reovirus. Avian Dis. 34:63-72.

Morishita, T. Y., P. P. Aye, B. S. Harr, C. W. Cobb, and J. R. Clifford. 1997. Evaluation of an avian-specific probiotic to reduce the colonization and shedding of Campylobacter jejuni in broilers. Avian Dis. 41:850-855.

Muller, H., M. R. Islam, and R. Raue. 2003. Research on infectious bursal disease--the past, the present and the future. Vet. Microbiol. 97:153-165.

Muller, H. and R. Nitschke. 1987. The two segments of the infectious bursal disease virus genome are circularized by a 90,000-Da protein. Virology 159:174-177.

Muller, H., C. Scholtissek, and H. Becht. 1979. The genome of infectious bursal disease virus consists of two segments of double-stranded RNA. J. Virol. 31:584589 .

Mundt, E. 1999. Tissue culture infectivity of different strains of infectious bursal disease virus is determined by distinct amino acids in VP2. J. Gen. Virol. 80 ( Pt 8):2067-2076.

Mundt, E. and H. Muller. 1995. Complete nucleotide sequences of 5'- and 3'-noncoding regions of both genome segments of different strains of infectious bursal disease virus. Virology 209:10-18.

Nachamkin, I., B. M. Allos, and T. Ho. 1998. Campylobacter species and GuillainBarre syndrome. Clin. Microbiol. Rev. 11:555-567.

Nachamkin, I., X. H. Yang, and N. J. Stern. 1993. Role of Campylobacter jejuni flagella as colonization factors for three-day-old chicks: analysis with flagellar mutants. Appl. Environ. Microbiol. 59:1269-1273.

Nieper, H. and H. Muller. 1996. Susceptibility of chicken lymphoid cells to infectious bursal disease virus does not correlate with the presence of specific binding sites. J. Gen. Virol. 77 ( Pt 6):1229-1237. 
Ogawa, M., T. Yamaguchi, A. Setiyono, T. Ho, H. Matsuda, S. Furusawa, H. Fukushi, and K. Hirai. 1998. Some characteristics of a cellular receptor for virulent infectious bursal disease virus by using flow cytometry. Arch. Virol. 143:2327-2341.

Ona, A., D. Luque, F. Abaitua, A. Maraver, J. R. Caston, and J. F. Rodriguez. 2004. The C-terminal domain of the pVP2 precursor is essential for the interaction between VP2 and VP3, the capsid polypeptides of infectious bursal disease virus. Virology 322:135-142.

Oppling, V., H. Muller, and H. Becht. 1991. The structural polypeptide VP3 of infectious bursal disease virus carries group- and serotype-specific epitopes. J. Gen. Virol. 72 ( Pt 9):2275-2278.

Owoade, A. A., M. N. Mulders, J. Kohnen, W. Ammerlaan, and C. P. Muller. 2004. High sequence diversity in infectious bursal disease virus serotype 1 in poultry and turkey suggests West-African origin of very virulent strains. Arch. Virol. 149:653672 .

Pantin-Jackwood, M. J. and T. P. Brown. 2003. Infectious bursal disease virus and proventriculitis in broiler chickens. Avian Dis. 47:681-690.

Parkhurst, R. T. 1964. On-the-farm studies of Gumboro Disease in broilers. Avian Dis. 584-596.

Parthiban, M. and V. Thiagarajan. 2002. The value of tissue imprint hybridization for rapid detection of infectious bursal disease virus from field outbreaks. Trop. Anim Health Prod. 34:391-398.

Pilipenko, E. V., S. V. Maslova, A. N. Sinyakov, and V. I. Agol. 1992. Towards identification of cis-acting elements involved in the replication of enterovirus and rhinovirus RNAs: a proposal for the existence of tRNA-like terminal structures. Nucleic Acids Res. 20:1739-1745.

Ragland, W. L., R. Novak, J. El Attrache, V. Savic, and K. Ester. 2002. Chicken anemia virus and infectious bursal disease virus interfere with transcription of chicken IFN-alpha and IFN-gamma mRNA. J. Interferon Cytokine Res. 22:437-441.

Raj, G. D., A. Thangavelu, S. Elankumaran, A. Koteeswaran, and A. T. Venugopalan. 1994. Quantitative counter-immunoelectrophoresis for estimation of antibodies to infectious bursal disease virus. Vet. Res. Commun. 18:289-293.

Raue, R. and A. Mazaheri. 2003. Real-time RT-PCR based on genome segment B for the detection of infectious bursal disese virus. 67:22-27. 
Raue, R., and Müller, H. 2001. Detection and quantification of IBDV by real-time RTPCR. In: Proc. $2^{\text {nd }}$ International Symposium on Infectious Bursal Disease and Chicken Infectious Anaemia. Rauischholzhausen, Germany. pp. 271-277.

Rautenschlein, S., H. Y. Yeh, M. K. Njenga, and J. M. Sharma. 2002. Role of intrabursal $\mathrm{T}$ cells in infectious bursal disease virus (IBDV) infection: $\mathrm{T}$ cells promote viral clearance but delay follicular recovery. Arch. Virol. 147:285-304.

Rautenschlein, S., H. Y. Yeh, and J. M. Sharma. 2003. Comparative immunopathogenesis of mild, intermediate, and virulent strains of classic infectious bursal disease virus. Avian Dis. 47:66-78.

Rodenberg, J., J. M. Sharma, S. W. Belzer, R. M. Nordgren, and S. Naqi. 1994. Flow cytometric analysis of $\mathrm{B}$ cell and $\mathrm{T}$ cell subpopulations in specific-pathogen-free chickens infected with infectious bursal disease virus. Avian Dis. 38:16-21.

Rodriguez-Chavez, I. R., J. K. Rosenberger, and S. S. Cloud. 2002. Characterization of the antigenic, immunogenic, and pathogenic variation of infectious bursal disease virus due to propagation in different host systems (bursa, embryo, and cell culture). II. Antigenicity at the epitope level. Avian Pathol. 31:473-483.

Sahin, O., T. Y. Morishita, and Q. Zhang. 2002. Campylobacter colonization in poultry: sources of infection and modes of transmission. Anim Health Res. Rev. 3:95-105.

Sahin, O., Q. Zhang, J. C. Meitzler, B. S. Harr, T. Y. Morishita, and R. Mohan. 2001. Prevalence, antigenic specificity, and bactericidal activity of poultry antiCampylobacter maternal antibodies. Appl. Environ. Microbiol. 67:3951-3957.

Saif, Y. M. 1998. Infectious bursal disease and hemorrhagic enteritis. Poult. Sci. 77:1186-1189.

Sanchez, A. B. and J. F. Rodriguez. 1999. Proteolytic processing in infectious bursal disease virus: identification of the polyprotein cleavage sites by site-directed mutagenesis. Virology 262:190-199.

Sapats, S. I. and J. Ignjatovic. 2000. Antigenic and sequence heterogeneity of infectious bursal disease virus strains isolated in Australia. Arch. Virol. 145:773-785.

Saravanan, P., S. Kumar, and J. M. Kataria. 2004. Use of multiple antigenic peptides related to antigenic determinants of infectious bursal disease virus (IBDV) for detection of anti-IBDV-specific antibody in ELISA--quantitative comparison with native antigen for their use in serodiagnosis. J. Immunol. Methods 293:61-70. 
Schnitzler, D., F. Bernstein, H. Muller, and H. Becht. 1993. The genetic basis for the antigenicity of the VP2 protein of the infectious bursal disease virus. J. Gen. Virol. 74 ( Pt 8):1563-1571.

Scott, A. N., M. S. McNulty, and D. Todd. 2001. Characterisation of a chicken anaemia virus variant population that resists neutralisation with a group-specific monoclonal antibody. Arch. Virol. 146:713-728.

Setiyono, A., T. Hayashi, T. Yamaguchi, H. Fukushi, and K. Hirai. 2001. Detection of cell membrane proteins that interact with virulent infectious bursal disease virus. J. Vet. Med. Sci. 63:219-221.

Shanker, S., A. Lee, and T. C. Sorrell. 1988. Experimental colonization of broiler chicks with Campylobacter jejuni. Epidemiol. Infect. 100:27-34.

Sharma, J. M., J. E. Dohms, and A. L. Metz. 1989. Comparative pathogenesis of serotype 1 and variant serotype 1 isolates of infectious bursal disease virus and their effect on humoral and cellular immune competence of specific-pathogen-free chickens. Avian Dis. 33:112-124.

Sharma, J. M. and T. L. Fredericksen. 1987. Mechanism of T cell immunosuppression by infectious bursal disease virus of chickens. Prog. Clin. Biol. Res. 238:283-294.

Sharma, J. M., K. Karaca, and T. Pertile. 1994. Virus-induced immunosuppression in chickens. Poult. Sci. 73:1082-1086.

Sharma, J. M., I. J. Kim, S. Rautenschlein, and H. Y. Yeh. 2000. Infectious bursal disease virus of chickens: pathogenesis and immunosuppression. Dev. Comp Immunol. 24:223-235.

Sharma, J. M. and L. F. Lee. 1983. Effect of infectious bursal disease on natural killer cell activity and mitogenic response of chicken lymphoid cells: role of adherent cells in cellular immune suppression. Infect. Immun. 42:747-754.

Shwed, P. S., P. Dobos, L. A. Cameron, V. N. Vakharia, and R. Duncan. 2002. Birnavirus VP1 proteins form a distinct subgroup of RNA-dependent RNA polymerases lacking a GDD motif. Virology 296:241-250.

Skirrow, M. B. and Blaser, M. J. 1992. Clinical and Epidemiological Considerations, p. 3-8. In Nachamkin, I., Blaser, M. J., and Tompkins, L. S. (eds.), Campylobacter jejuni - current status and future trends. American Society for Microbiology. 
Snyder, D. B., D. P. Lana, P. K. Savage, F. S. Yancey, S. A. Mengel, and W. W. Marquardt. 1988. Differentiation of infectious bursal disease viruses directly from infected tissues with neutralizing monoclonal antibodies: evidence of a major antigenic shift in recent field isolates. Avian Dis. 32:535-539.

Snyder, D. B., V. N. Vakharia, and P. K. Savage. 1992. Naturally occurringneutralizing monoclonal antibody escape variants define the epidemiology of infectious bursal disease viruses in the United States. Arch. Virol. 127:89-101.

Spies, U., H. Muller, and H. Becht. 1987. Properties of RNA polymerase activity associated with infectious bursal disease virus and characterization of its reaction products. Virus Res. 8:127-140.

Stern, N. J., R. J. Meinersmann, N. A. Cox, J. S. Bailey, and L. C. Blankenship. 1990. Influence of host lineage on cecal colonization by Campylobacter jejuni in chickens. Avian Dis. 34:602-606.

Sun, J. H., P. Lu, Y. X. Yan, X. G. Hua, J. Jiang, and Y. Zhao. 2003. Sequence and analysis of genomic segment $\mathrm{A}$ and $\mathrm{B}$ of very virulent infectious bursal disease virus isolated from China. J. Vet. Med. B Infect. Dis. Vet. Public Health 50:148-154.

Tacken, M., P. Rottier, A. Gielkens, and B. Peeters. 2000. Interactions in vivo between the proteins of infectious bursal disease virus: capsid protein VP3 interacts with the RNA-dependent RNA polymerase, VP1. 81:209-218.

Tacken, M. G., B. P. Peeters, A. A. Thomas, P. J. Rottier, and H. J. Boot. 2002. Infectious bursal disease virus capsid protein VP3 interacts both with VP1, the RNAdependent RNA polymerase, and with viral double-stranded RNA. J. Virol. 76:11301-11311.

Tacken, M. G., P. A. Van Den Beuken, B. P. Peeters, A. A. Thomas, P. J. Rottier, and H. J. Boot. 2003. Homotypic interactions of the infectious bursal disease virus proteins VP3, pVP2, VP4, and VP5: mapping of the interacting domains. Virology 312:306-319.

Tanimura, N. and J. M. Sharma. 1998. In-situ apoptosis in chickens infected with infectious bursal disease virus. J. Comp Pathol. 118:15-27.

Tiwari, A. K., R. S. Kataria, Indervesh, N. Prasad, and R. Gupta. 2003. Differentiation of infectious bursal disease viruses by restriction enzyme analysis of RT-PCR amplified VP1 gene sequence. Comp Immunol. Microbiol. Infect. Dis. 26:47-53. 
Vakharia, V. N., J. He, B. Ahamed, and D. B. Snyder. 1994. Molecular basis of antigenic variation in infectious bursal disease virus. Virus Res. 31:265-273.

van de Giessen, A. W., J. J. Tilburg, W. S. Ritmeester, and P. J. van der. 1998. Reduction of campylobacter infections in broiler flocks by application of hygiene measures. Epidemiol. Infect. 121:57-66.

van den Berg, T. P. 2000. Acute infectious bursal disease in poultry: a review. Avian Pathol. 29:175-194.

van den Berg, T. P. and M. Gonze. 1996. Acute infectious bursal disease in poultry: immunological and molecular basis of antigenicity of a highly virulent strain. Avian Pathol. 25:751-769.

van den Berg, T. P., D. Morales, N. Eterradossi, G. Rivallan, D. Toquin, R. Raue, K. Zierenberg, M. F. Zhang, Y. P. Zhu, C. Q. Wang, H. J. Zheng, X. Wang, G. C. Chen, B. L. Lim, and H. Muller. 2004. Assessment of genetic, antigenic and pathotypic criteria for the characterization of IBDV strains. Avian Pathol. 33:470476.

van Loon, A. A., N. de Haas, I. Zeyda, and E. Mundt. 2002. Alteration of amino acids in VP2 of very virulent infectious bursal disease virus results in tissue culture adaptation and attenuation in chickens. J. Gen. Virol. 83:121-129.

Vandamme, P. 2000. Taxonomy of the family Campylobacteraceae, p. 3-26. In Nachamkin, I. and Blaser, M. J. (eds.), Campylobacter. American Society for Microbiology.

von Einem, U. I., A. E. Gorbalenya, H. Schirrmeier, S. E. Behrens, T. Letzel, and E. Mundt. 2004. VP1 of infectious bursal disease virus is an RNA-dependent RNA polymerase. J. Gen. Virol. 85:2221-2229.

Wang, X. M., X. W. Zeng, H. L. Gao, C. Y. Fu, and P. Wei. 2004. Changes in VP2 gene during the attenuation of very virulent infectious bursal disease virus strain $\mathrm{Gx}$ isolated in China. Avian Dis. 48:77-83.

Weber, A. 1985. [Occurrence of Campylobacter jejuni in animals and its significance for the human]. Tierarztl. Prax. 13:151-157.

Widders, P. R., R. Perry, W. I. Muir, A. J. Husband, and K. A. Long. 1996. Immunisation of chickens to reduce intestinal colonisation with Campylobacter jejuni. Br. Poult. Sci. 37:765-778. 
Wood, G. W., J. C. Muskett, and D. H. Thornton. 1983. Use of inactivated oil emulsion infectious bursal disease vaccines in breeder chickens to prevent immunosuppression in progeny chicks. Res. Vet. Sci. 35:114-115.

Wyeth, P. J. 1975. Effect of infectious bursal disease on the response of chickens to S typhimurium and E coli infections. Vet. Rec. 96:238-243.

Wyeth, P. J. and N. Chettle. 1982. Comparison of the efficacy of four inactivated infectious bursal disease oil emulsion vaccines. Vet. Rec. 110:359-361.

Yamaguchi, T., M. Ogawa, Y. Inoshima, M. Miyoshi, H. Fukushi, and K. Hirai. 1996. Identification of sequence changes responsible for the attenuation of highly virulent infectious bursal disease virus. Virology 223:219-223.

Yao, K. and V. N. Vakharia. 2001. Induction of apoptosis in vitro by the 17-kDa nonstructural protein of infectious bursal disease virus: possible role in viral pathogenesis. Virology 285:50-58.

Young, C. R., R. L. Ziprin, M. E. Hume, and L. H. Stanker. 1999. Dose response and organ invasion of day-of-hatch Leghorn chicks by different isolates of Campylobacter jejuni. Avian Dis. 43:763-767.

Yu, W. and J. L. Leibowitz. 1995. A conserved motif at the 3' end of mouse hepatitis virus genomic RNA required for host protein binding and viral RNA replication. Virology 214:128-138. 